\author{
Universidade de São Paulo \\ Instituto de Astronomia, Geofísica e Ciências Atmosféricas \\ Departamento de Geofísica
}

Bruno de Barros Collaço

\title{
Tomografia de Ruído Ambiental na Bacia do Paraná
}

São Paulo

2014 

Universidade de São Paulo

Instituto de Astronomia, Geofísica e Ciências Atmosféricas

Departamento de Geofísica

Bruno de Barros Collaço

\section{Tomografia de Ruído Ambiental na Bacia do Paraná}

13 de junho de 2014 

Bruno de Barros Collaço

\section{Tomografia de Ruído Ambiental na Bacia do Paraná}

Dissertação apresentada ao Departamento de Geofísica do Instituto de Astronomia, Geofísica e Ciências Atmosféricas da Universidade de São Paulo como requisito parcial para a obtenção do título de Mestre em Ciências.

Versão corrigida. Original encontra-se disponível na unidade.

Área de Concentração: Geofísica

Orientador(a): Prof. Dr. Marcelo Assumpção

13 de junho de 2014 

Aos meus avós 



\section{Agradecimentos}

Devo agradecer à professora Leila S. Marques pela dedicação e cobrança destinadas aos seus alunos, por ter me mostrado como se faz ciência de maneira competente em meio às eventuais adversidades.

Ao professor Marcelo Assumpção, pela confiança, respeito e transparência dedicados ao seus alunos e funcionários. Por demonstrar que o exercício mais difícil é sempre o mais didático. Por compartilhar a experiência adquirida com esforço ao longo dos anos de maneira eficiente e pela paciência. Por ensinar o caminho até a resposta ao invés de simplesmente apresentá-la.

Agradeço também ao meu amigo Marlon Pirchiner, por sempre pensar à frente de seu tempo, trazendo consigo as pessoas ao seu redor que conseguem entender suas sinceras intenções. Pelo pensamento de comunidade, equipe. Pelas aulas de política.

Aos amigos do Centro de Sismologia da USP, pela convivência, suporte e entrega profissional de cada um, tornando mais fácil o trabalho diário.

Aos meus amigos argentinos, em especial à Maria Laura Rosa, pela hospitalidade e

colaboração científica internacional. À Meijian An, Michael Pasyanos e Morgan Moschetti, pelos códigos fontes dos softwares utilizados.

Aos meus pais, por terem me ensinado o caminho a seguir e à minha irmã, porque dizem que devemos agradecer às irmãs também, obrigado Mah.

À minha namorada Mari, pelo interesse, perguntas e palavras de apoio, fundamentais para a conclusão deste trabalho. Ao meu amigo Jurandir, pelos momentos offline. 

"For those who believe, no explanation is necessary. For those who do not believe, no explanation will suffice" Joseph Dunninger - Magician 



\section{Resumo}

A tomografia sísmica convencional apresenta baixa resolução em regiões de baixa sismicidade, como consequência, estudos prévios realizados na América do Sul não mapearam com clareza áreas menores do continente, como a região da bacia do Paraná. Para descrever a estrutura da crosta na região da bacia do Paraná, além de dados obtidos através da análise de terremotos andinos, foram utilizadas curvas de dispersão provenientes da correlação do ruído ambiental entre pares de estações sismográficas, técnica conhecida com Ambient Noise Tomography (ANT). Os mapas de velocidade de grupo obtidos correspondem bem com as principais províncias geológicas já conhecidas na América do Sul: baixas velocidades sob os andes e bacias sedimentares e altas velocidades sob regiões cratônicas. As anomalias de alta velocidade encontradas para o manto superior, concordam com trabalhos prévios que confirmam a presença de um núcleo cratônico sob a bacia. Contudo, não é possível afirmar se tal núcleo está intacto ou não, principalmente devido resultados anteriores que mostram evidências da existência de um núcleo dividido por zonas de sutura. No entanto, a tomografia de ondas de superfície não possui resolução para confirmar este modelo. Como as etapas do processamento de dados são bem definidas e independentes, à medida que novas estações forem instaladas com o avanço do projeto BRASIS, novos caminhos serão adicionadas à base inicial, aumentando a resolução e confiabilidade dos resultados futuros. 



\section{Abstract}

Conventional seismic tomography is known to have poor resolution in regions of low seismicity, therefore, studies carried out in South America did not mapped clearly smaller areas of the continent, for example the region of the Paraná basin. To describe the of the crustal structure of the Paraná basin, in addition to data obtained by analysis of Andean earthquakes, we used dispersion curves from ambient noise correlation between pairs of seismographic stations, a technique known by Ambient Noise Tomography (ANT). The obtained group velocity maps correspond well with the main geological provinces already known in South America: low velocities under the Andes and sedimentary basins and high velocities in cratonic regions. The high velocity anomalies encountered in the upper mantle, agree with previous studies that confirm the presence of a nucleus in the cratonic basin. However, it is not possible to say whether such a nucleus is intact or not, mainly because previous results showing evidence of the existence of a nucleus divided by suture zones. Nevertheless, surface wave tomography has no resolution to confirm this model. The steps of data processing of this work are well defined and independent, thus, as new stations will being deployed with the advance of BRASIS Project, new paths will be added to the database, increasing the resolution and reliability of the future results. 



\section{Lista de Figuras}

1.1 Rayleigh and S Velocities Maps from FENG et al. (2004). . . . . . . . . . . 19

1.2 Group velocity paths used by FENG et al. (2007), extracted from LLOYD et al. (2010) . . . . . . . . . . . . . . . . . . . 20

1.3 Paths for dispersion measurements obtained with ambient noise crosscorrelations. . . . . . . . . . . . . . . . . . 21

2.1 Geologic sketch of the Paraná Province showing the sediment supersequences, extracted from SILVA et al. (2003). . . . . . . . . . . . . . 24

2.2 Depth to the crystalline basement at the Paraná Basin . . . . . . . . . . . 24

2.3 Cratonic basement models for the Paraná basin extracted from JULIA et al.

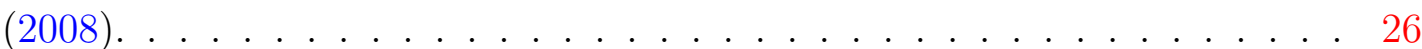

3.1 Ambient noise data processing scheme, similar to that described for Rayleigh waves by BENSEN et al. (2007) . . . . . . . . . . . . . . . . . . 30

3.2 An example of the time normalization method applied in this work, bandpass filtered between 20 and $100 \mathrm{~s}$ period to clarify the contamination by the earthquake signal. . . . . . . . . . . . . . . . . 32

3.3 (A) Raw and (B) spectrally whitened amplitude spectra for $2 \mathrm{~Hz}$ vertical component data at station AQDB (Aquidauana-MS, Brazil) for June 5, 2013. 33

3.4 Comparison of cross-correlations with and without spectral whitening, extratecd from BENSEN et al. (2007) . . . . . . . . . . . . . . . . . 34

3.5 Example of vertical-vertical cross-correlations between station PMNB (Minas Gerais, Brazil) and some of its possible pairs. . . . . . . . . . . . . 35 
3.6 Cross-correlations between stations PMNB (Brazil) and CPUP (Paraguay). 37

3.7 An example of a symmetric seismogram, vertical component of BSCB (Bom Sucesso-MG, Brazil) and PTGB (Pitanga-PR, Brazil) obtained by crosscorrelation, showing the Rayleigh waves used to generate dispersion curves. 37

3.8 An example of group velocity measurements made by PGSWMFA using two years of correlation data for the station pair BB19B-PLTB in Brazil. . 40

3.9 An example of a bad dispersion curve which needs to be eliminated, using about two years of cross-correlation between stations TER01, Brazil and LVC, in Chile. . . . . . . . . . . . . . . . . . . 40 40

3.10 An example of group velocity measurements for Love waves made by PGSWMFA using two years of correlation data for the station pair BB19B-ITAB in Brazil. 41

3.11 An example of layered velocity modelling . . . . . . . . . . . . . 46

4.1 Rayleigh waves group-velocities average residual (rms) according to chosen smoothing factor $(\lambda) \ldots \ldots \ldots \ldots \ldots$. . . . . . . . . . . . . . 48

4.2 Love waves group-velocities average residual (rms) according to chosen weighting factor $(\lambda) \ldots \ldots \ldots \ldots \ldots$

4.3 An example of quality control on tomographic maps. . . . . . . . . . . . . 49

4.4 Tomographic map after removing paths with large residuals. . . . . . . . . 50

4.5 Schematic map of South America displaying the most important geotectonic provinces. . . . . . . . . . . . . . . . . . 51

4.6 Number of paths as a function of period for Rayleigh and Love waves. . . . 52

4.7 Shear wave $\left(V_{s}\right)$ sensitivity kernels of (left) Love and (right) Rayleigh waves at periods ranging from 10 to 100s for a velocity profile that is typical for continental crust. . . . . . . . . . . . . . . . . 53

4.8 Group-velocity maps for $\mathrm{T}=15 \mathrm{~s} . \ldots \ldots \ldots \ldots$. . . . . . . . . 55

4.9 Path distribution for $\mathrm{T}=15 \mathrm{~s}$ for Rayleigh (left) and Love waves (right). . . 55

4.10 Group-velocity maps for $\mathrm{T}=50 \mathrm{~s} . \ldots \ldots \ldots \ldots$. . . . . . . . 57

4.11 Path distribution for $\mathrm{T}=50$ s for Rayleigh (left) and Love waves (right). . . 57

4.12 Group-velocity maps for $\mathrm{T}=100 \mathrm{~s} . \ldots \ldots \ldots$. . . . . . . . . . 59

4.13 Path distribution for $\mathrm{T}=100$ s for Rayleigh (left) and Love waves (right). . 59 
4.14 Maps of sedimentary thickness.

4.15 Comparison between inverted models for coordinate 24S,53W (black circles marked in Figure 4.13) . . . . . . . . . . . . . . . . . . . . 62

4.16 Comparison between crustal thickness maps. . . . . . . . . . . . . . 63

4.17 Models of crustal thickness from South America adapted from ASSUMPÇÃO et al. (2013). . . . . . . . . . . . . . . . . . 63

4.18 Comparison between $S_{n}$ velocity maps. . . . . . . . . . . . . . . . 65

4.19 S-wave at $100 \mathrm{~km}$ from joint inversion of Rayleigh group velocities and Moho depth constraints extracted from (FENG et al., 2007) . . . . . . . . . 65 



\section{Sumário}

1. Introdução . . . . . . . . . . . . . . . . . . . . . . . . . . . . 19

2. Bacia do Paraná - Geotectônica . . . . . . . . . . . . . . . . . . . . . 23

2.1 Evolução . . . . . . . . . . . . . . . . . . . . . . 23

2.2 Estrutura do Embasamento $\ldots \ldots \ldots \ldots \ldots \ldots$

3. Teoria e Métodos Empregados . . . . . . . . . . . . . . . . . . . . . . . . . 29

3.1 Base de Dados . . . . . . . . . . . . . . . . . . . . . . . . . . . . . 29

3.2 Processamento Individual de Estações . . . . . . . . . . . . . . . 30

3.2 .1 ObsPy Scripts . . . . . . . . . . . . . . . . . . . . . 31

3.2 .2 Normalização Temporal . . . . . . . . . . . . . . . . . . . 31

3.2.3 Normalização Espectral (Spectral Whitening) . . . . . . . . . . . 32

3.3 Correlação de Ruído Ambiental . . . . . . . . . . . . . . . . . . . . . 34

3.3 .1 Obtendo Ondas Rayleigh . . . . . . . . . . . . . . . . . . 34

3.3 .2 Obtendo Ondas Love . . . . . . . . . . . . . . . . . . . . . . 36

3.3 .3 Sismograma Simétrico . . . . . . . . . . . . . . . . . 37

3.4 Curvas de Dispersão: Medidas de Velocidade de Grupo . . . . . . . . . . 38

3.4 .1 Software Utilizado . . . . . . . . . . . . . . . . . . 38

3.4 .2 Dispersão de Ondas Rayleigh . . . . . . . . . . . . . . . . . . . 39

3.4 .3 Dispersão de Ondas Love . . . . . . . . . . . . . . . . . . . . . . . 41

3.5 Tomografia de Ruído Ambiental . . . . . . . . . . . . . . . . . . 42

3.5.1 Variação Lateral de Velocidades de Grupo . . . . . . . . . . . . . 42 
3.5.2 Perfil Vertical de Velocidades . . . . . . . . . . . . . . . . 44

4. Mapas de Tomografia: Resultados e Discussão . . . . . . . . . . . . . . . . . . 47

4.1 Análise de Resíduos e Filtro de Erros . . . . . . . . . . . . . . . . . . . 47

4.2 Mapas de Velocidade de Grupo: Inversão 2D . . . . . . . . . . . . . . . . 50

4.2.1 Rayleigh vs Love: Aspectos Importantes . . . . . . . . . . . . . . . 52

4.2 .2 Bacias Sedimentares . . . . . . . . . . . . . . . 53

4.2 .3 Espessura Crustal . . . . . . . . . . . . . . . . . 56

4.2.4 Litosfera e Manto Superior . . . . . . . . . . . . . . . . . . . 58

4.3 Informação em Profundidade: Inversão de Velocidade em Camadas . . . . 60

4.3.1 Mapas de Espessura de Sedimentos . . . . . . . . . . . . . . . . . 61

4.3.2 Mapas de Espessura da Crosta . . . . . . . . . . . . . . . . . . 62

4.3 .3 Onda $\mathrm{S}_{n}$ no Manto Superior . . . . . . . . . . . . . . . . . . 64

5. Conclusões . . . . . . . . . . . . . . . . . . . . . . 67

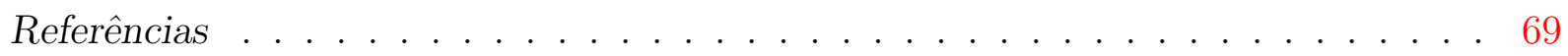

$\begin{array}{ll}\text { Apêndice } & 75\end{array}$

A. Inversão 2D: Resultados ． . . . . . . . . . . . . . . . . . 77

A.1 Mapas de Velocidade de Grupo . . . . . . . . . . . . . . . . . 77

A.2 Distribuição de Percursos . . . . . . . . . . . . . . . . . . 83 
Capítulo 1

\section{Introdução}

Estudos de tomografia de ondas de superfície realizados anteriormente na América do Sul FENG et al. (2004, 2007) mapearam com clareza as principais características em grande-escala do continente, como altas velocidades em áreas cratônicas e baixas velocidades na província patagônica e em parte dos Andes - Figura 1.1. Contudo, áreas menores como a Bacia do Paraná não foram imageadas com boa resolução devido à baixa densidade de caminhos sísmicos curtos. Isto é, a tomografia de ondas de superfície convencional tem baixa resolução em regiões de baixa sismicidade, como é o caso do Brasil e da porção mais oriental da Argentina.
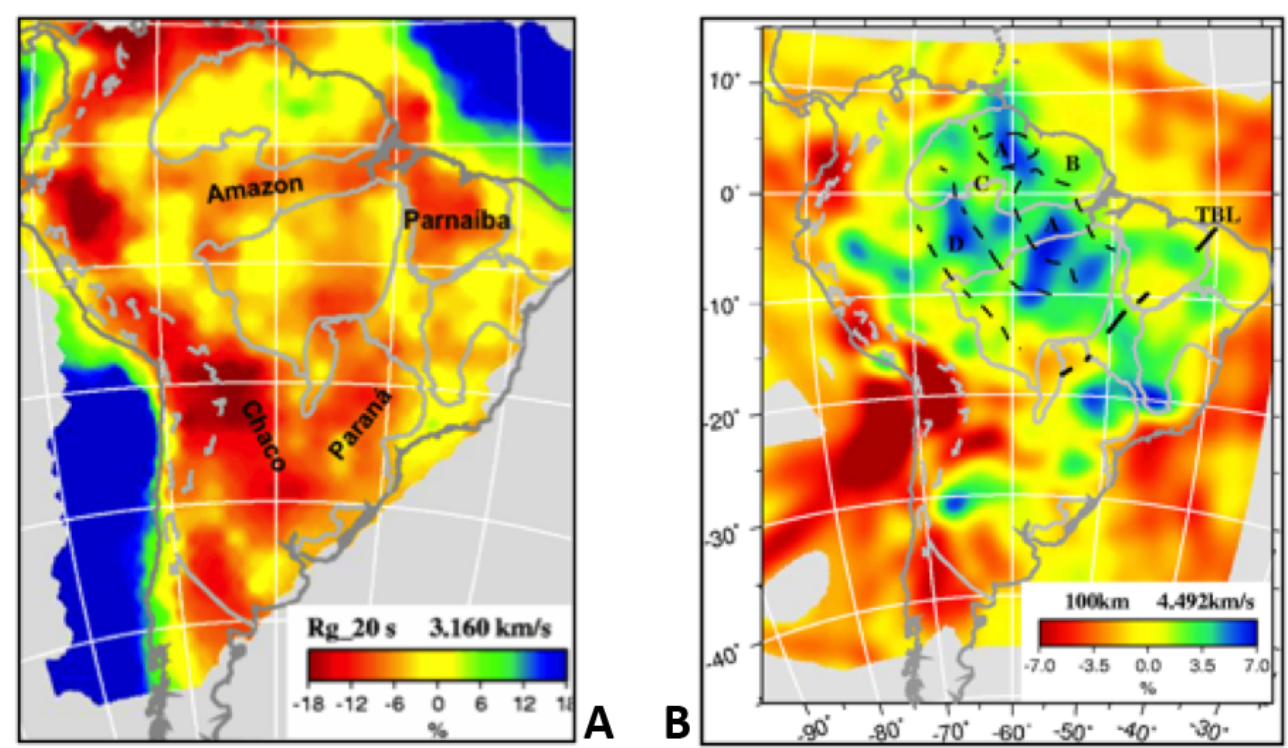

Figura 1.1: A: Rayleigh group velocities for $\mathrm{T}=20$ s (FENG et al., 2004); B: S-wave at $100 \mathrm{~km}$ depth from joint inversion of group, waveform and Moho depth constraints (FENG et al., 2007). 
A estrutura crustal das regiões sul e sudeste do Brasil é pouco conhecida. A maioria dos caminhos sísmicos que atravessam essa parte do continente, utilizados por FENG et al. (2007), são aproximadamente paralelos - Figura 1.2, impedindo que as inversões tomográficas apresentem uma boa resolução espacial.

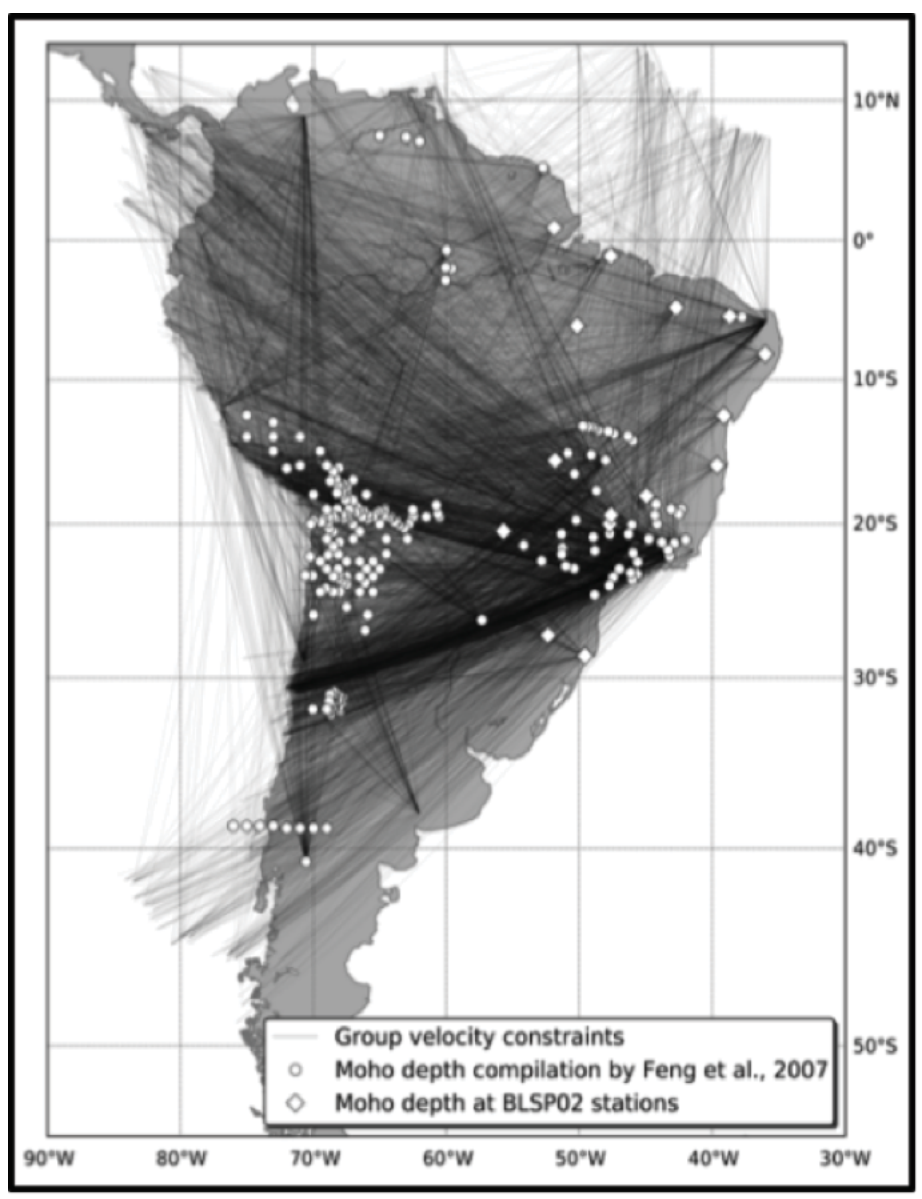

Figura 1.2: Group velocity paths used by FENG et al. (2007), extracted from LLOYD et al. (2010); circles and squares are Moho depths constraints. Note very few paths crossing Southern Brazil causing poor resolution in tomography inversions.

Este trabalho faz parte de um projeto maior que visa aumentar os conhecimentos sobre a estrutura da crosta terrestre na parte sul do Brasil e leste da Argentina e foi realizado pelo IAG-USP, em colaboração com a Universidade Nacional de La Plata (UNLP) e o Instituto Nacional de Prevenção Sísmica (INPRES), ambos da Argentina.

O objetivo deste trabalho é, portanto, descrever a estrutura da crosta na região da Bacia do Paraná utilizando curvas de dispersão obtidas com a correlação de ruído ambiental 
(cerca de dois anos e meio de sismogramas contínuos) entre pares de estações sismográficas recentemente instaladas pelo projeto BRASIS (PIRCHINER et al., 2011) — Figura 1.3.

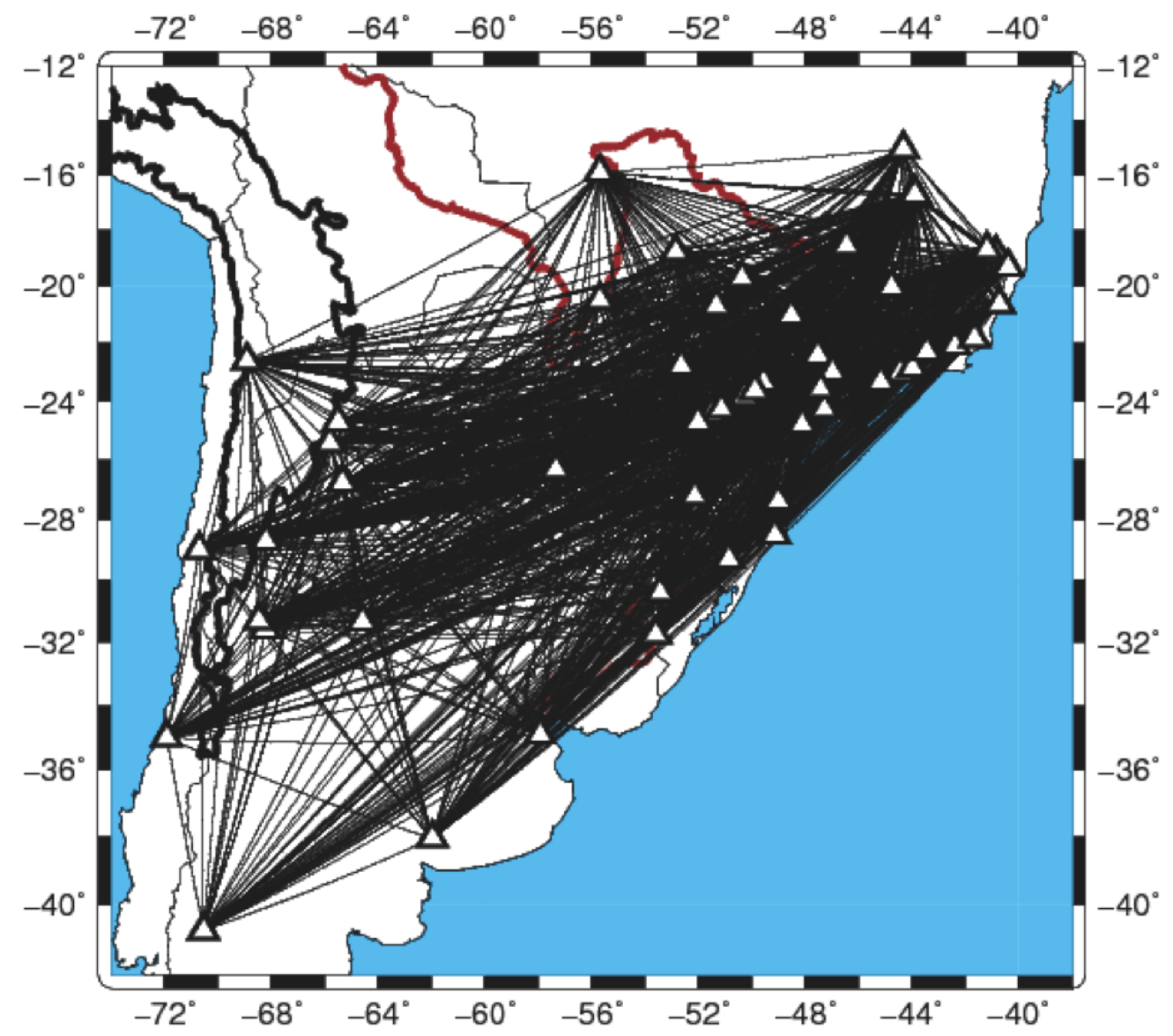

Figura 1.3: Paths for dispersion measurements obtained with ambient noise crosscorrelations. Broadband stations: INPRES, LPA, BL network in southern Brazil, and GSN stations CPUP and TRQA.

Foram utilizadas ainda curvas de dispersão derivadas do processamento de sismogramas de terremotos andinos, registrados por estações sismográficas localizadas principalmente na parte sudeste do Brasil e norte da Argentina, incluindo estações pertencentes à Rede Sismográfica Mundial (Global Seismographic Network, GSN), como por exemplo as estações: LPA, TRQA, CPUP.

A técnica de correlacionar o ruído ambiental para gerar mapas de tomografia é conhecida como Ambient Noise Tomography (ANT). A ideia básica deste método é que a correlação cruzada de um campo de ondas aleatórias calculada entre um par de receptores, vai resultar em uma forma de onda que difere apenas por um fator de amplitude 
da função empírica de Green entre estes receptores (LOBKIS e WEAVER, 2001; WAPENAAR, 2004).

Esta metodologia foi empregada inicialmente por SHAPIRO et al. (2005), mas sua aplicação têm aumentado nos últimos anos, (BENSEN et al., 2007; LIN et al., 2008; MOSCHETTI et al., 2010), principalmente em regiões onde existe uma grande densidade de estações sismográficas. Estes estudos demonstraram que as funções de Green obtidas com ANT são coerentes aos dados observados de terremotos, assim como as curvas de dispersão derivadas por ambas as técnicas. Ainda, os mapas de tomografia resultantes apresentam uma correlação razoável com estruturas geológicas conhecidas, como bacias sedimentares e cadeias de montanhas.

O emprego da ANT supera várias limitações importantes dos métodos convencionais baseados em terremotos, como por exemplo: a distribuição desigual das fontes (eventos), a incerteza na localização dos epicentros e ainda, a atenuação das ondas de superfície de período curtos, que são mais sensíveis às estruturas mais rasas. De acordo com LIN et al. (2008), ANT é um método bem estabelecido para estimar as velocidades das ondas de superfície de curto período $(<20 \mathrm{~s})$ e períodos intermediários $(20-50$ s), tanto em escalas regionais como continentais.

Com o desenvolvimento nos últimos anos do Projeto BRASIS (PIRCHINER et al., 2011), o Brasil tornou-se uma região extramente favorável ao emprego desta técnica, por possuir então uma rede sismográfica nacional (em fase de implantação até a presente data) e por ser uma região de baixa sismicidade (MOSCHETTI et al., 2007).

Em relação à bacia do Paraná, os mecanismos para a sua formação continuam a ser uma questão de disputa. Como será descrito mais adiante, diferentes modelos foram propostos na tentativa de explicar a origem e subsidência não só da bacia do Paraná mas de bacias intracratônicas no geral. Mais informações sobre a estrutura crustal do planeta, especialmente sob a pouco conhecida bacia do Paraná, podem contribuir para uma melhor compreensão da sua origem. 
Capítulo 2

\section{Bacia do Paraná - Geotectônica}

\subsection{Evolução}

Em razão do seu posicionamento geotectônico atual e de seus atributos tectonosedimentares, a bacia do Paraná é considerada uma típica bacia intracratônica. O termo bacia cratônica refere-se a uma região de sedimentação suportada por um embasamento consolidado, inserida em um domínio crustal conhecido por possuir alta resistência a esforços originados em margens de placas (LEIGHTON e KOLATA, 1990).

MILANI e RAMOS (1984) sugerem que a configuração atual da bacia do Paraná é resultado de seis episódios de sedimentação separados (geográfica e temporalmente) em três diferentes bacias, cada uma com sua própria geometria - Figura 2.1

Uma primeira bacia provavelmente se desenvolveu entre 440 e $370 \mathrm{Ma}$, em um golfo aberto após a subsidência original do Ordoviciano, sendo preenchida por sedimentos do Siluriano e Devoniano. A segunda bacia teria se formado em um ambiente marinho há 310-250 Ma, após um evento tardio do Paleozóico, sendo coberta por sedimentos desde o Carbonífero até o início do Triássico. Ainda, uma terceira bacia iniciaria há 150 Ma e seria interrompida após o grande derrame basáltico entre 137 e 127 Ma (MILANI, 2004), reativando-se posteriormente no Cretáceo com a super-sequência Bauru de sedimentos. A espessura total dos sedimentos na bacia do Paraná pode chegar a até $6 \mathrm{~km}$ - Figura 2.2. 


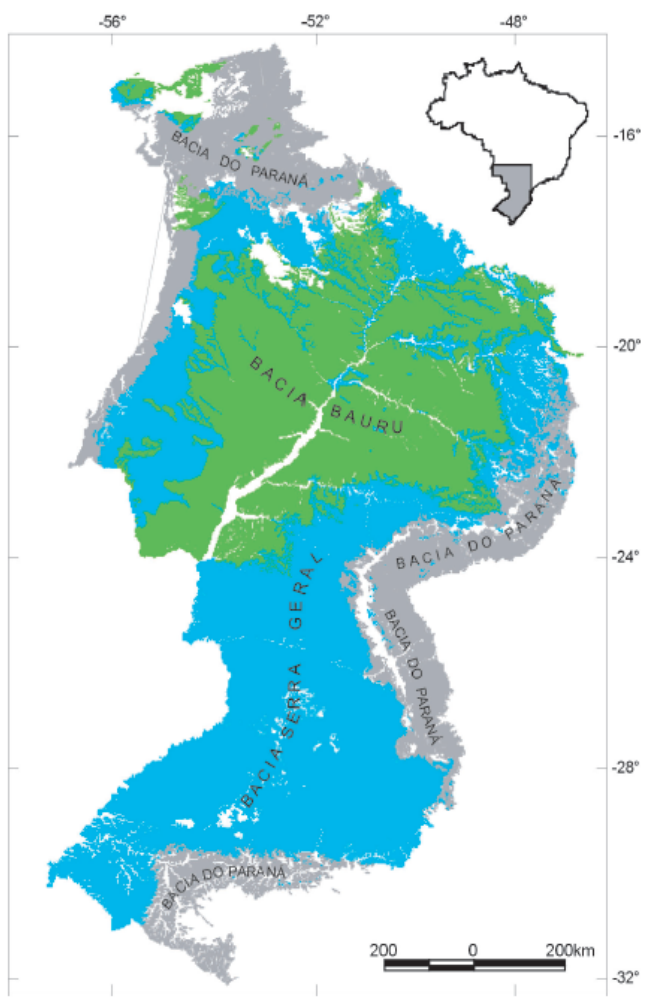

Figura 2.1: Geologic sketch of the Paraná Province showing the sediment supersequences, extracted from SILVA et al. (2003).

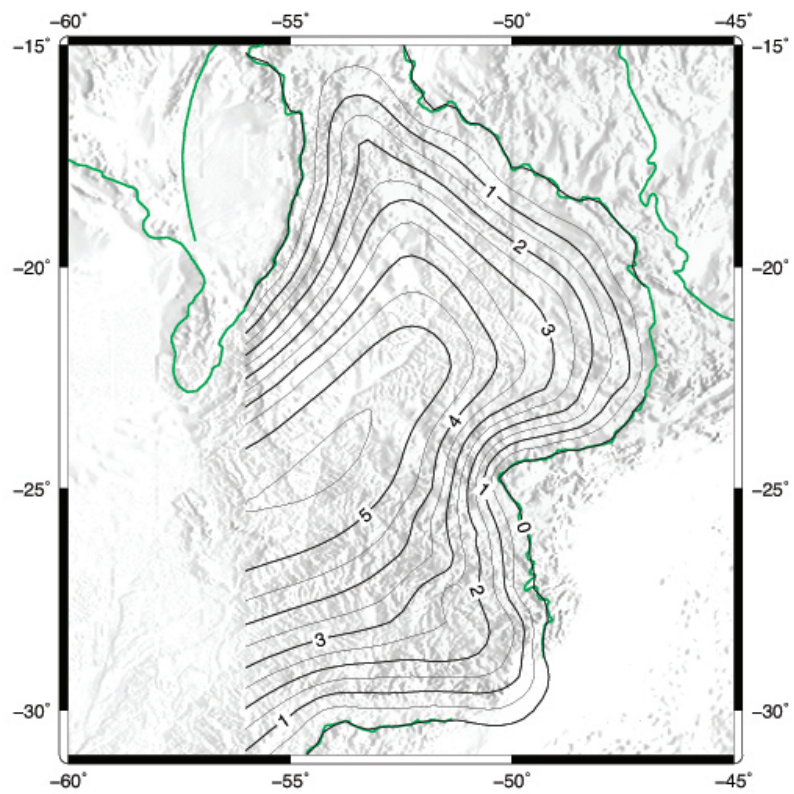

Figura 2.2: Map of the Paraná Basin showing the sediment thickness from Petrobrás and Paulipetro data compilation. Contours in kilometers. 
Muitas hipóteses tentam explicar a origem dos eventos deposicionais ocorridos na região da bacia do Paraná. O trabalho de MILANI e RAMOS (1984) correlaciona os ciclos de subsidência da bacia com as principais fases orogênicas da subducção da crosta oceânica do Pantalassa, interpretando o início da formação da bacia do Paraná como uma larga bacia antepaís gerada pela carga de sedimentos na borda SW do Gondwana.

A subsidência do Paleozóico teria ocorrido em consequência do movimento do manto ocasionado pela penetração e acomodação da placa subduzida acima da descontinuidade de $660 \mathrm{~km}$, na região do manto inferior (PYSKLYWEC e QUINTAS, 2000).

Por fim, o evento deposicional ocorreria pela sobrecarga originada em decorrência da extrusão de basaltos, segundo hipótese de ZALAN et al. (1990) e MILANI (2004) ou alternativamente, seria explicada pelo resfriamento de intrusões magmáticas na crosta profunda (AN e ASSUMPÇÃO, 2006).

A bacia do Paraná é ainda delimitada pelos cinturões de Brasília e Paraguai-Araguaia do Paleozóico, que separam a bacia dos crátons do Amazonas e do São Francisco. Essa geometria sugere que o embasamento da bacia seria formado por um núcleo cratônico isolado das unidades cratônicas circundantes por zonas de sutura mais recentes (ALMEIDA et al., 2000).

\subsection{Estrutura do Embasamento}

O trabalho de CORDANI et al. (1984), com base na datação radiométrica de duas amostras do embasamento (2 Ga) e outras inferências geológicas, foi o primeiro a propor a existência de um núcleo cratônico sob os sedimentos. Tal núcleo seria constituído por um bloco único localizado sob o eixo principal da bacia como mostra a Figura 2.3(A).

Em contrapartida, dados de gravimetria e magnetometria, assim como perfis de reflexão sísmica, revelaram uma estrutura de orientação SW-NE interpretada como sendo o centro de um rift em estágio inicial (MILANI e RAMOS, 1984). Os autores sugerem 
ainda que tais estruturas surgem da colagem de diversos blocos cratônicos separados por zonas de sutura - Figura 2.3(B)

Posteriormente, resultados de um levantamento gravimétrico realizado na bacia do Paraná revelaram uma grande anomalia positiva de forma triangular (MANTOVANI et al., 2005). Tal feição foi interpretada como resultado de um núcleo central cratônico, denominado bloco Paranapanema - Figura 2.3(C).
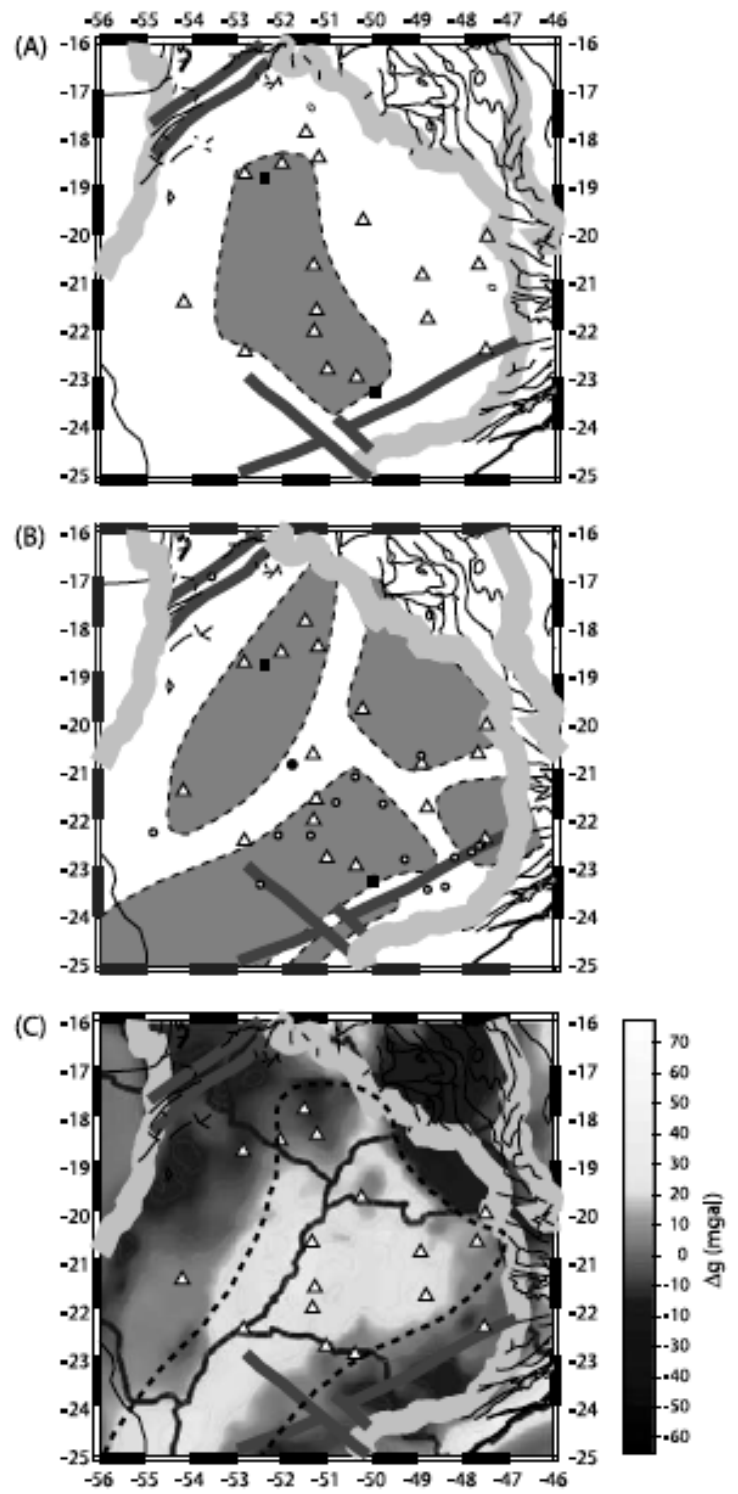

Figura 2.3: Cratonic basement models for the Paraná basin extracted from JULIA et al. (2008). (A) Cratonic nucleus of CORDANI et al. (1984). (B) Fragmented basement model of MILANI e RAMOS (1984). (C) Paranapanema block of MANTOVANI et al. (2005) (thick dashed line), as defined by gravimetric anomalies. 
Estudos sismológicos de estrutura profunda da crosta, ex. (JULIA et al., 2008), podem ajudar a definir qual modelo de embasamento é mais adequado. Um dos objetivos desta dissertação é contribuir para esclarecer este problema. 
Capítulo 3

\section{Teoria e Métodos Empregados}

\subsection{Base de Dados}

Foram processados os sismogramas contínuos de 57 estações de banda-larga localizadas na América do Sul, sendo 41 delas no Brasil - Figura 1.3. Os dados das três componentes dos sismogramas (leste, norte e vertical) foram utilizados neste trabalho, tendo em vista que as componentes horizontais são necessárias para a recuperação das ondas Love, discutidas mais adiante.

O processamento dos dados de ruído ambiental é similar ao apresentado por BENSEN et al. (2007) e baseia-se em cinco etapas principais: (1) preparação individual dos dados das estações, (2) correlação cruzada e empilhamento temporal ("stacking", obtido com aproximadamente dois anos de dados contínuos), (3) medidas de curvas de dispersão para períodos de 5 a 100s, com controle de qualidade, avaliação de erros e seleção de dados com medidas confiáveis, (4) inversão lateral dos dados obtidos com as curvas de dispersão geradas e (5) inversão em profundidade, utilizando-se softwares adaptados de PASYANOS et al. (2001) e FENG et al. (2007). - Figura 3.1 

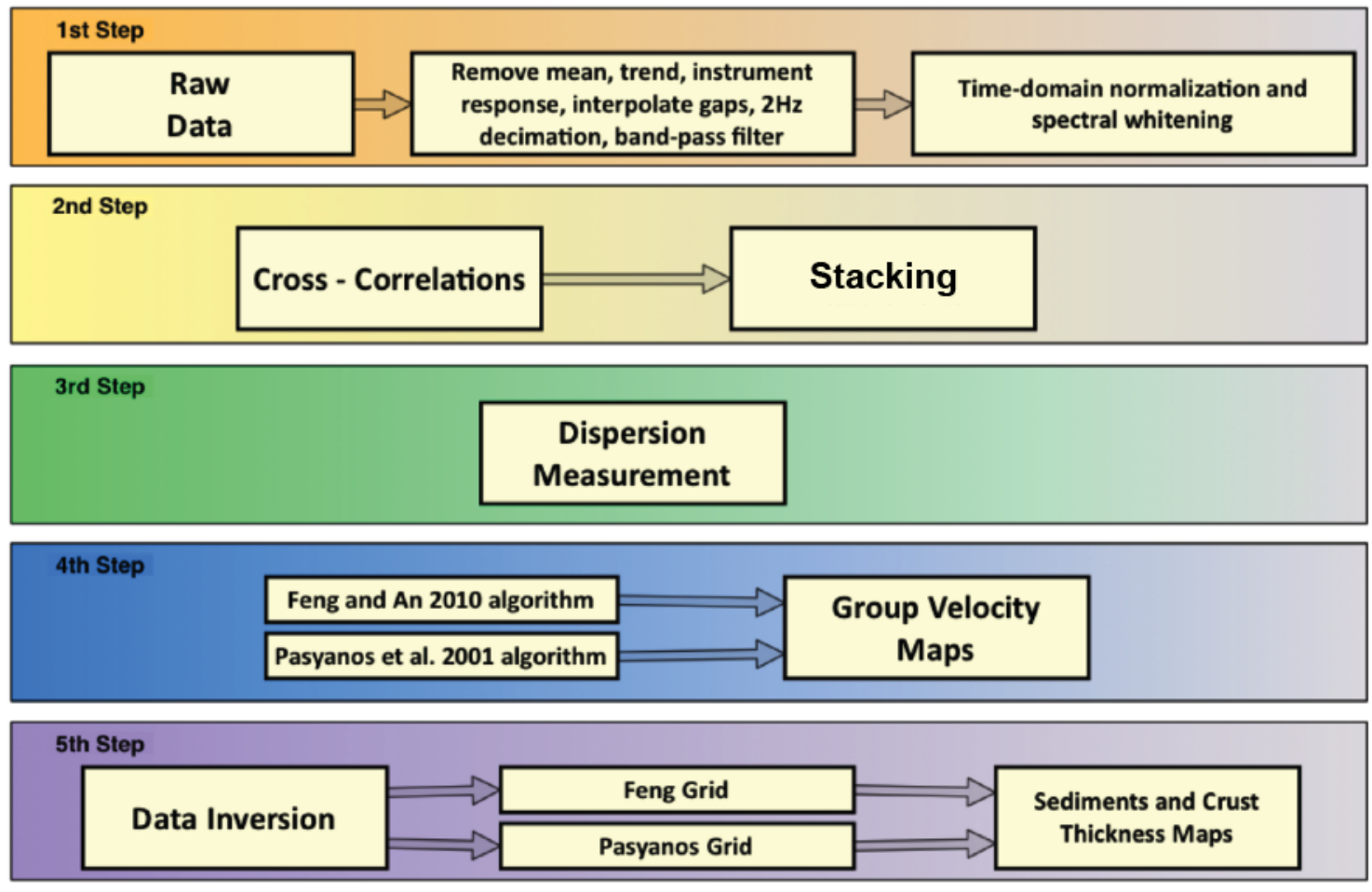

Figura 3.1: Ambient noise data processing scheme, similar to that described for Rayleigh waves by BENSEN et al. (2007)

\subsection{Processamento Individual de Estações}

A primeira fase do processamento de dados consiste na preparação dos sismogramas para cada estação individualmente. O intuito principal desta etapa é tentar remover a influência dos registros de terremotos e de irregularidades instrumentais que, por possuírem amplitudes elevadas, acabam por ocultar os sinais do ruído ambiental (SHAPIRO et al., 2005).

Os processos a seguir são aplicados a sismogramas contendo $24 \mathrm{~h}$ de dados contínuos. Os arquivos cujas estações não operaram por ao menos $95 \%$ de um determinado dia, foram automaticamente descartados. 


\subsubsection{ObsPy Scripts}

Em um trabalho com cooperação entre diferentes instituições, o intercâmbio de dados nem sempre é tarefa simples. A grande variedade de plataformas computacionais, formatos de arquivos (diferentes fabricantes de equipamentos) e até mesmo seu acesso requer um esforço considerável em seu pré-processamento (BEYREUTHER et al., 2010).

A fim de contornar este problema e com o escopo na utilização de software livre, foram desenvolvidos scripts de pré-processamento baseados na linguagem Python e nas bibliotecas de sismologia ObsPy (MEGIES et al., 2011).

Tais scripts são capazes de ler e processar qualquer formato de arquivo sismológico, simplificando tarefas como download de dados, recorte de janelas de tempo, interpolação de gaps, deconvolução, filtros de onda, etc. Por se tratar de software livre, os scripts e programas desenvolvidos para este trabalho estão acessíveis por meio do servidor de código do laboratório de sismologia do IAG-USP, disponível em: http://www.moho.iag.usp.br/gitlab.

\subsubsection{Normalização Temporal}

A ocorrência de um terremoto é talvez o maior impeditivo quando tratamos de processamentos automáticos. Além de ocorrerem de maneira aleatória no tempo, a própria utilização de catálogos oficiais torna-se dificultada pela existência de pequenos tremores que muitas vezes não foram relacionados.

Este fato agrava-se no caso do Brasil, por apresentar uma deficiência ou até mesmo ausência de estações em determinadas regiões. Por essa razão, a remoção dos terremotos presentes nos dados processados deve levar em consideração a sismicidade da região de estudo ao invés de basear-se em catálogos, mesmo que estes sejam locais.

Para identificar e remover o efeito de eventos sísmicos e outros sinais que contaminam os dados de ruído ambiental, foi utilizado o método de normalização por média absoluta. 
Esta técnica calcula a média do valor absoluto das amplitudes em uma determinada janela de tempo fixa, cuja largura é dada pela metade do período máximo do filtro passa-banda utilizado (BENSEN et al., 2007). Um exemplo do resultado do emprego deste método pode ser verificado na Figura 3.2.

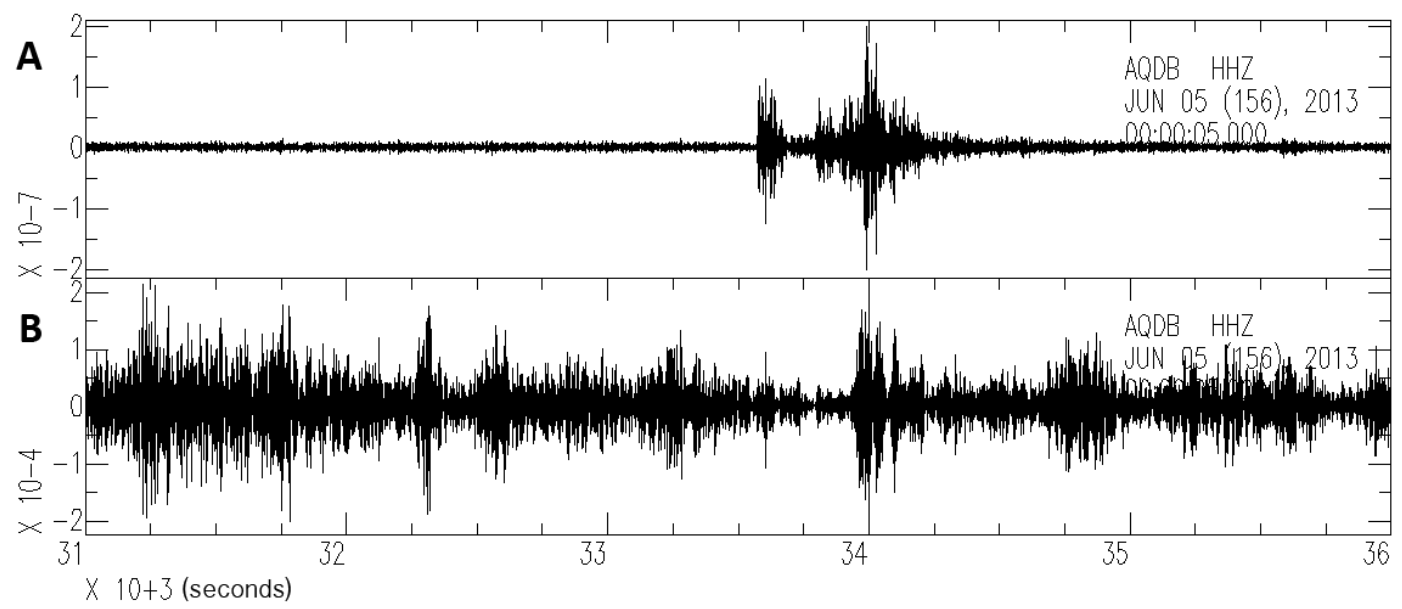

Figura 3.2: An example of the time normalization method applied in this work, bandpass filtered between 20 and $100 \mathrm{~s}$ period to clarify the contamination by the earthquake signal. A:Raw data showing a large earthquake $(\mathrm{Ms}=5.9$, Peru-Brazil Border Region ) recorded at station AQDB in Brazil. B: Running absolute mean normalization method in which the weights are defined on the bandpass filtered data in (a)

\subsubsection{Normalização Espectral (Spectral Whitening)}

O ruído ambiental não é plano no domínio de frequência, apresentando picos próximo a $15 \mathrm{~s}(0.07 \mathrm{~Hz}$ - ruído microssísmico primário) e a $7.5 \mathrm{~s}(0.13 \mathrm{~Hz}$ - ruído microssísmico secundário), além de aumentar consideravelmente a partir de $50 \mathrm{~s}(0.02 \mathrm{~Hz})$, constituindo o sinal conhecido como Earth's Hum (RHIE e ROMANOWICS, 2004).

A Figura 3.3 mostra um exemplo de um espectro de amplitude de um sismograma com 24h de dados contínuos (estação AQDB em Aquidauana-MS), gerado após ter sido realizada a normalização espectral. É possível notar claramente a presença dos picos microssísmicos primário e secundário.

Pode-se verificar facilmente que a amplitude do ruído ambiental é minima entre os 
períodos de 30 e 70s. A normalização espectral atua, então, para ampliar a banda do sinal de ruído ambiental em correlações cruzadas e também combater a degradação causada por outras possíveis fontes de ruído (MOSCHETTI et al., 2007).

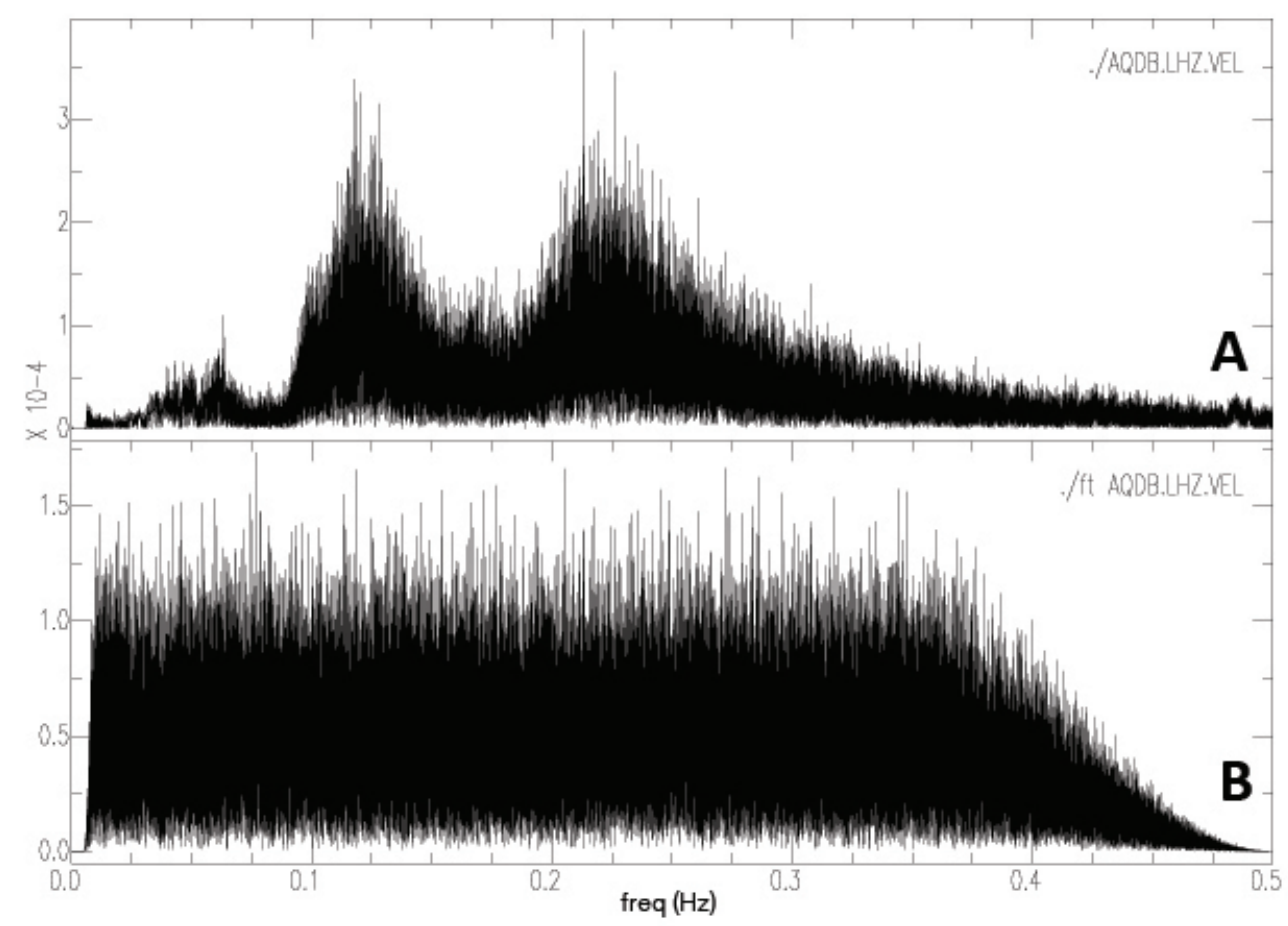

Figura 3.3: (A) Raw and (B) spectrally whitened amplitude spectra for $2 \mathrm{~Hz}$ vertical component data at station AQDB (Aquidauana-MS, Brazil) for June 5, 2013.

Nota-se que a normalização espectral auxilia na produção de curvas de dispersão de banda-larga. O exemplo da figura 3.4, retirada de BENSEN et al. (2007), mostra a comparação entre a correlação cruzada, com e sem o emprego da normalização espectral, para um mês de dados contínuos envolvendo duas estações instaladas nos Estados Unidos.

É possível notar que sem a aplicação da normalização espectral, a correlação cruzada é dominada por sinais oriundos da banda microssísmica, principalmente de 15 a $17 \mathrm{~s}$ e de 6 a 9s. A normalização espectral produz, portanto, um sinal de banda mais larga. 

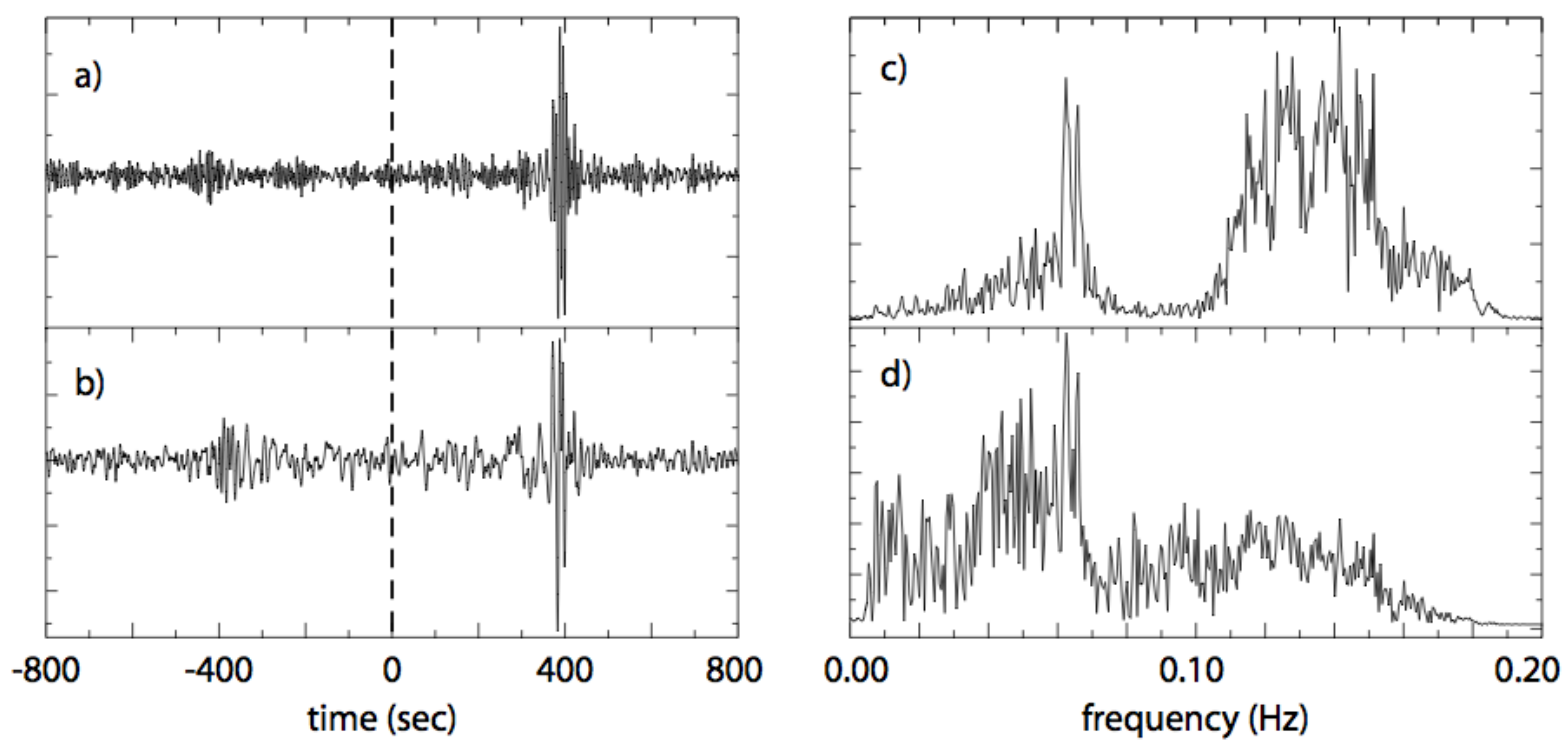

Figura 3.4: Comparison of cross-correlations with and without spectral whitening. Cross-correlation are for the month April, 2004 for data from stations CCM (Cathedral Cave, MO, USA) and SSPA (Standing Stone, PA, USA) bandpass filtered from 7 to 150 s period. (a) Cross-correlation without spectral whitening. (b) Cross-correlation with spectral whitening. (c) Amplitude spectrum of the unwhitened waveform in (a). The primary and secondary microseisms dominate the spectrum. (d) Amplitude spectrum of the pre-whitened waveform in (b) (BENSEN et al., 2007).

\subsection{Correlação de Ruído Ambiental}

Algumas estações apresentam distância ora muito longas (atenuação inelástica), ora muito curtas (insuficiente para o desenvolvimento de ondas de superfície) para que seja possível se obter medidas de dispersão confiáveis. Apesar disso, a correlação entre todos os possíveis pares foram calculadas (1596 Rayleigh e 1081 Love) e o controle de qualidade é feito em uma etapa posterior.

\subsubsection{Obtendo Ondas Rayleigh}

As ondas Rayleigh são obtidas através da correlação cruzada entre as componentes verticais dos diversos pares de estações. Como dito anteriormente, a correlação cruzada utiliza arquivos contínuos diários e é feita no domínio de frequência. 
Com a correlação calculada, o arquivo resultante é empilhado (agora no domínio do tempo) com outros do mesmo par de estações, gerando um arquivo final que possui uma série temporal maior (semanas, meses, anos). Este empilhamento em séries maiores aumenta a razão sinal-ruído do sismograma resultante (WAPENAAR, 2004).

O resultado deste processo é um sismograma que representa uma função temporal de dois lados, um com tempo negativo e outro positivo. - Figura 3.5. A parte positiva é comumente chamada de sinal "causal"e a negativa por sua vez, "acausal". Juntas, elas representam ondas viajando em direções opostas entre as estações.

Se as fontes de ruído ambiental fossem homogeneamente distribuídas em azimute, os sinais causais e acausais de uma determinada correlação deveriam ser idênticos. Contudo, como pode ser observado na Figura 3.5, muitas vezes existe uma assimetria entre estes sinais, indicando uma diferença tanto no processo de origem das fontes de ruído quanto em suas distâncias aos respectivos receptores.

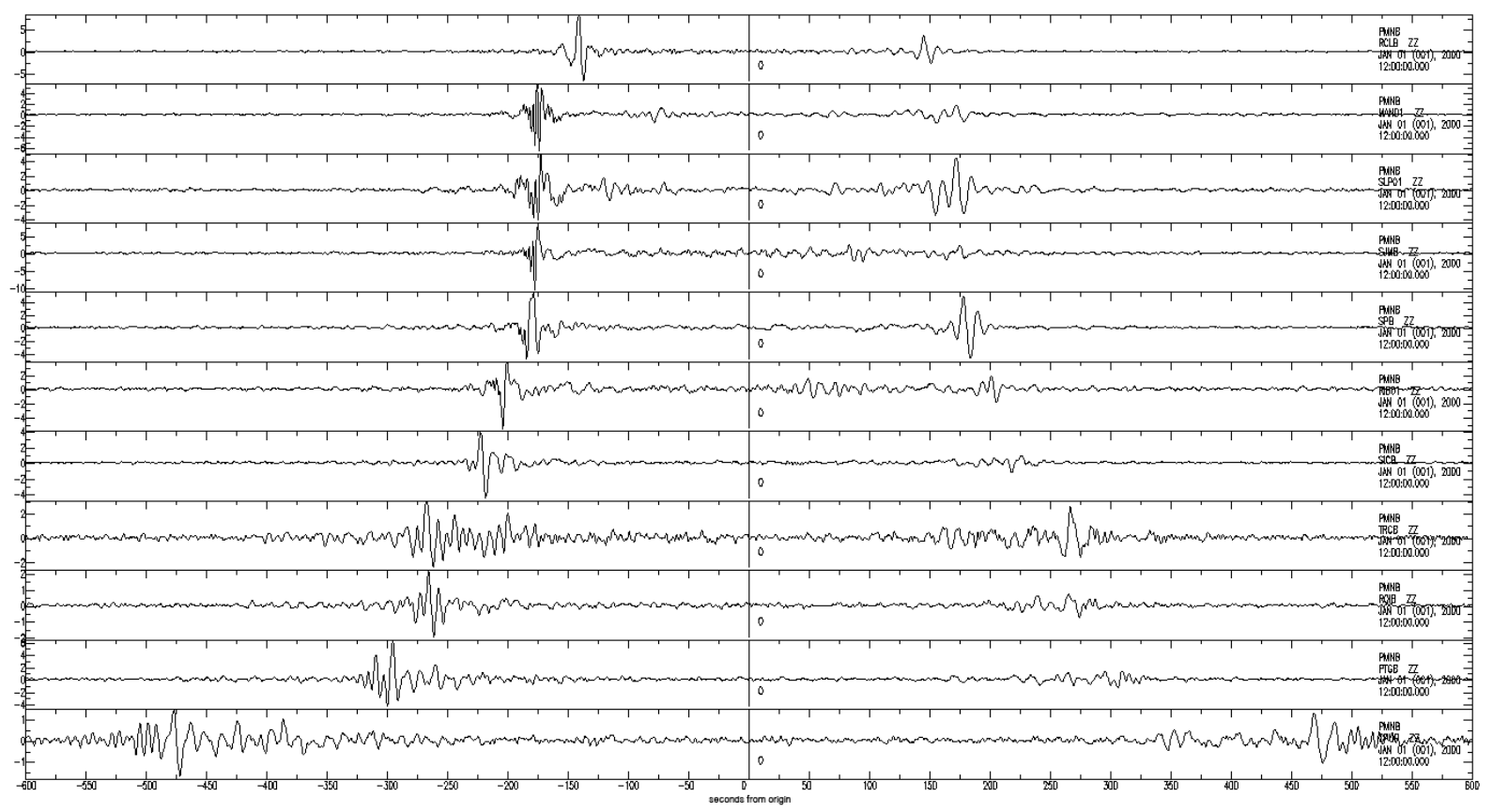

Figura 3.5: Example of vertical-vertical cross-correlations between station PMNB (Patos de MinasMG, Brazil) and some of its possible pairs. The asymmetry observed in amplitude indicates differences in both the source process and distance to the source in the directions radially away from the stations. 


\subsubsection{Obtendo Ondas Love}

A maioria dos trabalhos que envolvem o método ANT, possuem foco apenas na obtenção de ondas Rayleigh, devido principalmente ao alto ruído gerado localmente nas componentes horizontais das estações e ainda, por existir uma dúvida geral quanto à capacidade das fontes de ruído ambiental gerarem ondas Love diretamente. Contudo, estudos mostraram que as ondas Love, surgem claramente da correlação cruzadas das componentes transversais entre dois receptores (RHIE e ROMANOWICS, 2004; STEHLY et al., 2006).

Possuir tanto medidas de dispersão de ondas Rayleigh como Love é importante se for esperada na região de estudo, a ocorrência de anisotropia radial (bifurcação de Vsv e Vsh) como propõe LIN et al. (2008).

Neste trabalho, as ondas Love foram geradas rotacionando-se as componentes horizontais de cada estação em relação às coordenadas de cada possível par. Depois, as componentes transversais obtidas são correlacionadas de maneira semelhante ao procedimento descrito para ondas Rayleigh.

A depender do número de estações, este processo pode ficar bem lento, consumindo muitas horas de processamento computacional mesmo em um servidor apropriado. Uma maneira mais rápida, mas mais susceptível a erros, poderia ser como a descrita por LIN et al. (2008), que rotaciona os sismogramas após a correlação entre todas as componentes terem sido calculadas.

A Figura 3.6 mostra a correlação vertical-vertical e transversal-transversal entre as estações PMNB (Patos de Minas-MG, Brasil) e CPUP (Vila Florida, Paraguai). É possível notar que os sinais surgem tanto na parte negativa quanto na positiva da série temporal e que as ondas Love (componente TT) viajam mais rapidamente, como esperado. Este fato contribui para validar a possibilidade real de extrair ondas Love a partir do ruído ambiental. 


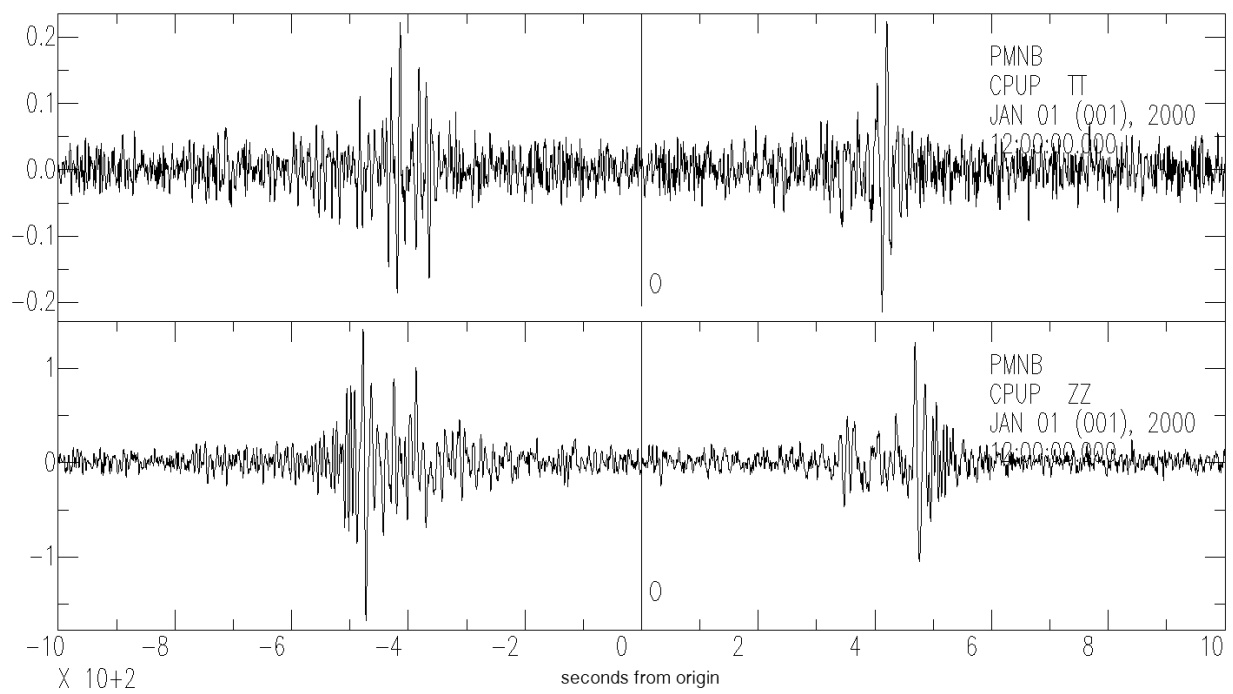

Figura 3.6: Cross-correlations between stations PMNB (Brazil) and CPUP (Paraguay). Signals emerge at both positive and negative correlation lags for Rayleigh(ZZ) and Love(TT) waves. Rayleigh waves clearly travel slower than Love waves, as expected.

\subsubsection{Sismograma Simétrico}

Para a etapa seguinte de processamento, onde são calculadas as curvas de dispersão das onda Rayleigh e Love, os sinais causais e acausais das correlações são comprimidos em um único sismograma cujas amplitudes são uma média dos dois lados da correlação. Este sismograma resultante é denominado sinal simétrico — Figura 3.7.

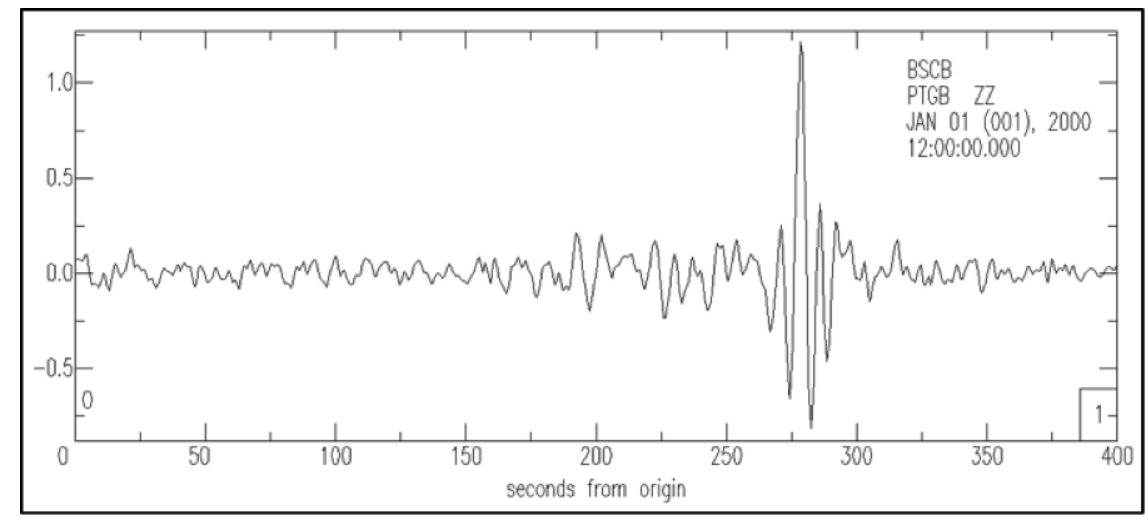

Figura 3.7: An example of a symmetric seismogram, vertical component of BSCB (Bom Sucesso-MG, Brazil) and PTGB (Pitanga-PR, Brazil) obtained by cross-correlation, showing the Rayleigh waves used to generate dispersion curves. 


\subsection{Curvas de Dispersão: Medidas de Velocidade de Grupo}

Nesta seção estão descritas as técnicas empregas para a obtenção das medidas de dispersão de curvas geradas apenas com ANT, contudo, para as etapas de inversão foram também adicionadas leituras derivadas de terremotos andinos, pré-processados anteriormente seguindo os métodos relatados por FENG et al. (2004). As formas de onda provenientes da tomografia convencional são as mesmas utilizadas por FENG et al. (2007), somadas ainda à base de dados de ROSA et al. (2012).

As curvas de dispersão são obtidas aplicando-se um filtro gaussiano aos sismogramas correlacionados (tanto para as componentes verticais quanto para as transversais), em diferentes períodos, como proposto por HERRMANN (1973).

A máxima amplitude (m/s) em cada período é usada para formar a função envoltória da curva dispersão e o tempo de chegada correspondente ao maior pico de amplitude, é empregado no cálculo da velocidade de grupo (PASYANOS, 2005).

A melhor largura do filtro gaussiano deve variar em função da distância entre os pares de estações e o período, calculado assumindo-se os valores da tabela PREM (DZIEWONSKI e ANDERSON, 1981) para as velocidades de grupo, mas mantido constante para menos de 30s, onde os valores do PREM não são uma boa aproximação.

\subsubsection{Software Utilizado}

As medidas de dispersão foram realizadas com uma versão do programa PGplot Surface Wave Multiple Filter Analysis (PGSWFMA), desenvolvido por Chuck Ammon (Universidade de St. Louis) e aplicado com sucesso por PASYANOS et al. (2001).

O código do PGSWFMA foi originalmente desenvolvido para trabalhar com curvas de dispersão tradicionais, ou seja, obtidas por meio do processamento de dados de terremotos. Para esta pesquisa, algumas modificações no programa original foram necessárias, 
tornando possível a análise da correlação entre pares de estações e, ainda, o processamento das componentes transversais no caso da dispersão da onda Love.

Nesta etapa do trabalho, certo controle de qualidade é necessário para garantir medidas de dispersão confiáveis. A distância entre os pares de estações, irregularidades instrumentais e imperfeições no caminho percorrido pelas ondas, podem resultar em curvas de dispersão muito irregulares. Para eliminar estes potenciais erros, apenas velocidades de grupo medidas a partir de curvas de dispersão contínuas foram aproveitadas.

\subsubsection{Dispersão de Ondas Rayleigh}

A Figura 3.8 apresenta um exemplo de como uma curva de dispersão (onda Rayleigh entre as estações BB19B e PLTB, no Brasil) é analisada usando o PGSWMFA. O painel da esquerda mostra a curva de dispersão a ser analisada, com os contornos do espectro de velocidade e as incertezas associadas.

O painel central exibe o sismograma simétrico em estudo, oriundo da correlação cruzada e base para o cálculo da curva de dispersão. À direita, é possível visualizar o espectro de amplitude como função do período.

Das 970 curvas Rayleigh analisadas, 105 foram eliminadas. Um exemplo de uma curva de dispersão que deve ser descartada, por não apresentar medidas de velocidades confiáveis, pode ser verificada na Figura 3.9 (onda Rayleigh entre as estações TER01 no Brasil e LVC no Chile). A distância entre as estações, neste caso, pode ter sido grande demais. Nota-se que nem mesmo é possível visualizar a onda Rayleigh emergindo na correlação cruzada exibida no sismograma do painel central. 


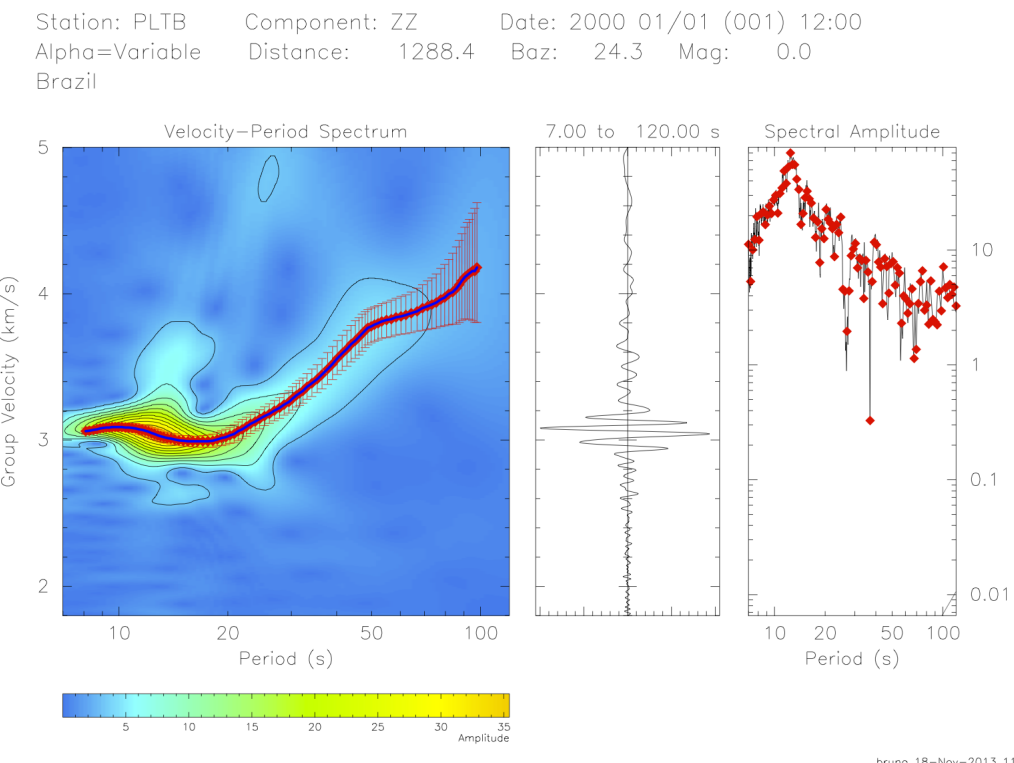

Figura 3.8: An example of group velocity measurements made by PGSWMFA using two years of correlation data for the station pair BB19B-PLTB in Brazil. The countours of the velocity-period spectrum are shown in the left figure. The Rayleigh wave is in the center and the right figure shows the spectral amplitude as a function of period.

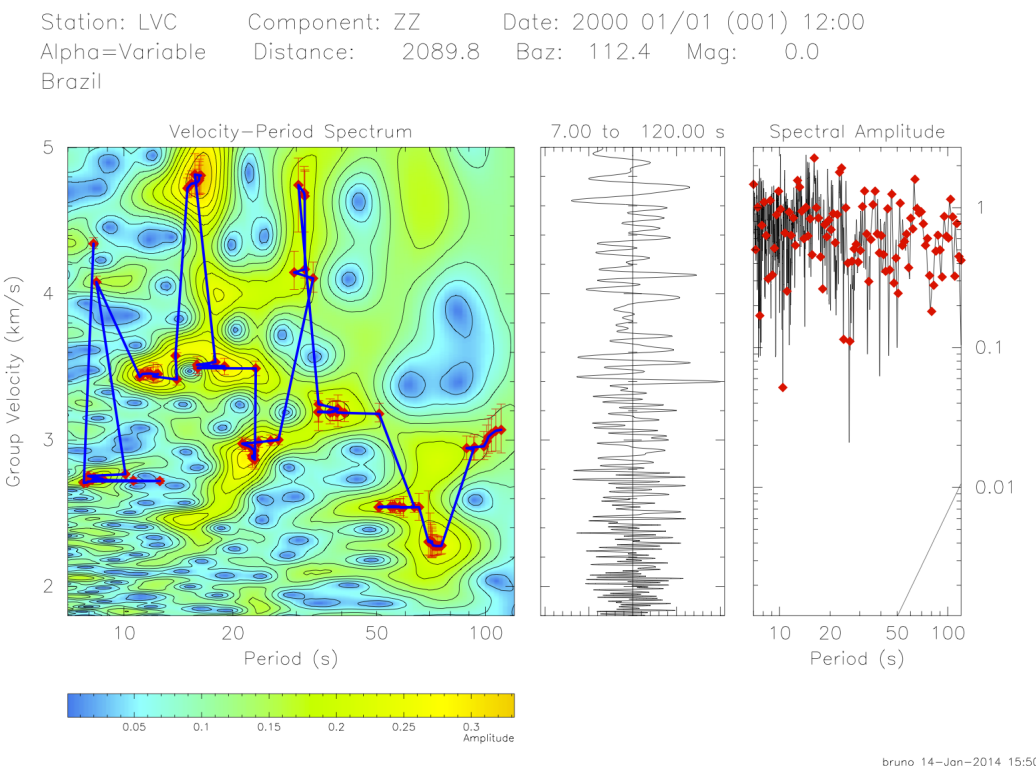

Figura 3.9: An example of a bad dispersion curve using about two years of cross-correlation between stations TER01, Brazil and LVC, in Chile. Note that not even a Rayleigh wave can be seen in the seismogram of the center painel. This might indicate some problem in one of the stations. 


\subsubsection{Dispersão de Ondas Love}

As curvas de dispersão de ondas Love são obtidas aplicando-se o mesmo filtro gaussiano para Rayleigh, mas agora nas correlações entre as componentes transversais dos possíveis pares de estações. Ao todo foram geradas 971 curvas de dispersão Love, das quais foram aproveitadas 718 .

A Figura 3.10 exibe a curva de dispersão gerada pela correlação de ruído entre as estações BB19B e ITAB no Brasil. Como esperado, a curva apresenta de um modo geral velocidades superiores para cada período quando comparada com a Figura 3.8. Ainda, é fácil perceber que a energia se concentra nos períodos mais curtos, propriedade característica das ondas Love.

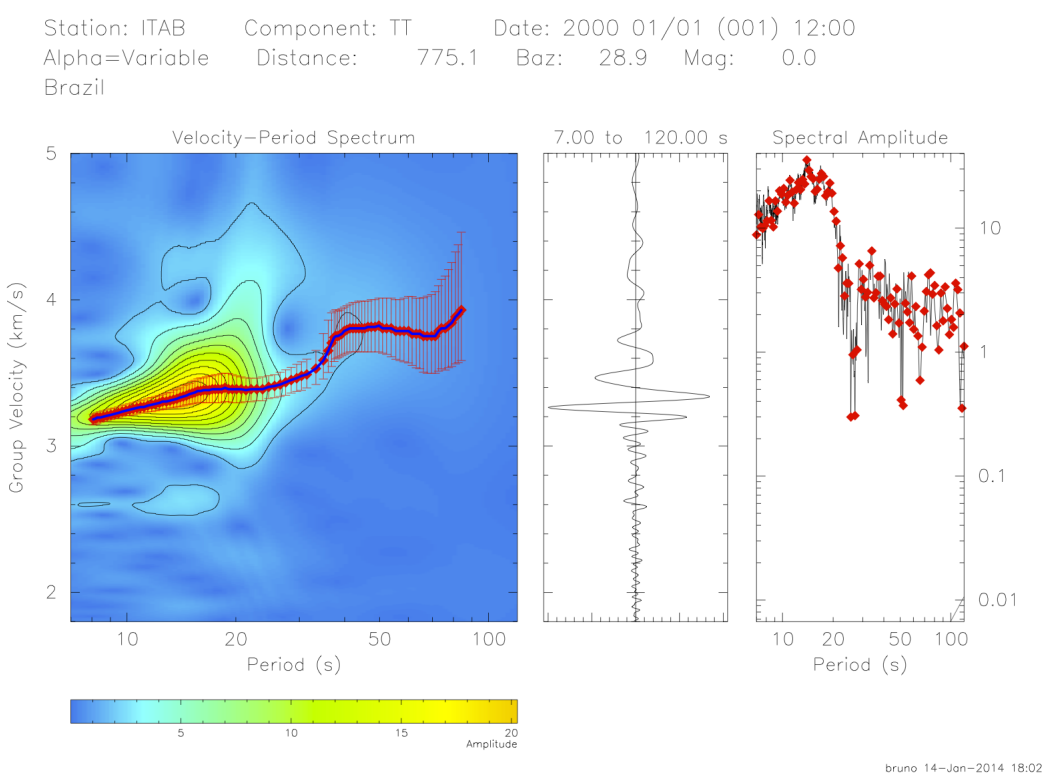

Figura 3.10: An example of group velocity measurements for Love waves made by PGSWMFA using two years of correlation data for the station pair BB19B-ITAB in Brazil. Note that energy is concentrated in the shorter periods. 


\subsection{Tomografia de Ruído Ambiental}

A tomografia desenvolvida neste trabalho é baseada em duas inversões independentes: a inversão dos tempos de percurso para a variação lateral das velocidades de grupo (tomografia 2D, descrita nesta seção) e em seguida, a inversão 1D das curvas de dispersão regionais para obter espessuras de sedimentos, profundidades da crosta e manto superior (etapa a ser discutida na próxima seção).

Este método de dividir a tomografia em duas etapas distintas é o normalmente empregado, com sucesso, em trabalhos anteriores (RITZWOLLER e LESHVIN, 1998; VUAN et al., 2000; VILLASEÑOR et al., 2001; PASYANOS et al., 2001; HUANG et al., 2003; YANOVSKAYA e KOZHEVNIKOV, 2003; FENG et al., 2004; PASYANOS, 2005; FENG et al., 2007).

\subsubsection{Variação Lateral de Velocidades de Grupo}

Por se tratar de uma metodologia relativamente nova (empregada inicialmente por SHAPIRO et al. (2005)), não constam registros na literatura sobre o emprego de ANT no Brasil ou até mesmo na América do Sul. Posto isto, será apresentada nesta seção uma comparação entre duas técnicas distintas para a confecção dos mapas de tomografia 2D, no intuito de avaliar possíveis instabilidades e/ou limitações.

Apesar de empregarem diferentes técnicas de suavização, como será mencionado adiante, ambas as metodologias utilizam o método do gradiente conjugado, eficiente processo iterativo para resolução de grandes sistemas lineares e usualmente empregado em tomografia (ex. VAN DER LEE e NOLET (1997); PASYANOS et al. (2001); MARONE et al. (2003); SCHIMMEL et al. (2003); FENG et al. (2004)). 
Gradiente Conjugado (1 ${ }^{a}$ Derivada)

Utilizado por FENG et al. (2004), este método confecciona um grid que subdivide a região de estudo em células, cujas dimensões foram definidas como sendo 1 x 1 grau. A velocidade de grupo em cada célula é determinada minimizando-se a função:

$$
\left\|T s-t^{2}\right\|^{2}+\lambda\|\Delta S\|^{2}
$$

onde $T$ é a matriz do comprimentos dos percursos em cada célula, $s$ é o vetor de vagareza e $t$ é o vetor tempo de percurso observado. O parâmetro $\Delta S$ representa o primeiro gradiente espacial do modelo, possuindo a função de suavizar os mapas finais de velocidade. Por fim, $\lambda$ é o fator que controla o ajuste dos dados e a suavização do modelo, quanto maior o período, maior deve ser o $\lambda$ escolhido. Neste trabalho foi escolhido $\lambda=5$ para todos os períodos.

Os resultados vão depender, em parte, do valor escolhido para $\lambda$. Se o grau de suavização for muito pequeno, a inversão ajusta demais os dados e os mapas apresentam vários artefatos devido à mudança abrupta nos valores de velocidades. Se $\lambda$ for grande demais, o ajuste dos dados é pobre e poucas anomalias se sobressaem nos mapas.

\section{Gradiente Conjugado (2a Derivada)}

Este método foi executado com sucesso por PASYANOS et al. (2001) e PASYANOS (2005). Para estimar a variação lateral nas velocidades de grupo, é construído um grid que divide a área de estudo e a vagareza (inverso da velocidade de grupo) é determinada em cada célula (foram escolhidas células de 1 x 1 grau). A equação do tempo de percurso é a seguinte:

$$
t=\sum d_{i} s_{i}
$$


onde $\mathrm{d}_{i}$ é a distância percorrida pela onda na célula $i$ e $\mathrm{s}_{i}$ é a vagareza no meio. Para um determinado número de percursos, a série dessas equações pode ser representada pela matriz:

$$
T=D s
$$

Além disso, é imposta ainda uma constante de suavização para o ajuste dos dados, criando-se o laplaciano ( $2^{a}$ Derivada) da vagareza e fixando este como sendo zero (LEES e CROSSON, 1989), por meio da matriz:

$$
\lambda \Delta s=0
$$

onde $\Delta s$ é o laplaciano da vagareza. A constante $\lambda$ controla o equilíbrio entre o ajuste dos tempos de percurso e a suavização do modelo. Assim como outros métodos que utilizam gradiente conjugado, a convergência da equação será atingida quando a quantidade de iterações atingir o total de equações de restrição (PAIGE e SAUNDERS, 1982), por exemplo: quantidade de percursos mais número de constantes de suavização.

Na prática, a convergência depende de ambos os resíduos e distâncias entre as sucessivas iterações e é atingida neste conjunto de dados, bem mais rapidamente, em média após 30 iterações.

\subsubsection{Perfil Vertical de Velocidades}

Esta última fase do processamento consiste em construir uma curva de dispersão para cada célula presente no grid de inversão (subsequente da etapa anterior), de maneira semelhante à aplicada por PASYANOS et al. (2001). As curvas são construídas tomandose os resultados da inversão 2D para todos os períodos em um mesmo ponto do grid. Estas curvas de dispersão resultantes são então invertidas utilizando-se um modelo de velocidades em camadas (1D) que minimize os resíduos. 
Para a confecção dos modelos, quatro camadas com características e espessuras diferentes foram aplicadas: sedimentos, crosta e manto superior. A espessura dos sedimentos variou de 0-6 km, 30-50km para o total de espessura crustal, velocidades de $6,2-6,6 \mathrm{~km} / \mathrm{s}$ para a onda $\mathrm{P}$ na crosta e $7,8-8,2 \mathrm{~km} / \mathrm{s}$ no manto superior.

Nos modelos sintéticos, a crosta foi ainda divida em superior e inferior, com densidades de 2.8 e $3.0 \mathrm{~g} / \mathrm{cm}^{3}$ e as velocidades foram tomadas multiplicando-se os valores escolhidos por 0,95 e 1,05 respectivamente. A mesma razão $\mathrm{Vp} / \mathrm{Vs}$ foi aplicada a todas as camadas, mantendo portando constante o coeficiente de Poisson.

É possível modelar a estrutura crustal na região da Bacia do Paraná, portanto, realizando uma inversão 1D em intervalos regulares de 1 grau de distância. A Figura 3.11 ilustra um exemplo de inversão 1D para um ponto localizado na parte norte da Bacia do Paraná.

Esta etapa poderia ser chamada de inversão 3D, contudo, inversões mais robustas deveriam levar em consideração uma maior quantidade de camadas, além de um número mais expressivo de variáveis (modelos sedimentares, velocidades de fase, funções do receptor, etc.) a fim de garantir a unicidade dos resultados. 


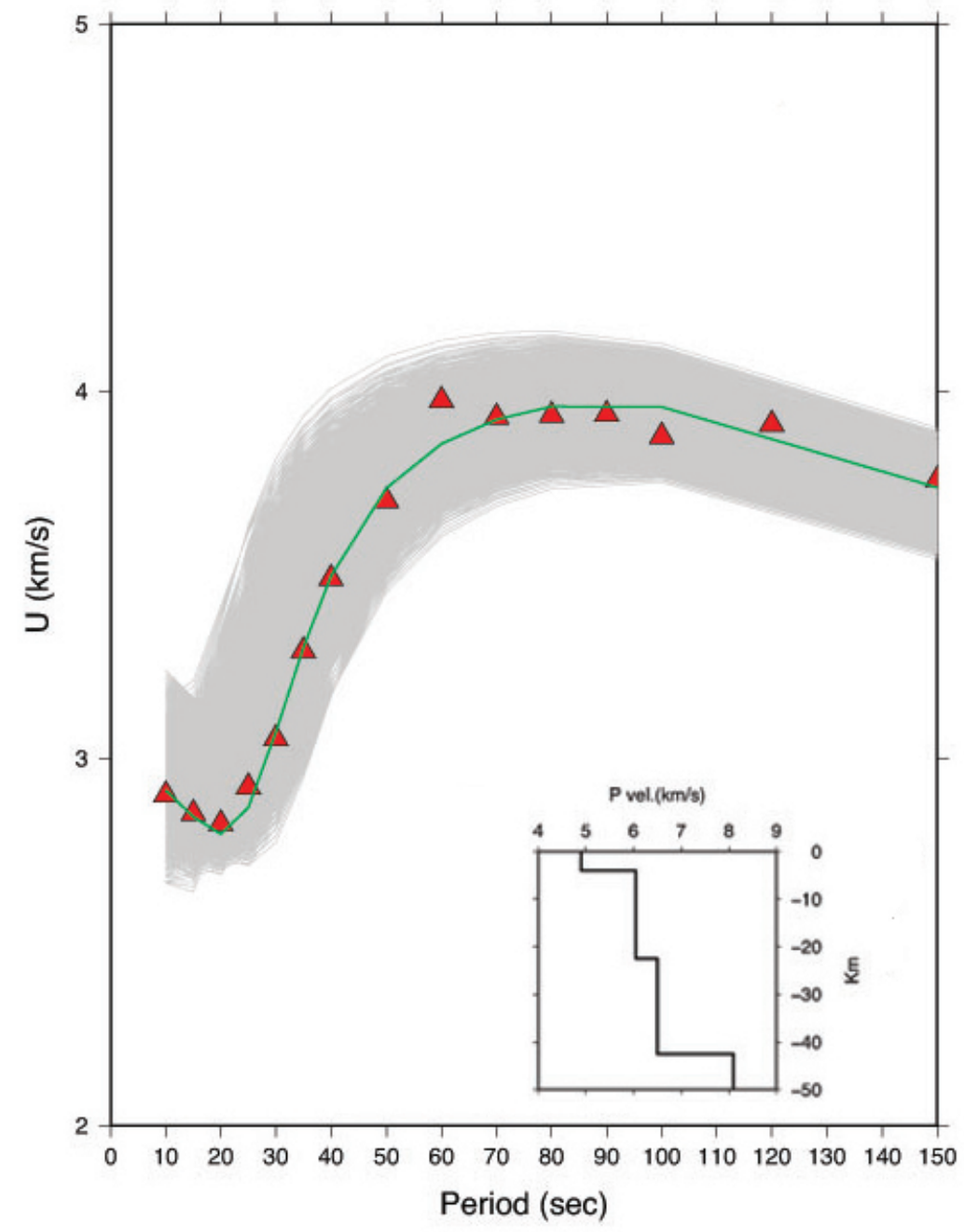

Figura 3.11: An example of layered velocity modelling. Red triangles are observed velocities and green line is the best dispersion curve among all gray curves. The inset shows the best-fitting velocity model derived from the green dispersion curve. 


\section{Capítulo 4}

\section{Mapas de Tomografia: Resultados e Discussão}

\subsection{Análise de Resíduos e Filtro de Erros}

A análise dos resíduos médios (rms) das velocidades de grupo é um dos principais fatores para avaliar as inversões de modelos tomográficos (RITZWOLLER e LESHVIN, 1998; VDOVIN et al., 1999), calculado através da expressão:

$$
r m s=\sqrt{\frac{1}{N} \sum_{i=1}^{N}\left(t_{i}^{o b s}-t_{i}^{c a l c}\right)^{2}}
$$

onde $N$ é o número de percursos de um determinado período (e tipo de onda), $t_{i}^{\text {obs }}$ e $t_{i}^{c a l c}$ são os tempos de percurso observados e calculados, respectivamente, para o i-ésimo percurso.

As figuras a seguir mostram a média dos resíduos obtida para cada período das ondas Rayleigh (Figura 4.1) e Love (Figura 4.2), e para cada grau de suavização escolhido. Embora $\lambda=2$ apresente a menor média rms, os mapas tomográficos apresentados neste trabalho foram elaborados utilizando-se $\lambda=5$, por melhor suavizar as feições geológicas sem aumentar demasiadamente o nível $\mathrm{rms}$. 
Average Residuals for Rayleigh Waves

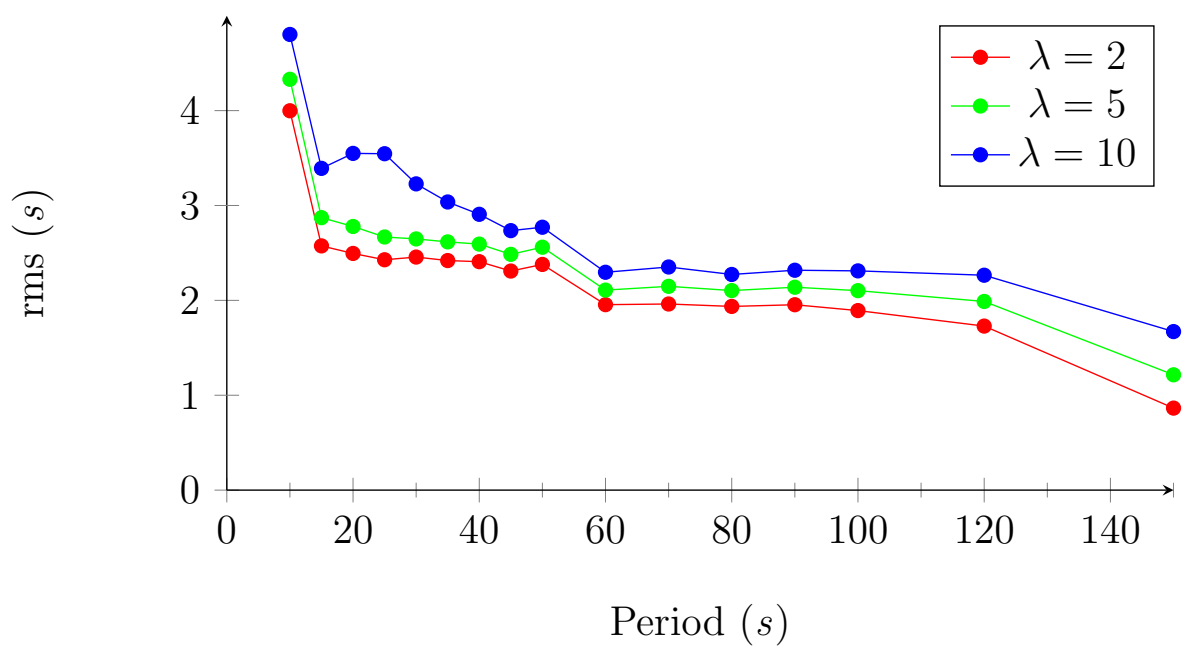

Figura 4.1: Rayleigh waves group-velocities average residual (rms) according to chosen smoothing factor $(\lambda)$. All the tomographic maps were built using $\lambda=5$, the best choice between fitting the travel-times and smoothing the model.

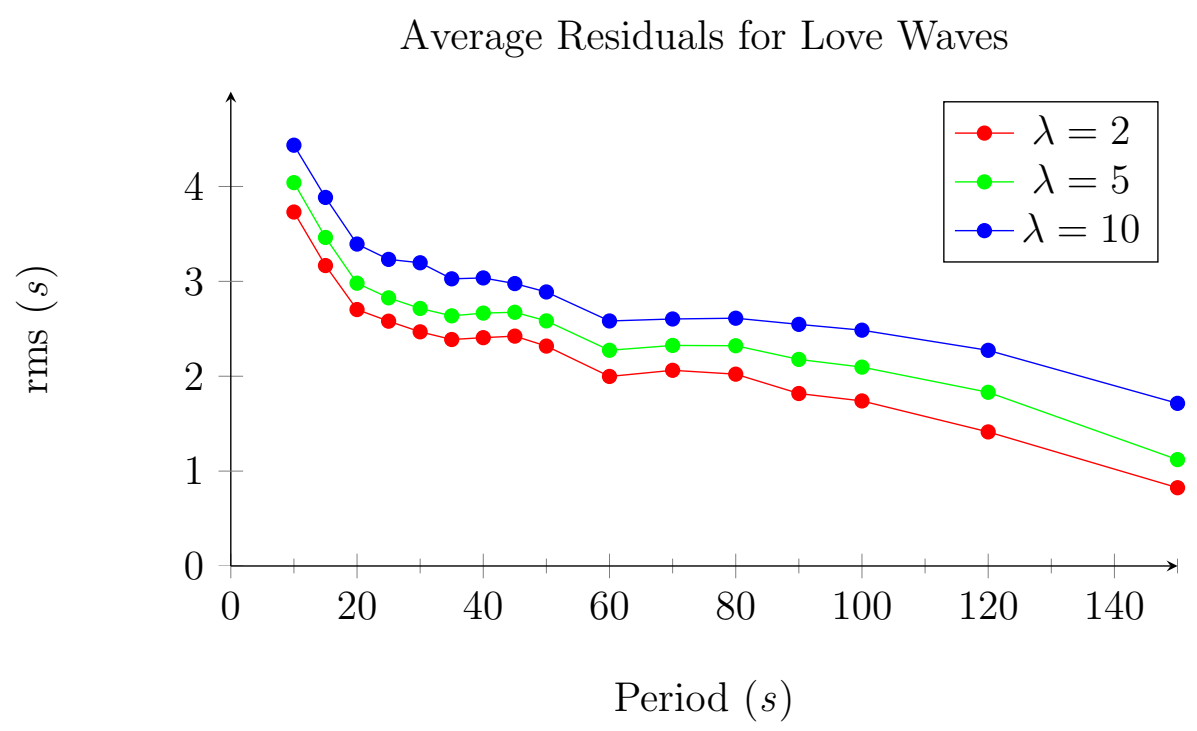

Figura 4.2: Love waves group-velocities average residual (rms) according to chosen smoothing factor $(\lambda)$. 
Além da avaliação dos resíduos rms, a análise de cada dado também é muito importante em qualquer inversão ou ajuste. Programas de inversão robustos deveriam se proteger de medidas errôneas, mas nem sempre isso acontece. Essa proteção pode ser feita através de uma inversão preliminar com todos os dados e uma segunda, ou várias outras, colocando pesos menores aos dados com resíduos altos da iteração anterior (inversão "robusta").

Ambos os métodos de inversão descritos acima possuem esse artifício, o problema é que nem sempre, dados muito errados são eliminados, principalmente nos dados provenientes das leituras de terremotos e quando a suavização é baixa. Como consequência, o modelo final pode apresentar feições estranhas, por ter de ajustar alguns poucos percursos com dados ruins.

Pode-se comprovar um exemplo deste problema através da Figura 4.3, que mostra um mapa preliminar das velocidades de grupo (Rayleigh) para o período de 100s.

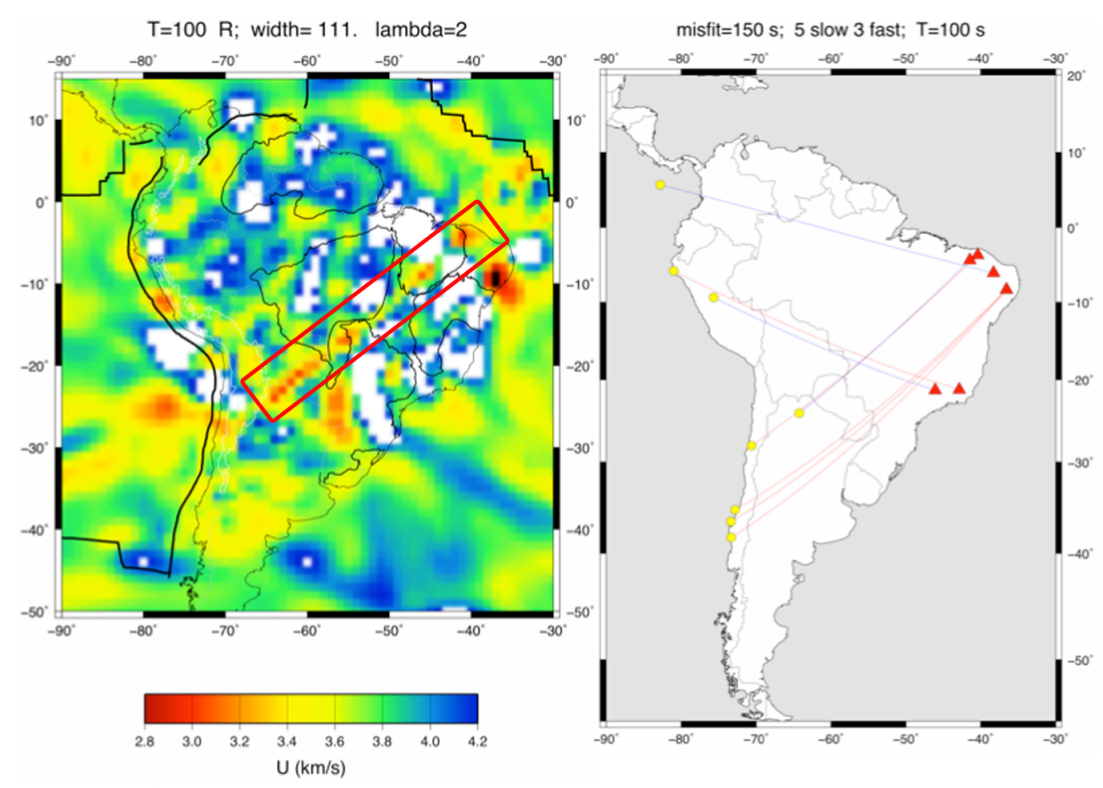

Figura 4.3: Left) Rayleigh group velocity map for $\mathrm{T}=100$ s. Note a strange "Transbrasiliano Lineament", feature generated by a path with too high residual. Right) Paths with residuals more than 150s (red lines) and less than -150s (blue lines).

Um único percurso (destacado) entre um evento no Chile e uma estação em Natal-RN, apresentou um resíduo de 400s, gerando um artefato no mapa de velocidades exatamente na localização do Lineamento Transbrasiliano. 
A velocidade medida para este percurso foi de $2.04 \mathrm{~km} / \mathrm{s}$, muito baixa para $\mathrm{T}=100 \mathrm{~s}$. $\mathrm{O}$ uso de um filtro que remove as velocidades menores que $2.5 \mathrm{~km} / \mathrm{s}$ elimina a feição artificial do mapa. - Figura 4.4.

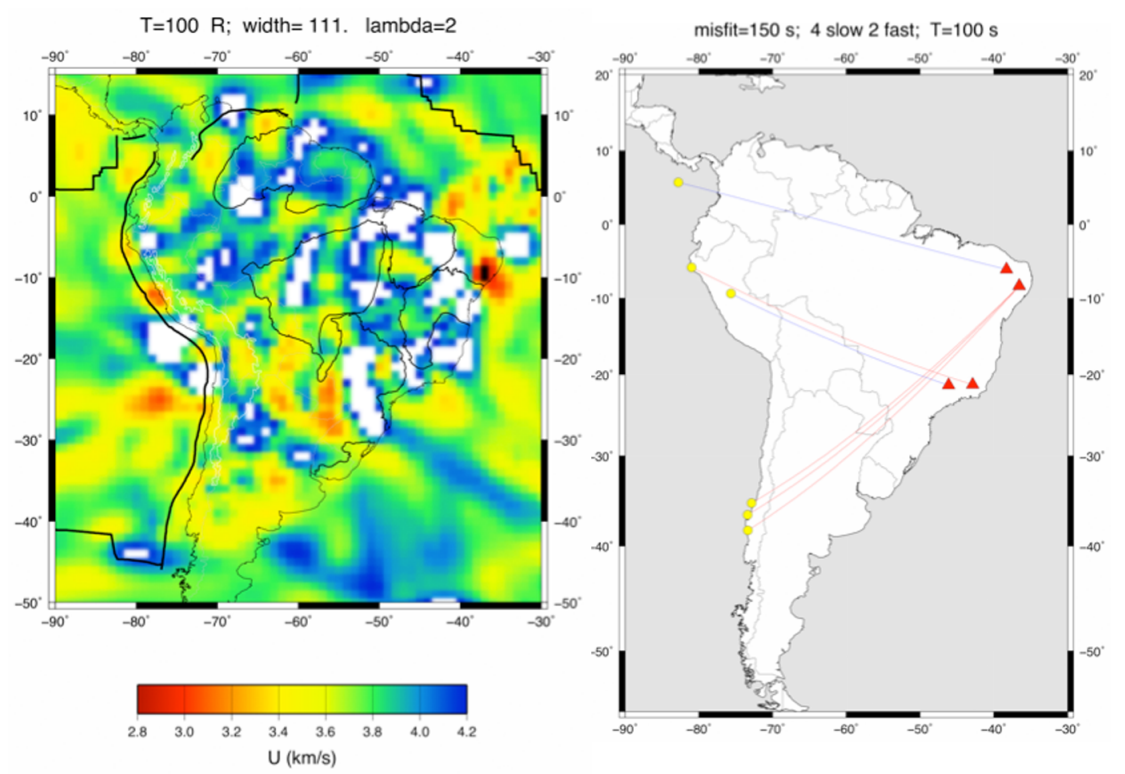

Figura 4.4: Rayleigh group velocity map for $\mathrm{T}=100$ s after removing one bad path.

Erros dessa grandeza, quase 7 minutos, podem ser gerados por diversos fatores que merecem investigação: problemas no cabeçalho dos sismogramas (mais comum), eventos registrados com baixa razão sinal/ruído ou profundidades grandes, ou ainda, percursos com efeitos de refração sísmica, em que a hipótese de trajetória retilínea não se aplica.

\subsection{Mapas de Velocidade de Grupo: Inversão 2D}

Foram elaborados mapas de velocidade de grupo (Rayleigh e Love, disponíveis no Apêndice A) para períodos entre 10 e 150s, mas apenas os períodos de 15, 50 e 100s serão analisados nesta seção, por melhor ressaltarem as feições geológicas de interesse neste estudo. 
As interpretações dos mapas de tomografia a seguir são baseadas nas principais províncias geotectônicas da América do Sul, exibidas na Figura 4.5.

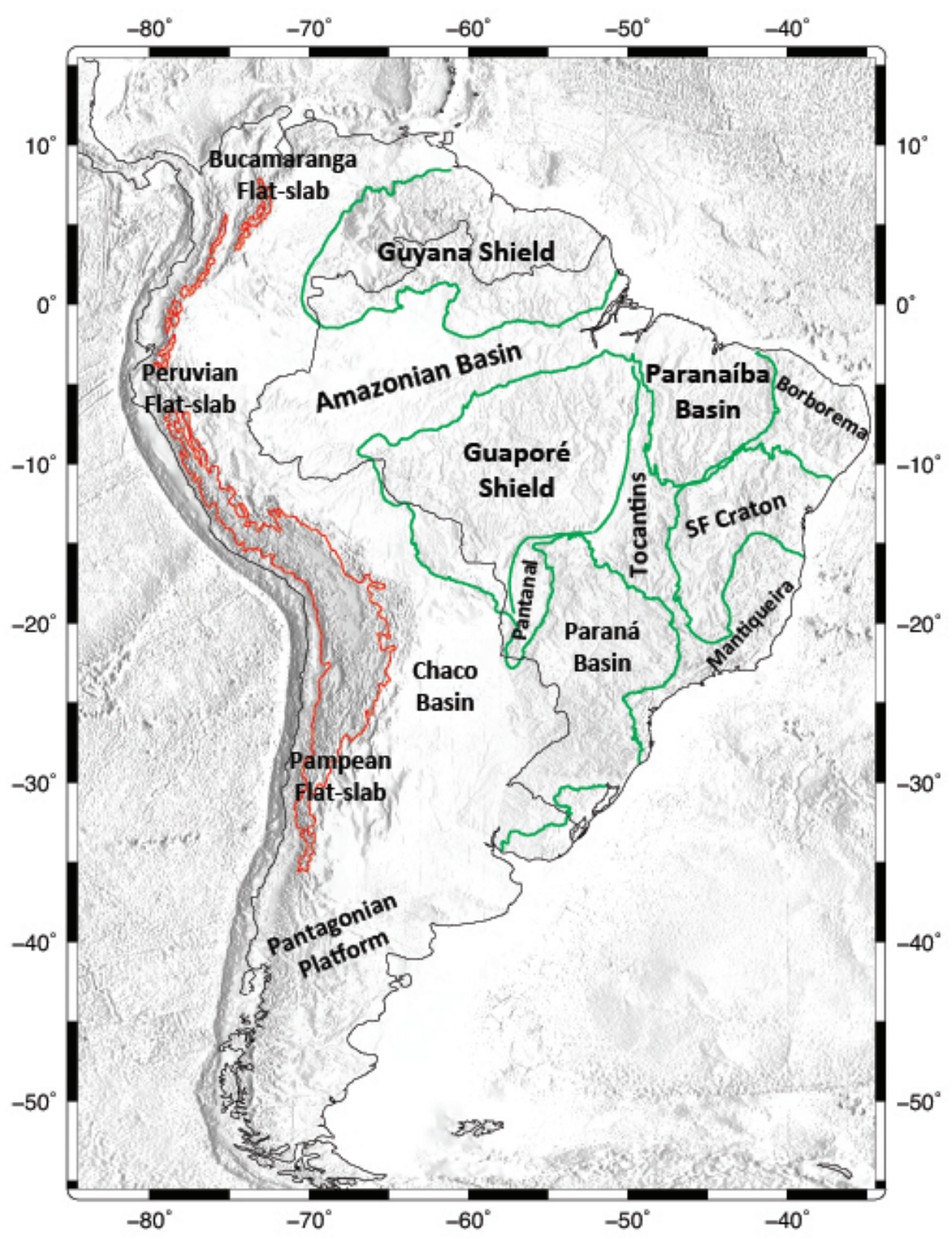

Figura 4.5: Schematic map of South America displaying the most important geotectonic provinces. 


\subsubsection{Rayleigh vs Love: Aspectos Importantes}

A quantidade de percursos em função do período é fator importante na análise de resultados, pois delimita as regiões onde a inversão apresenta maior resolução. O gráfico da Figura 4.6 exibe o total de percursos para cada período, e evidencia a diferença entre a resolução dos mapas de velocidades Rayleigh e Love.

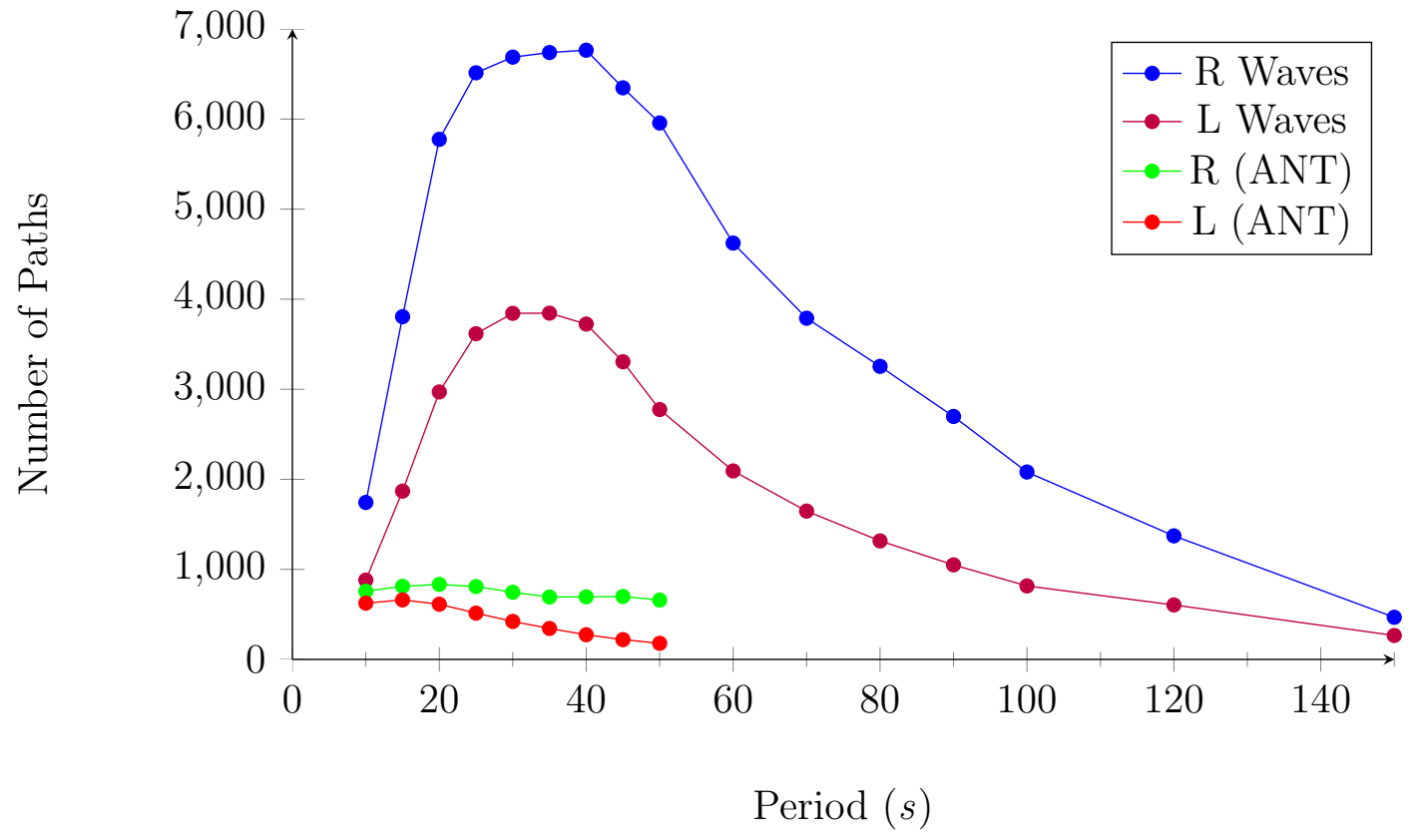

Figura 4.6: Number of paths as a function of period for Rayleigh and Love waves.

Para auxiliar na interpretação dos mapas de velocidade, é utilizado o chamado kernel de sensibilidade das ondas superficiais, que mostra a relação entre as velocidades medidas nas curvas de dispersão e a estrutura interna da Terra — Figura 4.7.

De uma maneira geral, com o aumento do período, as ondas de superfície tornam-se mais sensíveis às estruturas mais profundas. Entretanto, existem diferenças no comportamento das ondas Rayleigh e Love. O kernel de sensibilidade das ondas Love possui forma semelhante à uma função exponencial, enquanto que para as ondas Rayleigh, o kernel apresenta uma forma mais gaussiana. 


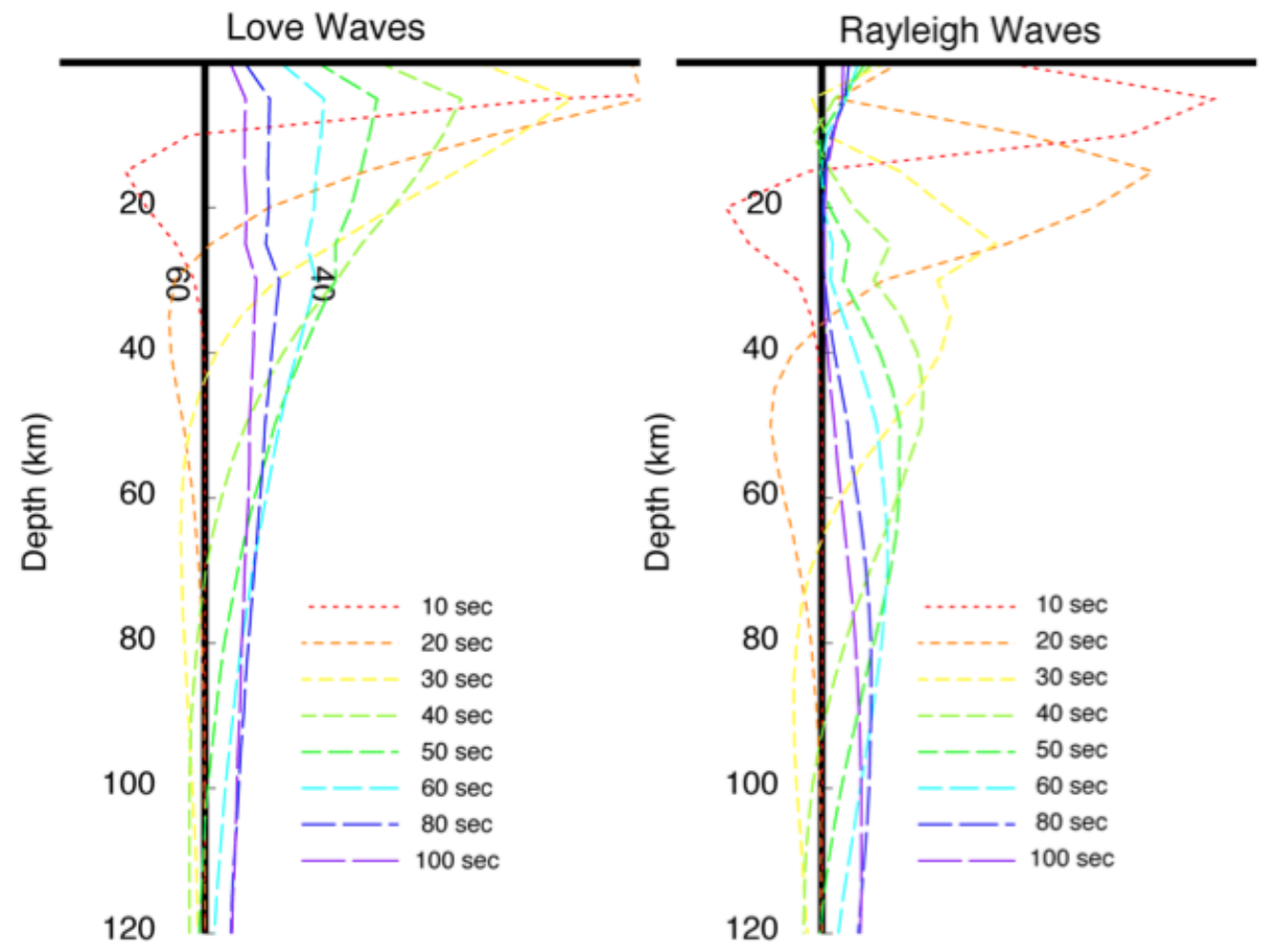

Figura 4.7: Shear wave $\left(V_{s}\right)$ sensitivity kernels of (left) Love and (right) Rayleigh waves at periods ranging from 10 to 100 s for a velocity profile that is typical for continental crust. Extracted from PASYANOS (2005).

Para os períodos maiores, as ondas Love continuam de certa forma sendo mais sensíveis às estruturas mais rasas, o kernel de sensibilidade se apresenta mais plano e sem picos. Em contrapartida, para as ondas Rayleigh, o kernel exibe vários picos em profundidade, por exemplo: $10 \mathrm{~km}$ em $\mathrm{T}=10 \mathrm{~s}, 20 \mathrm{~km}$ em $\mathrm{T}=20 \mathrm{~s}$, etc. Usando essas informações, vamos correlacionar os mapas de velocidade de grupo com as estruturas tectônicas de interesse nesse estudo.

\subsubsection{Bacias Sedimentares}

Como visto com a ajuda do kernel de sensibilidade, nos períodos mais curtos, as ondas superficiais são sensíveis às estruturas mais rasas. Essa característica fica mais clara ao observarmos a Figura 4.8, que mostra os mapas de velocidade de grupo para o período 
de $15 \mathrm{~s}$ (Rayleigh e Love). Em $\mathrm{T}=15 \mathrm{~s}$, as ondas estão amostrando os primeiros $15 \mathrm{~km}$ de crosta, aproximadamente.

Existe uma boa correlação entre as velocidades mostradas para $\mathrm{T}=15 \mathrm{~s}$ e a espessura sedimentar na América do Sul, de um modo geral. Através dos sedimentos as ondas superficiais se deslocam com velocidade bem inferior quando comparadas às regiões de crosta cristalina, característica comprovada nos mapas de ambas as ondas Rayleigh e Love.

Nos mapas, nota-se que as áreas onde estão as bacias sedimentares aparecem destacadas, principalmente nas Figuras 4.8(A) e 4.8(B), que são os mapas de ondas Rayleigh gerados com os métodos de suavização de $1^{a}$ e $2^{a}$ derivadas, respectivamente.

Apesar dos distintos métodos de suavização, os mapas para as velocidades Rayleigh são muito semelhantes e evidenciam as mesmas estruturas. As anomalias de baixa velocidade aqui coincidem com as bacias do Amazonas, do Parnaíba, do Chaco e a própria bacia do Paraná, que se apresenta menos evidente, porém. Parte da assinatura dos sedimentos da Bacia do Paraná, pode estar sendo encoberta pelas intrusões de basalto presentes nesta região segundo VDOVIN et al. (1999).

O mapa de velocidades Love, Figura 4.8(C), apresenta maior instabilidade, pois para o mesmo período as ondas Love sofrem muito a influência de feições de menor escala e mais rasas, quando comparadas às Rayleigh.

Para as ondas Love, o mapa mostra claramente as bacias subandinas, do Chaco e do Paraná, mas as do Amazonas e Parnaíba são menos evidentes. Isso ocorre principalmente devido ao menor número de percursos nestas regiões — Figura 4.9.

Curiosamente, apesar da menor quantidade de percursos no mapa de ondas Love, as baixas velocidades relacionadas aos sedimentos da Foz do Amazonas aparecem em todos os mapas da Figura 4.8. Este fato pode ser explicado pela própria espessura dos sedimentos, que pode chegar a até $8 \mathrm{~km}$ (DRISCOLL e KARNER, 1994). 

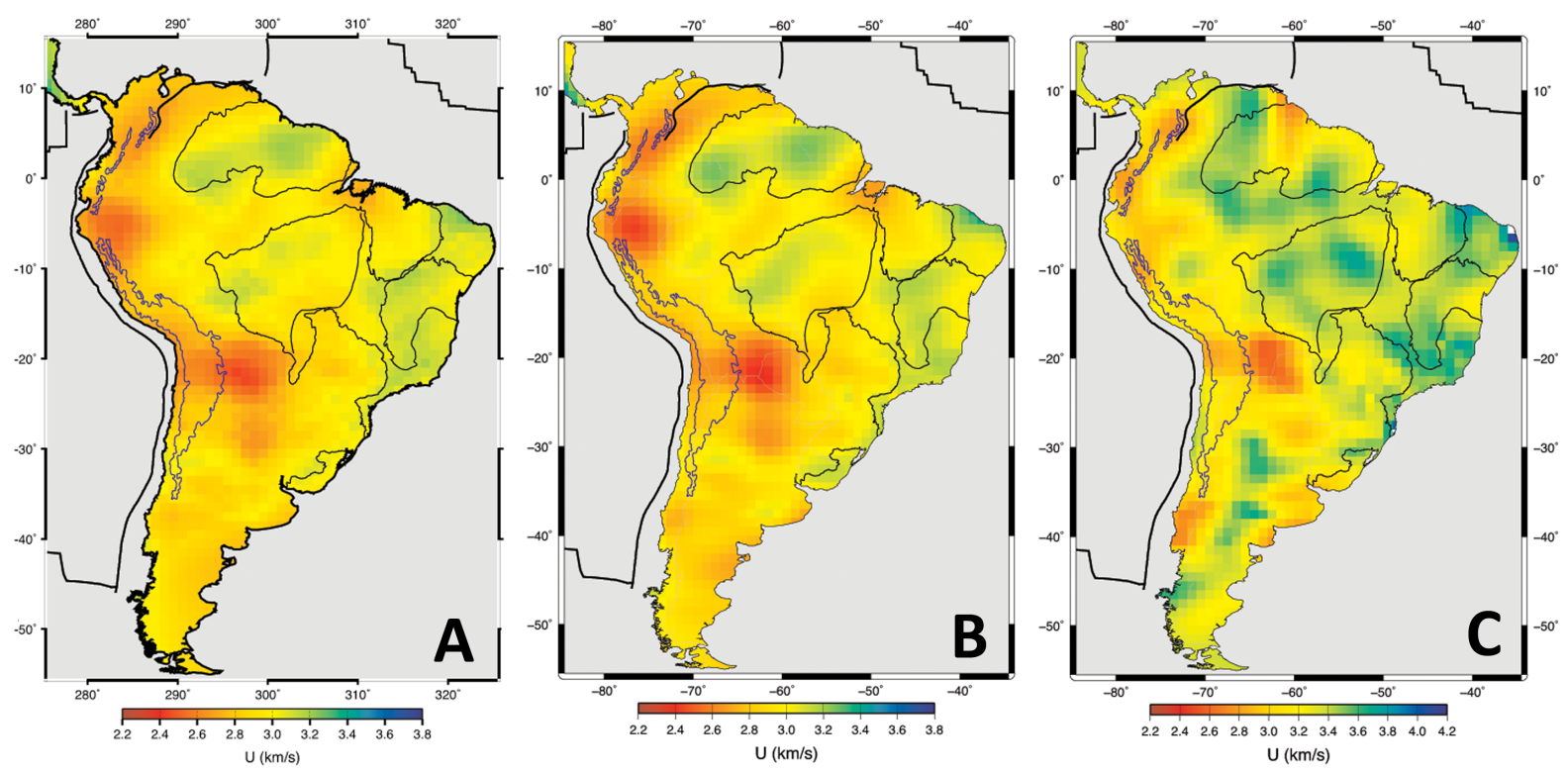

Figura 4.8: Group-velocity maps for $\mathrm{T}=15 \mathrm{~s}$. A) Rayleigh waves with $1^{\text {st }}$ derivative smoothing method. B) Rayleigh waves with $2^{\text {nd }}$ derivative smoothing. C) Love waves with $2^{\text {nd }}$ derivative smoothing. At shorter periods, surface waves are more sensitive to shallow crustal structures, like sedimentary basins.

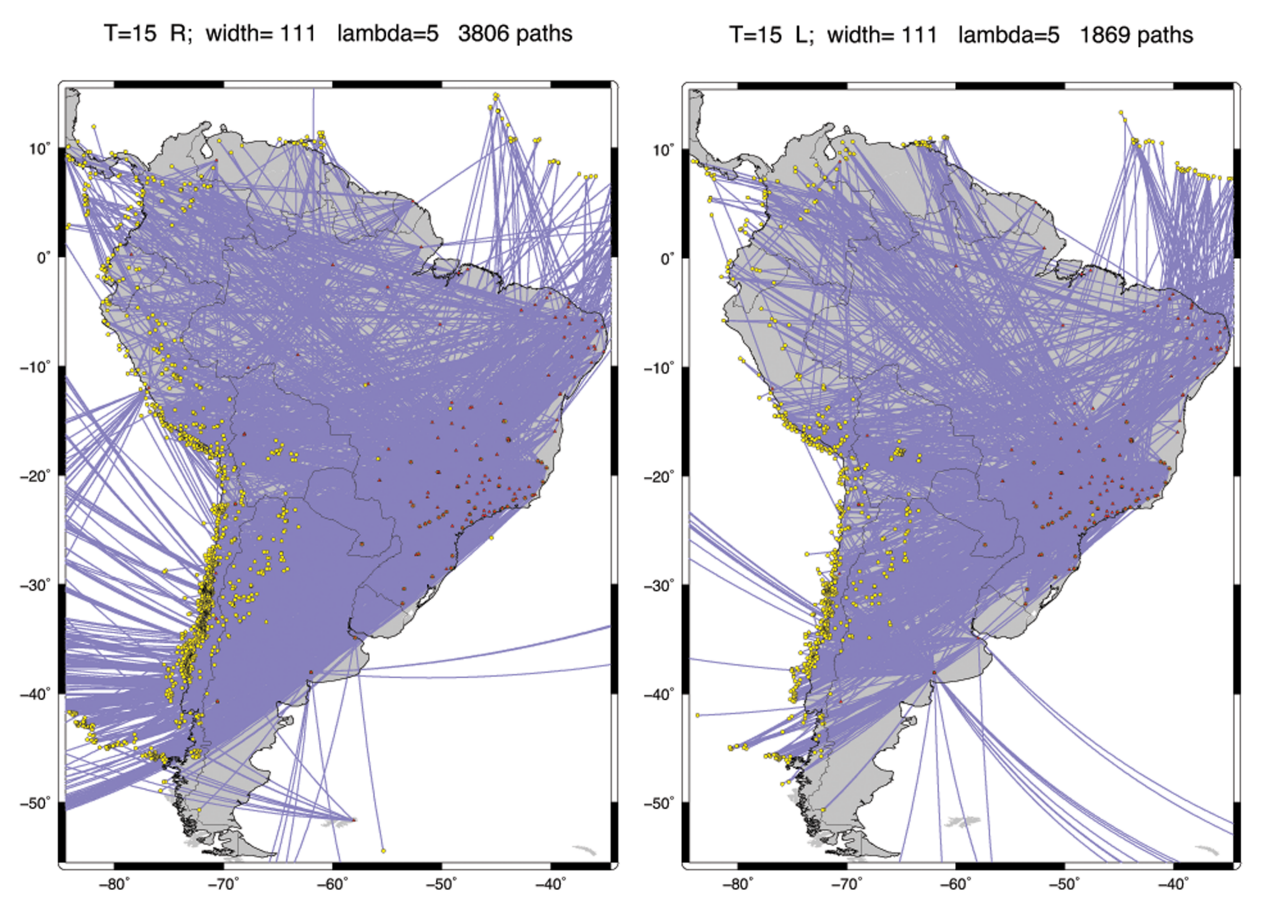

Figura 4.9: Path distribution for $\mathrm{T}=15 \mathrm{~s}$ for Rayleigh (left) and Love waves (right). 


\subsubsection{Espessura Crustal}

Nos períodos intermediários (30-50s), as ondas superficiais são mais sensíveis à espessura da crosta. O mapa para $\mathrm{T}=50 \mathrm{~s}$ (Figura 4.10) pode ser relacionado inversamente com a profundidade da Moho, ou seja, as anomalias de baixa velocidade se encontram em áreas onde a crosta é mais espessa.

Obviamente, para os mapas da Figura 4.10, a feição mais evidente é a anomalia de baixa velocidade que se estende por quase toda a costa do pacífico, seguindo a localização dos Andes. A área de menor velocidade se concentra desde o Altiplano, Bolívia e vai até o sul do Peru, indicando a região onde a raíz dos Andes é mais profunda. Isto pode ser comprovado tanto nos mapas de Rayleigh (A,B), quanto Love (C).

Novamente, são poucas as diferenças entre os mapas de velocidades Rayleigh gerados com os métodos de suavização de $1^{a}$ e $2^{a}$ derivadas, Figuras 4.10(A,B) respectivamente. Apesar da boa correlação entre os mapas Rayleigh, notam-se anomalias de alta velocidade mais ressaltadas na parte sul da Bacia do Pantanal e norte da Bacia do Chaco, além da região oeste do Planalto das Guianas (norte da bacia Amazônica). Porém, de um modo geral e em ambos os casos, toda a Plataforma Continental apresenta anomalias de alta velocidade, o que corresponde com a área mais antiga e estável do continente.

Esta característica não é tão visível para o mapa de velocidades das ondas Love — Figura 4.10(C). É possível perceber, por exemplo, baixas velocidades na parte central da Bacia do Paraná, evidenciando crosta mais profunda nessa região.

O mapa de velocidades Love apresenta ainda, uma estrutura com velocidade alta ao sul do Uruguai e nordeste da Argentina (40S, 65W). Observando as distribuições de percursos, nota-se que esta anomalia muito provavelmente é um artefato devido à própria distribuição dos percursos nesta área (apenas uma estação, LPA em La Plata - Argentina) ou à baixa razão sinal-ruído das ondas Love oriundas da correlação de ruído — Figura 4.11 


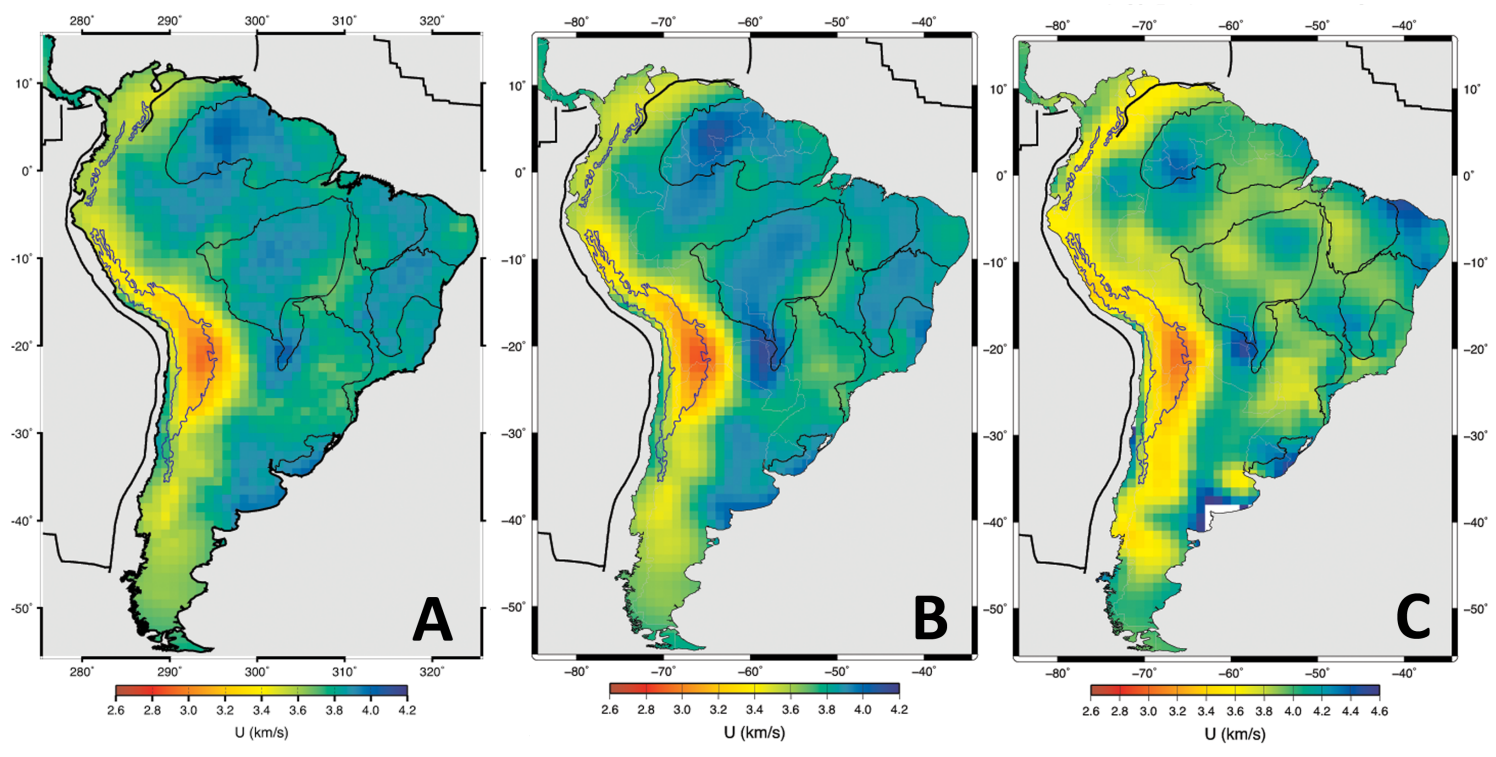

Figura 4.10: Group-velocity maps for $\mathrm{T}=50 \mathrm{~s}$. A) Rayleigh waves with $1^{\text {st }}$ derivative smoothing method. B) Rayleigh waves with $2^{\text {nd }}$ derivative smoothing. C) Love waves with $2^{\text {nd }}$ derivative smoothing. For intermediate periods, surface waves become more sensitive to the average crustal seismic velocity and crustal thickness.
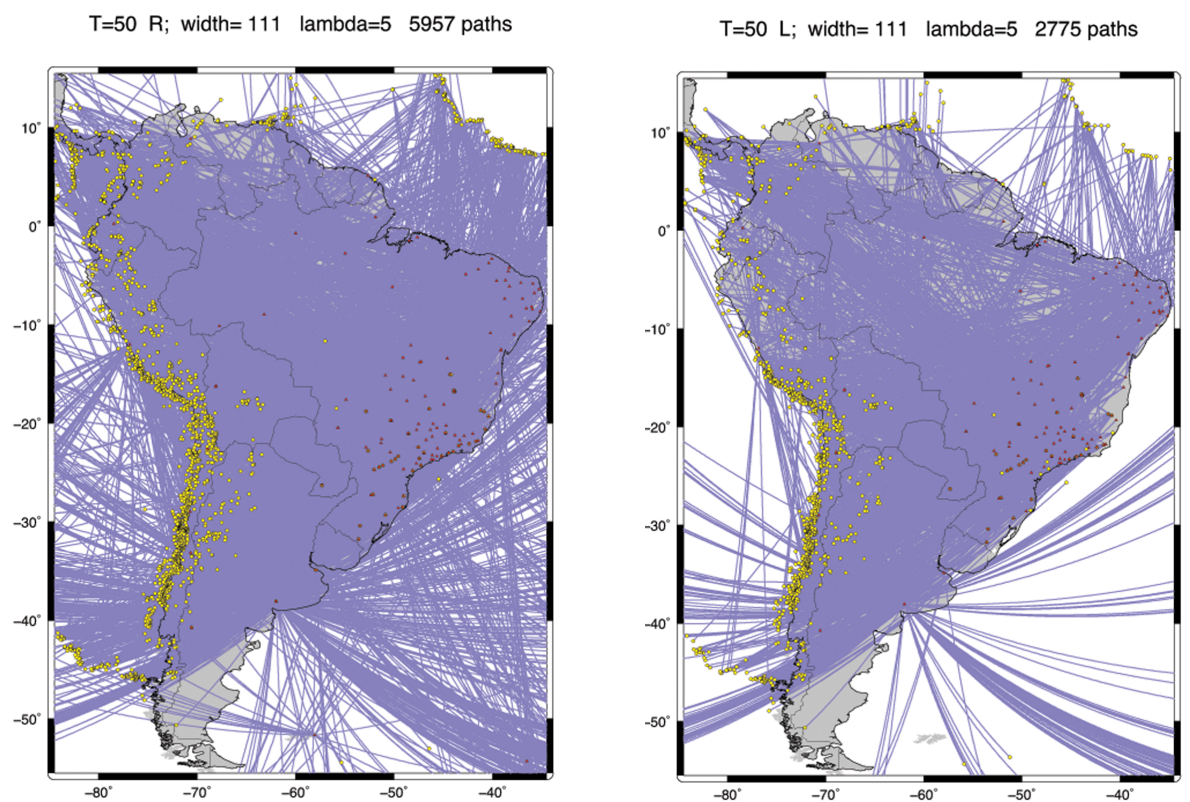

Figura 4.11: Path distribution for $\mathrm{T}=50$ s for Rayleigh (left) and Love waves (right). 


\subsubsection{Litosfera e Manto Superior}

Os períodos mais altos $(>70 \mathrm{~s})$ começam a imagear o manto superior. Para $\mathrm{T}=100 \mathrm{~s}$, as velocidades de grupo Rayleigh (Figura 4.12) são sensíveis até mesmo à estruturas mais profundas no manto, com um máximo de sensibilidade em aproximadamente $100 \mathrm{~km}$ (PASYANOS et al., 2001). É natural que o material da astenosfera apresente velocidades baixas e em contrapartida, o mais frio (litosfera cratônica) possua velocidades altas.

As principais anomalias destacadas nos mapas de velocidades Rayleigh, nas Figuras 4.12(A) e 4.12(B), são as altas velocidades nas regiões do Cráton do Amazonas e do São Francisco e baixas velocidades na Província da Patagônia.

Tais estruturas são visíveis em ambos os mapas Rayleigh, mas estão mais nítidas com o método de suavização de $2^{a}$ derivada - Figura 4.12(B). Curiosamente, para este mapa, podemos notar uma anomalia de alta velocidade em $2 \mathrm{~S} / 50 \mathrm{~W}$ que corresponde ao cráton de São Luís, região mais estável remanescente da união da América do Sul e África.

É possível até mesmo identificar claramente a separação dos Escudos Guaporé e do Cráton do São Francisco, áreas de alta velocidade e portanto litosfera mais espessa, por uma feição de baixa velocidade com direção NE-SW, sugerindo uma possível relação com o Lineamento Transbrasiliano ou com a faixa Araguaia-Paraguai, sendo este portanto, uma faixa de litosfera mais fina.

Ainda com o foco nos mapas de velocidades Rayleigh, pode-se dizer que, grosso modo, toda a extensão da costa do Pacífico apresenta baixas velocidades, causadas provavelmente pela presença de água na astenosfera (ASSUMPCAO et al., 2002). Entretanto, observando-se principalmente o mapa da Figura 4.12(B), percebe-se que a faixa de baixa velocidade ao longo do Andes sofre ao menos três interrupções (10N,75W; 8S,75W; 30S,72W), correspondendo às regiões onde a subducção é mais plana (FENG et al., 2004, 2007) e o fluxo de calor é menor (HAMZA e MUÑOZ, 1996). 


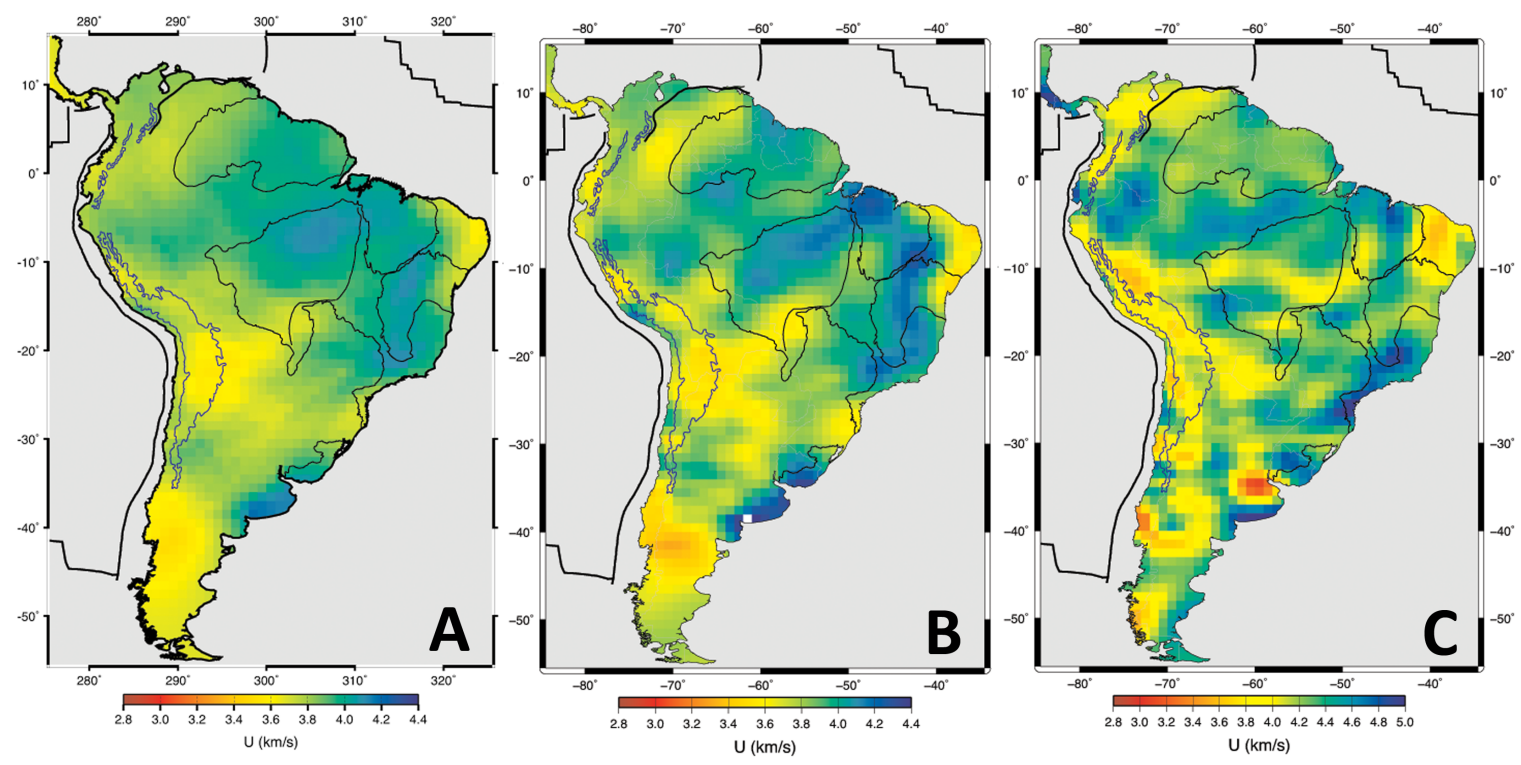

Figura 4.12: Group-velocity maps for $\mathrm{T}=100 \mathrm{~s}$. A) Rayleigh waves with $1^{\text {st }}$ derivative smoothing method. B) Rayleigh waves with $2^{\text {nd }}$ derivative smoothing. C) Love waves with $2^{\text {nd }}$ derivative smoothing. At higher periods, surface waves start to sample the uppermost mantle.
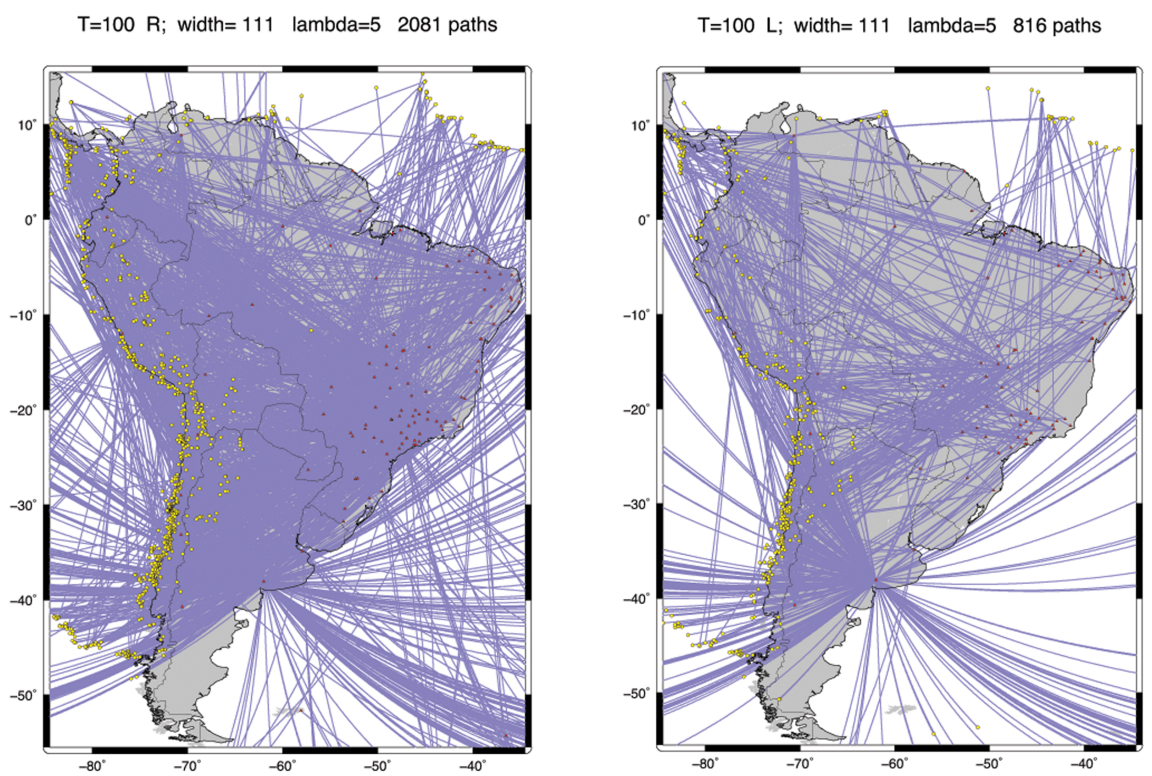

Figura 4.13: Path distribution for $\mathrm{T}=100$ s for Rayleigh (left) and Love waves (right). 
Outro ponto que merece destaque nos mapas é a anomalia de baixa velocidade que surge para a região da Plataforma da Patagônia. Baixas velocidades contrastam com a região mais estável do continente onde a Plataforma da Patagônia está inserida. Tal comportamento fora também percebido em trabalhos anteriores como VDOVIN et al. (1999); FENG et al. (2004), os quais sugerem uma litosfera mais fina para a Patagônia. Contudo, estes resultados podem estar mascarados pela baixa quantidade de percursos nesta região - Figura 4.13.

Baixas velocidades dominam a região da Província Borborema (Figura 4.12), mas estão mais evidentes para as ondas Love - muito provavelmente por sua característica de imagear estruturas mais rasas em relação às Rayleigh. Este comportamento é compatível com uma área de litosfera mais fina. Nota-se ainda que o mapa de ondas Love, para T=100s não é sensível ao possível núcleo cratônico existente na Bacia do Paraná.

O mapa de velocidades de grupo Love exibe também valores extremamente baixos na região de La Plata, Argentina (35S,60W). Observando-se o mapa de densidade de percursos (Figura 4.13), é possível notar que além da baixa quantidade, não existem caminhos que se cruzam nesta área, fatores responsáveis pela criação deste artefato.

\subsection{Informação em Profundidade: Inversão de Velocidade em Camadas}

Para a inversão 1D, a área de estudo restringiu-se apenas à região da Bacia do Paraná, (objetivo do trabalho) e não mais à América do Sul no geral. Foram confeccionados mapas de espessura de sedimentos, espessura da crosta e ainda, um mapa de velocidades das ondas S no manto superior.

Os mapas das figuras seguintes mantêm a comparação dos métodos de suavização de $1^{a}$ e $2^{a}$ derivadas, além da adição de velocidades de ondas Love. Para a inversão das medidas de velocidades Rayleigh, foram utilizados períodos entre 10 e 150s. Em contrapartida,

para as ondas Love, a inversão limitou-se aos períodos entre 15 e 100s devido ao baixo número de percursos relacionados aos demais períodos. 


\subsubsection{Mapas de Espessura de Sedimentos}

A Figura 4.14 mostra a comparação entre os mapas de espessura de sedimentos obtidos com ondas Rayleigh e suavização de $1^{a}$ derivada em (A), Rayleigh e $2^{a}$ derivada em (B) e por fim, uma inversão conjunta de ondas Rayleigh e Love, com o método da suavização de $2^{a}$ derivada em $(\mathrm{C})$.

Deveríamos esperar uma espessura maior de sedimentos na parte central da bacia e na porção mais oeste dos mapas, onde já se inicia outra importante bacia sedimentar da América do Sul, a Bacia do Chaco. Esta característica é observada em todos os mapas, mas é mais clara na Figura 4.14(B).

É possível perceber que a adição de dados provenientes das ondas Love trouxe muita instabilidade ao mapa da Figura 4.14(C). Apesar da maior espessura de sedimentos na parte norte da bacia, surgem valores muito baixos na porção central, devido à menor quantidade de percursos em relação aos dados de ondas Rayeleigh e à menor razão sinalruído dos sismogramas de ondas Love. Além disso, para profundidades tão pequenas (6 $\mathrm{km}$ ), as ondas Love podem sofrer influência de estruturas menores e mais rasas presentes nesta porção da crosta (MOSCHETTI et al., 2010).
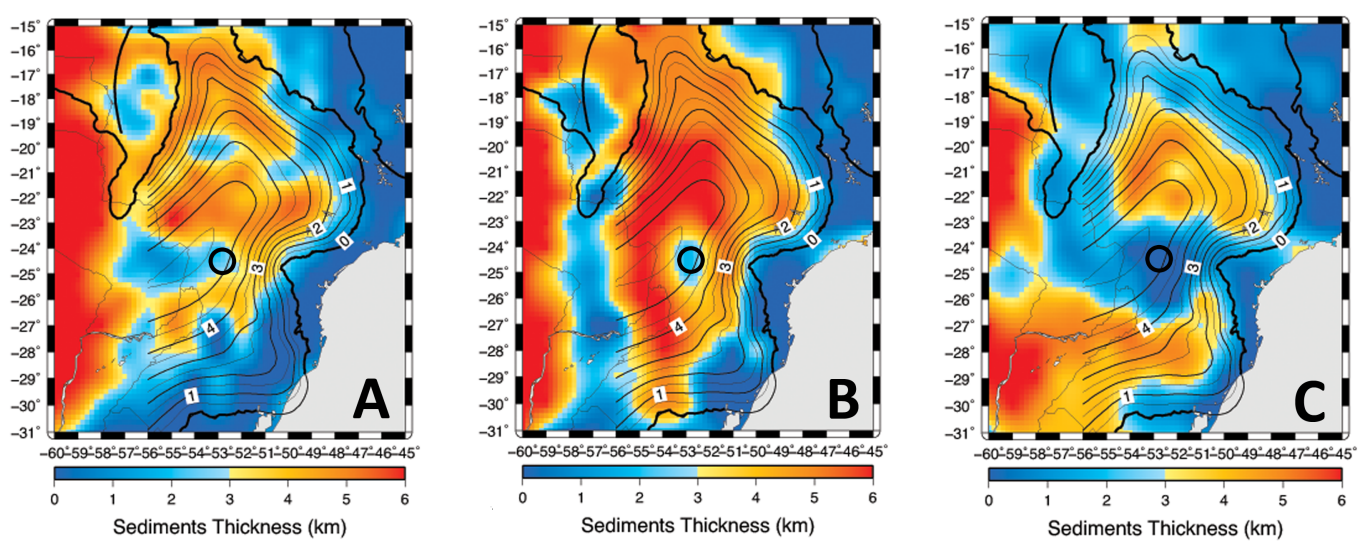

Figura 4.14: Maps of sedimentary thickness built with Rayleigh waves and $1^{\text {st }}$ derivative method (A), $2^{\text {nd }}$ derivative method (B) and for both Rayleigh and Love waves with $2^{\text {nd }}$ derivative method (C). The marked circles are points of instability discussed further. 
Os círculo pretos marcados nos mapas da Figura 4.14 foram assinalados intencionalmente por apontarem um ponto comum nos mapas onde ocorre uma curiosa ausência de sedimentos. Este ponto, localizado aproximadamente em 24S,53W está inserido na parte central da bacia onde eram esperadas as maiores espessuras.

A Figura 4.15 mostra o resultado da inversão para a coordenada $24 \mathrm{~S}, 53 \mathrm{~W}$ dos mapas aqui analisados. Nota-se que por alguma razão não há um bom ajuste do modelo, e a inversão calculada neste ponto não é tão estável, principalmente para os dados de ondas Love mostrados na Figura 4.14(C).
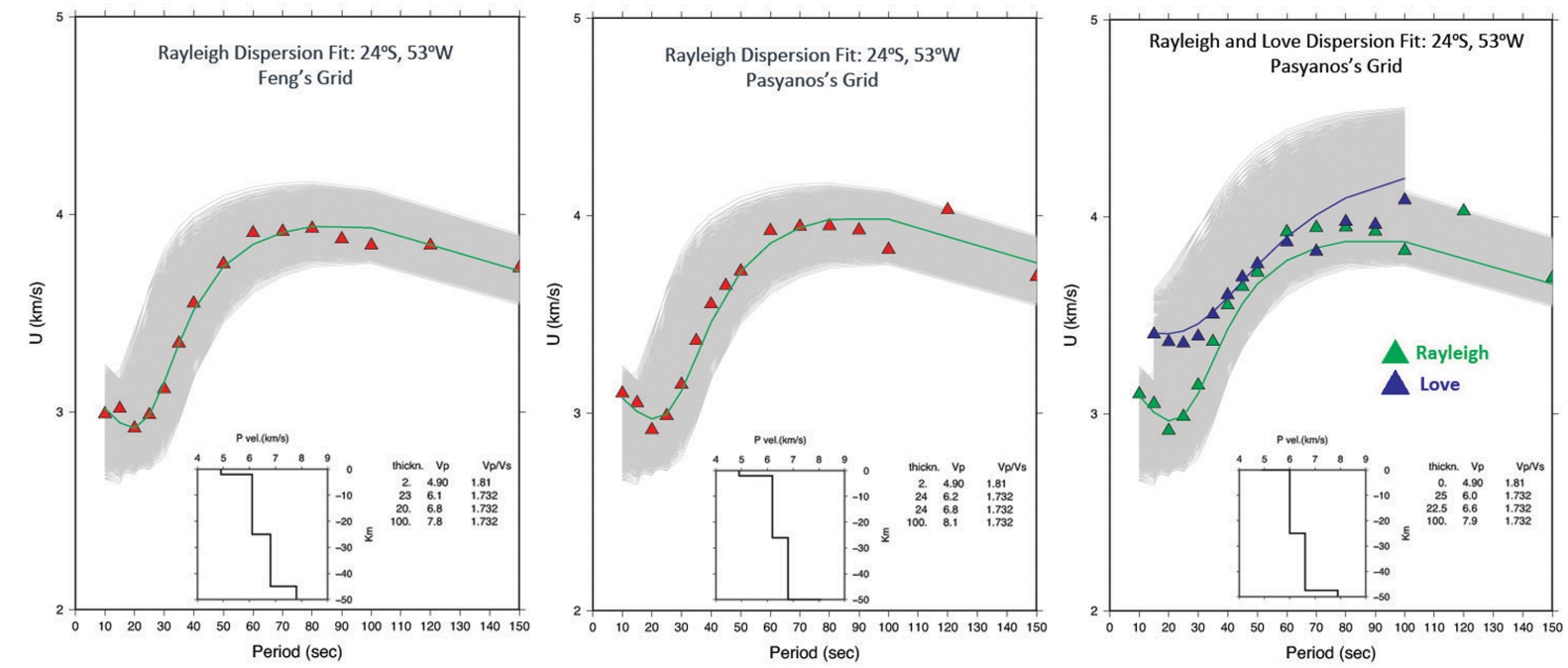

Figura 4.15: Comparison between inverted models for coordinate 24S,53W (black circles marked in Figure 4.13). Rayleigh waves and $1^{\text {st }}$ derivative method (A), $2^{\text {nd }}$ derivative method (B) and both Rayleigh and Love waves with $2^{\text {nd }}$ derivative method $(\mathrm{C})$.

\subsubsection{Mapas de Espessura da Crosta}

A Figura 4.16 compara os mapas de espessura crustal elaborados para os diferentes métodos de suavização aplicados neste trabalho.

De um modo geral, e apesar dos diferentes métodos empregados, os resultados da espessura crustal apresentados na Figura 4.16 concordam entre si e se mostram mais estáveis quando comparados às espessuras de sedimentos discutidas anteriormente. 

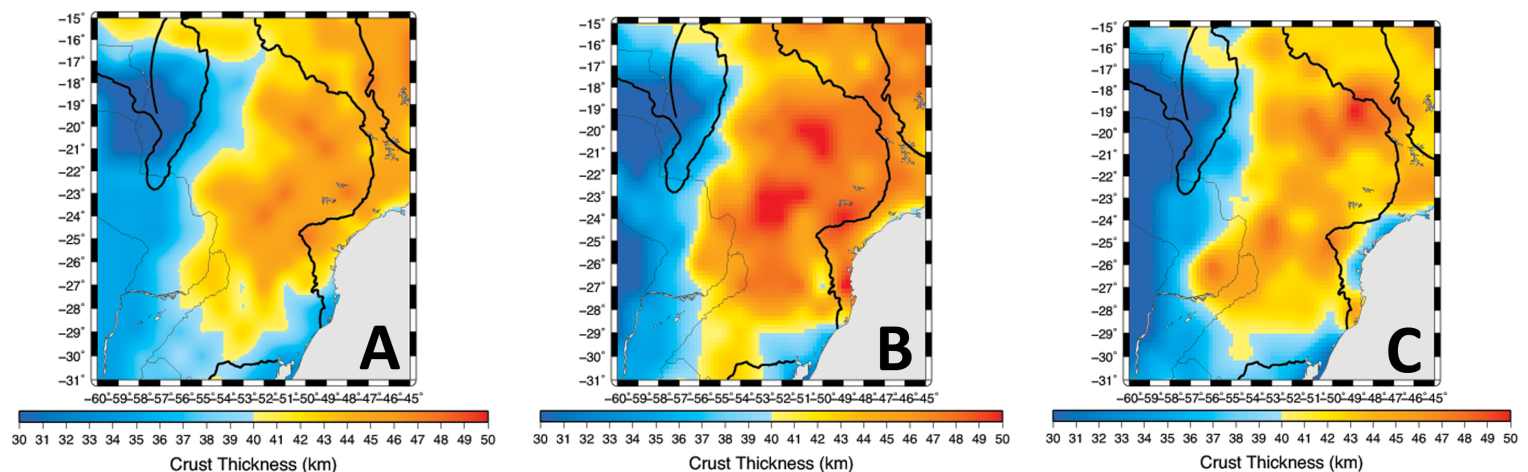

Figura 4.16: Comparison between crustal thickness maps built with Rayleigh waves and $1^{\text {st }}$ derivative method (A), $2^{\text {nd }}$ derivative method (B) and for both Rayleigh and Love waves with $2^{\text {nd }}$ derivative method (C).

A média de 40-45km para a profundidade da Moho encontrada para a parte central da Bacia nos mapas da Figura 4.16 é compatível com resultados prévios de dispersão de ondas de superfície (AN e ASSUMPÇÃO, 2006), função do receptor JULIA et al. (2008) e com os mais recentes modelos de espessura crustal da América do Sul (que contam inclusive com dados de ruído ambiental fornecidos por esta pesquisa) propostos por ASSUMPÇÃO et al. (2013) - Figura 4.17.
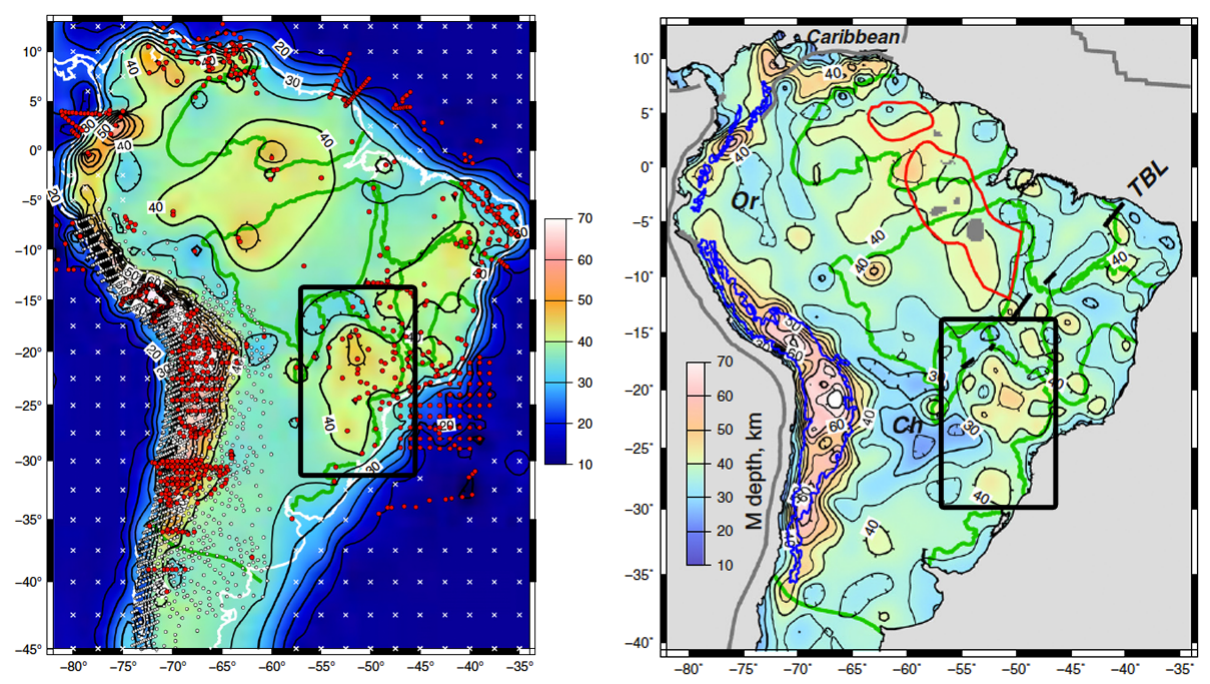

Figura 4.17: Contour map of crustal thickness obtained by using seismic constraints complemented by gravity-based estimates (left). Model of Moho depths using waveform modeling, group velocity dispersion, seismic constraints and gravity information (right). Black rectangles define the Paraná Basin area. Maps adapted from ASSUMPÇÃO et al. (2013) 
Pode-se dizer que o mapa da Figura 4.16(A), confeccionado com o método de suavização de $1^{a}$ derivada é o que melhor se relaciona com os modelos da Figura 4.17, principalmente por concentrar os maiores valores de espessura na parte central da bacia.

Os mapas gerados com o método de suavização de $2^{a}$ derivada se mostram um pouco mais instáveis, especialmente quando se utiliza apenas ondas Rayleigh, Figura 4.16(B). Valores de espessura crustal de 50km para regiões próximas à costa podem ter sido gerados pelo próprio método de suavização que, de modo a evitar impor constantes a priori, não reduz seu fator de suavização em regiões de descontinuidade conhecidas, como áreas de transição continente/oceano (PASYANOS et al., 2001).

É possível notar também que a adição de dados provenientes da correlação de ondas Love contribui para diminuir a instabilidade do mapa, em especial nas regiões de costa onde a contribuição é mais perceptível - Figura 4.16(C).

\subsubsection{Onda $S_{n}$ no Manto Superior}

Aparentemente, a bacia do Paraná é sustentada por uma região de altas velocidades no manto superior, de acordo com os mapas da Figura 4.18. Estes mapas apresentam o comportamento da onda $S_{n}$ para os diferente métodos de suavização empregados: ondas Rayleigh e $1^{a}$ derivada em (A), ondas Rayleigh e $2^{a}$ derivada em (B) e ondas Love e Rayleigh e $2^{a}$ derivada em $(\mathrm{C})$.

De um modo geral, os mapas confeccionados com os diversos métodos de suavização apresentam resultados semelhantes à exceção da Figura 4.18(C), em que dados provenientes da dispersão de ondas Love foram adicionados. Além da anomalia central de alta velocidade comum a todos os mapas, também surge uma segunda anomalia na região mais ao sul da bacia do Paraná, concordando com o resultado obtido por FENG et al. (2007) - Figura 4.19. 

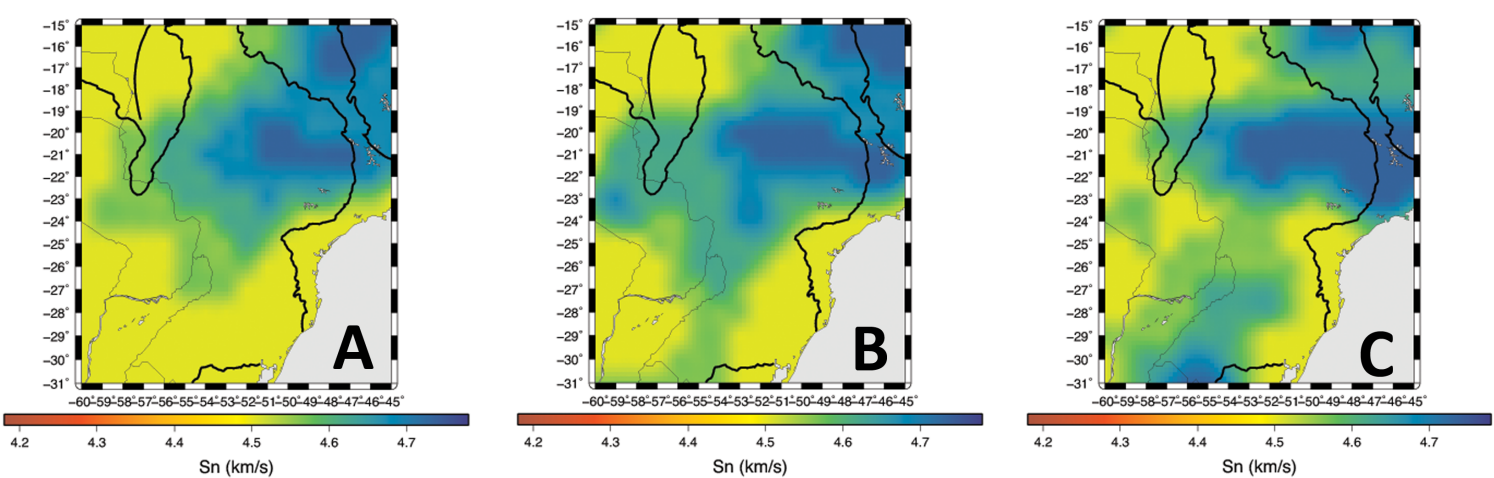

Figura 4.18: Comparison between $\mathrm{S}_{n}$ velocity maps built with rayleigh waves and $1^{\text {st }}$ derivative method (A), $2^{\text {nd }}$ derivative method (B) and for both Rayleigh and Love waves with $2^{\text {nd }}$ derivative method (C). The central high-velocity anomaly can be interpreted as the presence of a cratonic block as first mentioned by CORDANI et al. (1984), and later by MILANI e RAMOS (1984), SCHIMMEL et al. (2003) and JULIA et al. (2008).

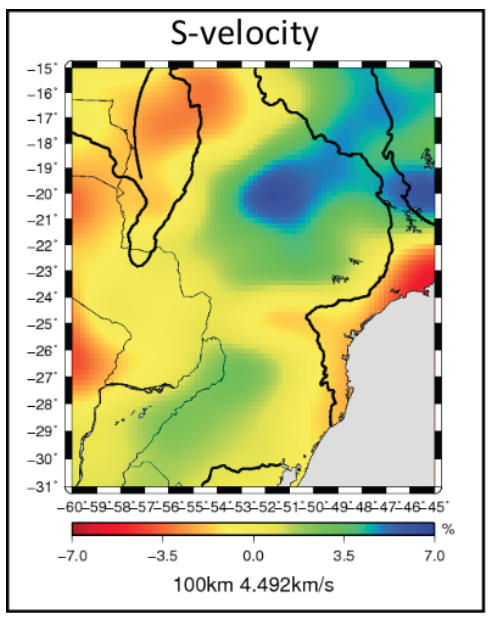

Figura 4.19: S-wave at 100km from joint inversion of group velocities and Moho depth constraints extracted from (FENG et al., 2007).

Com base em dados de datação radiométrica e da geologia estrutural regional, o trabalho de CORDANI et al. (1984), sugeriram a existência de um núcleo proterozóico (cratônico) sob a bacia do Paraná. As anomalias de alta velocidade presentes nos mapas da Figura 4.18 são compatíveis com essa hipótese. Essa característica se compara bem com resultados prévios obtidos para a América do Norte, onde bacias intracratônicas 
também se localizam em regiões de alta velocidade para o manto superior (VAN DER LEE e NOLET, 1997; VAN DER LEE e FREDERIKSEN, 2005).

Em contrapartida, MILANI e RAMOS (1984) mostraram evidências da presença de uma zona de rift nesta região da bacia do Paraná, assim como uma atividade ígnea mais recente, aspectos incompatíveis com um núcleo mais antigo e totalmente estável. Mais tarde, os resultados da inversão conjunta de funções do receptor e dispersão de ondas Rayleigh apresentados por JULIA et al. (2008) também concordaram com esta proposta, sugerindo a presença de um núcleo cratônico dividido por zonas de sutura.

Os resultados obtidos neste trabalho, entretanto, não têm resolução espacial suficiente para confirmar tal processo de divisão. Qualquer episódio desta natureza não foi forte o bastante para afetar a espessura da litosfera em uma escala mais regional e detectável pelo método tomográfico empregado. Contudo, tal hipótese não pode ser descartada. 


\section{Capítulo 5}

\section{Conclusões}

O estudo da estrutura crustal através da inversão da dispersão de ondas de superfície pode contribuir significativamente para o conhecimento da evolução da bacia do Paraná.

A técnica da extração de ondas de superfície através da correlação de ruído ambiental (ANT), foi empregada aos mais recentes dados procedentes da implantação da Rede Sismográfica Brasileira, especialmente com as primeiras estações instaladas nas regiões Sul e Sudeste do país. Este trabalho contribuiu para aumentar a densidade de percursos de tomografia na região da Bacia do Paraná, onde a dependência dos terremotos andinos implicava na baixa resolução de estudos anteriores nesta porção do continente.

Os mapas de velocidade de grupo obtidos correspondem bem com as principais estruturas geológicas já conhecidas na América do Sul, independente do método de suavização empregado. Como esperado, períodos mais baixos são sensíveis à espessura dos sedimentos, períodos intermediários relacionam-se com a profundidade da Moho e os períodos maiores são influenciados pelas características do manto superior.

Dos diferentes métodos de suavização utilizados, o de $2^{a}$ derivada mostrou-se mais estável para períodos baixos e intermediários $(<80 \mathrm{~s})$, principalmente para os mapas de velocidade de grupo e de espessura dos sedimentos. 
A adição de dados provenientes da dispersão de ondas Love estabilizou a inversão para a espessura crustal sob a bacia do Paraná, ao preço de afetar os mapas de espessura de sedimentos. Tal interferência pode estar relacionada com a menor razão sinal-ruído encontrada nas dispersões de ondas Love, a influência de estruturas menores e mais rasas ou ainda, com anisotropia nas camadas sedimentares.

As anomalias de alta velocidade encontradas para o manto superior, concordam com trabalhos prévios que confirmam a presença de um núcleo cratônico sob a bacia. Contudo, não é possível afirmar se tal núcleo está intacto ou não, principalmente devido resultados anteriores que mostram evidências da existência de um núcleo dividido por zonas de sutura (MILANI, 2004; JULIA et al., 2008), no entanto, a tomografia de ondas de superfície não possui resolução para confirmar este modelo.

Como as etapas do processamento de dados são bem definidas e independentes, à medida que novas estações forem instaladas com o avanço da implementação da Rede Sismográfica Brasileira, novos caminhos serão adicionadas à base de dados inicial, aumentando a resolução e confiabilidade dos resultados futuros. 


\section{Referências Bibliográficas}

ALMEIDA F. F. M., NEVES B. B., CARNEIRO C. D. R., The origin and evolution of the South American platform, Earth Science Reviews, 2000, vol. 50

AN M., ASSUMPÇÃO M., Crustal and upper mantle strcuture in the intracratonic Parana Basin, SE Brazil, from surface wave dispersion using genetic algorithms, Journal of South American Eartch Sciences, 2006, vol. 21, p. 173,184

ASSUMPCAO M., JAMES D. E., SNOKE J., Crustal Thickness in SE Brazililian shield by receiver functions analysis: implications for isostatic compensation, Journal of Geophysical Research, 2002, vol. 107

ASSUMPÇÃO M., FENG M., TASSARA A., JULIA J., Models of crustal thickness for South America from seismic refraction, receiver functions and surface wave tomography, Tectonophysics, 2013, vol. 609, p. 82,96

BENSEN G. D., RITZWOLLER M. H., BARMIN M. P., LEVSHIN A. L., LIN F., MOSCHETTI M. P., SHAPIRO N. M., YANG Y., Processing seismic ambient noise data to obtain reliable broad-band surface wave dispersion measurements, Geophysical Journal International, 2007, vol. 169, p. 1239,1260

BEYREUTHER M., BARSCH R., KRISCHER L., MEGIES T., BEHR Y., WASSERMAN J., ObsPy: A Python toolbox for Seismology., Seismological Research Letters, 2010, vol. 81 , p. 530,533 
CORDAni U. G., NEves B. B., FUCK R. A., FILHO A. T., CUnha M. B., Estudo preliminar de integração do pré-Cambriano com os eventos tectônicos das bacias sedimentares brasileiras, Ciência Técnica Petróleo, 1984, pp 1,70

DRISCOLL N. W., KARNER G. D., Flexural deformation due to Amazon Fan loading: a feedback mechanism affecting sediment delivery to margins., Geology, 1994, vol. 22, p. 1015,1018

DZIEWONSKI A. M., ANDERSON D. L., Preliminary Reference Earth Model, Physics of The Earth and Planetary Interiors, 1981, vol. 25, p. 297,356

FENG M., ASSUMPÇÃO M., VAN DER LEE S., Group-velocity tomography and lithospheric S-velocity structure of the South American continet, Physics of The Earth and Planetary Interiors, 2004, vol. 147, p. 315,331

FENG M., VAN DER LEE S., ASSUMPÇÃO M., Upper mantle structure of South America from joint inversion of waveforms and fundamental mode group velocities of Rayleigh waves, Journal of Geophysical Research, 2007, vol. 112

HAMZA V. M., MUÑOZ M., Heat flow map of South America, Geothermics, 1996, vol. 25, p. 599,646

HERRMANN R. B., Some aspects of bandpass filtering of surface waves, Bulletin of the Seismological Society of America, 1973, vol. 63, p. 663,671

HUANG Z., SU W., PENG Y., ZHENG Y. LI H., Rayleigh wave tomography of China and adjacent regions, Journal of Geophysical Research, 2003, vol. 108

JULIA J., ASSUMPCAO M., ROCHA M. P., Deep crustal sctructure of the Paraná basin from receiver functions and Rayleigh-wave disersion: evidence for a fragmented cratonic root, Journal of Geophysical Reasearch, 2008, vol. 113

LEES J. M., CROSSON R. S., Tomographic inversion for threedimensional velocity structure at Mount St. Helens using earthquake data, Journal of Geophysical Research, 1989, vol. 94 , p. 5716,5728 
LEIGHTON M. W., KOLATA D. R., Selected interior cratonic basins and their place in the scheme of global tectonics - a synthesis, Tulsa: American Associalion of Petroleum Geologists Memoir., 1990, vol. 51, p. 729,797

LIN F. M., MOSCHETTI M. P., RITZWOLLER M. H., Surface wave tomography of the western United States from ambient seismic noise: Rayleigh and Love wave phase velocity maps, Geophysical Journal International, 2008, vol. 173, p. 281,298

LLOYD S., VAN DER LEE S., FRANCA G. S., ASSUMPCAO M., FENG M., Moho map of South America, Journal of Geophysical Research, 2010, vol. 115

LOBKIS O. I., WEAVER R. L., On the emergence of the Greens function in the correlations of a diffuse field, Journal of the Acoustical Society of America, 2001, vol. 110, p. 894,903

MANTOVANI M. S. M., QUINTAS M. C. L., SHUKOWSKY W., NEVES B. B., Delimitation of the Paranapanema block: A geophysical contribution, Episodes, 2005, vol. 28, p. 18,22

MARONE F., VAN DER MEIJDE M., VAN DER LEE S., GIARDINI D., Joint inversion of local, regional and teleseismic data for crustal thickness in the Eurasia-Africa plate boundary region, Geophysical Journal International, 2003, vol. 154, p. 499,514

MEGIES T., BEYREUTHER M., BARSCH R., KRISCHER L., WASSERMAN J., ObsPy ? What can it do for data centers and observatories?, Annals of Geophysics, 2011, vol. 54 , p. 47,58

MILANI E. J., Comentários sobre a origem e evolução tectônica da Bacia do Paraná. In Geologia do Continente Sul-Americano: Evolução da Obra de Fernando Flávio Marques de Almeida, Beca, São Paulo, Brazil, 2004, p. 265,279

MILANI E. J., RAMOS V., Orogenias paleozóicas no domínio sul-ocidental do Gondwana e os ciclos de subsidência da bacia do Paraná, Revista Brasileira de Geociências, 1984, vol. 28 , p. 473,484 
MOSChETTI M. P., RITZWOLLER M. H., LIN F., YANG Y., Seismic evidence for widespread crustal deformation caused by extension in the western USA, Nature, 2010, vol. 464 , p. 885,889

MOSCHETTI M. P., RITZWOLLER M. H., SHAPIRO N. M., Surface wave tomography of the western United States from ambient noise: Rayleigh wave group velocity maps, Geochemistry Geophysics Geosystems, 2007, vol. 8

PAIGE C. C., SAUNDERS M. A., LSQR: An Algorithm for Sparse Linear Equations and Sparse Least Squares, ACM Transactions on Mathematical Software, 1982, vol. 8, p. 43,71

PASYANOS M. E., A variable-resolution surface wave dispersion study of western Eurasia and North Africa, Journal of Geophysical Research, 2005, vol. 11

PASYANOS M. E., WALTER W. R., HAZLER S. E., A surface wave dispersion study of the Middle East and North Africa for monitoring the Comprehensive Nuclear-Test-Ban Treaty, Pure and Applied Geophysics, 2001, vol. 158, p. 1445,1474

PIRChineR M., COLlAÇO B., CALHAU J., ASSUMPÇÃO M. S., DOURADO J. C., BRAzilian Seismographic Integrated Systems (BRASIS): infrastructure and data management., Annals of Geophysics, 2011, vol. 54, p. 17,22

PYSKLYWEC R. N., QUINTAS M. C. L., A mantle flow mechanism for the late Paleozoic subsidence of the Paraná basin, Journal of Geophysical Reasearch, 2000, vol. 105, p. 16359,16370

RHIE J., ROMANOWICS B., Excitation of Earth's incessant free oscillations by Atmosphere-Ocean-Seafloor coupling, Nature, 2004, vol. 431, p. 552,556

RITZWOLLER M. H., LESHVIN A. L., Eurasian surface wave tomography: Group velocities, Journal of Geophysical Research, 1998, vol. 103, p. 4839,4878

ROSA M. L., COLlACO B., SANCHEZ G., ASSUMPÇÃO M., SABBIONE M., ARAUJO M., Crustal thickness beneath the Chaco Paraná Basin, NE Argentina, using 
surface-waves and ambient noise tomography, XVI Congr. Geological Soc. of Peru, Lima, Peru, 2012

SCHIMMEL M., ASSUMPÇÃO M., VAN DECAR J. C., Seismic velocity anomalies beneath SE Brazil from P and S wave travel time inversions, Journal of Geophysical Research, 2003, vol. 108

SHAPIRO N. M., CAMPIllO M., STEHLY L., RITZWOLlER M. H., High resolution surface wave tomography from ambient seismic noise, Science, 2005, vol. 307, p. 1615,1618

SILVA A. J., LOPES R. C., VASCONCELOS A. M., BAHIA R. C., Bacias Sedimentares Paleozóicas e Meso-Cenozóicas Interiores. In Geologia, Tectônica e Recursos Minerais do Brasil , CPRM, 2003, p. 55,85

STEHLY L., CAMPILlO M., SHAPIRO N. M., A study of the seismic noise from its long-range correlation properties, Journal of Geophysical Research, 2006, vol. 111

VAN DER LEE S., FREDERIKSEN A., Surface wave tomography applied to the North American upper mantle, Seismic Earth: Array Analysis of Broadband Seismograms, Geophys. Monogr, Ser., 2005, vol. 157, p. 67,80

VAN DER LEE S., NOLET G., Uppermantle S velocity structure of North America, Journal of Geophysical Research, 1997, vol. 102, p. 22815,22838

VDOVIN O., RIAL J. A., LESHVIN A. L., RITZWOLLER M. H., Group-velocity tomography of South America and the surrounding oceans., Geophysical Journal International, 1999, vol. 136, p. 324,340

VILLASEÑOR A., RITZWOLLER M. H., LESHVIN A. L., BARMIN M. P. ENGDAHL E. R., SPARKMAN W., TRAMPERT J., Shear velocity structure of central Eurasia from inversion of surface wave velocities, Physics of The Earth and Planetary Interiors, 2001, vol. 123 , p. 169,184

VUAN A., RUSSI M., PANZA G. F., Group velocity tomography in the subantarctic Scotia sea region, Pure and Applied Geophysics, 2000, vol. 157, p. 1337,1357 
WAPENAAR K., Retrieving the elastodynamic Green's function of an arbitrary inhomogeneous medium by cross correlation, Physical Review Letters, 2004, vol. 93

YANOVSKAYA T. B., KOZHEVNIKOV V. M., 3D S-wave velocity pattern in the upper mantle beneath the continent of Asia from Rayleigh wave data, Physics of The Earth and Planetary Interiors, 2003, vol. 138, p. 263,278

ZALAN P. V., WOLFF S., CONCEIÇÃO J. C. J., MARQUES A., ASTOLFI M. A. M., VIEIRA I. S., APPI V. T., ZANOTTO O. A., Bacia do Paraná. In Origem e Evolução das Bacias Sedimentares, Petrobrás, Rio de Janeiro, Brazil, 1990, p. 135,168 
Apêndice 

Apêndice A

\section{Inversão 2D: Resultados}

\section{A.1 Mapas de Velocidade de Grupo}

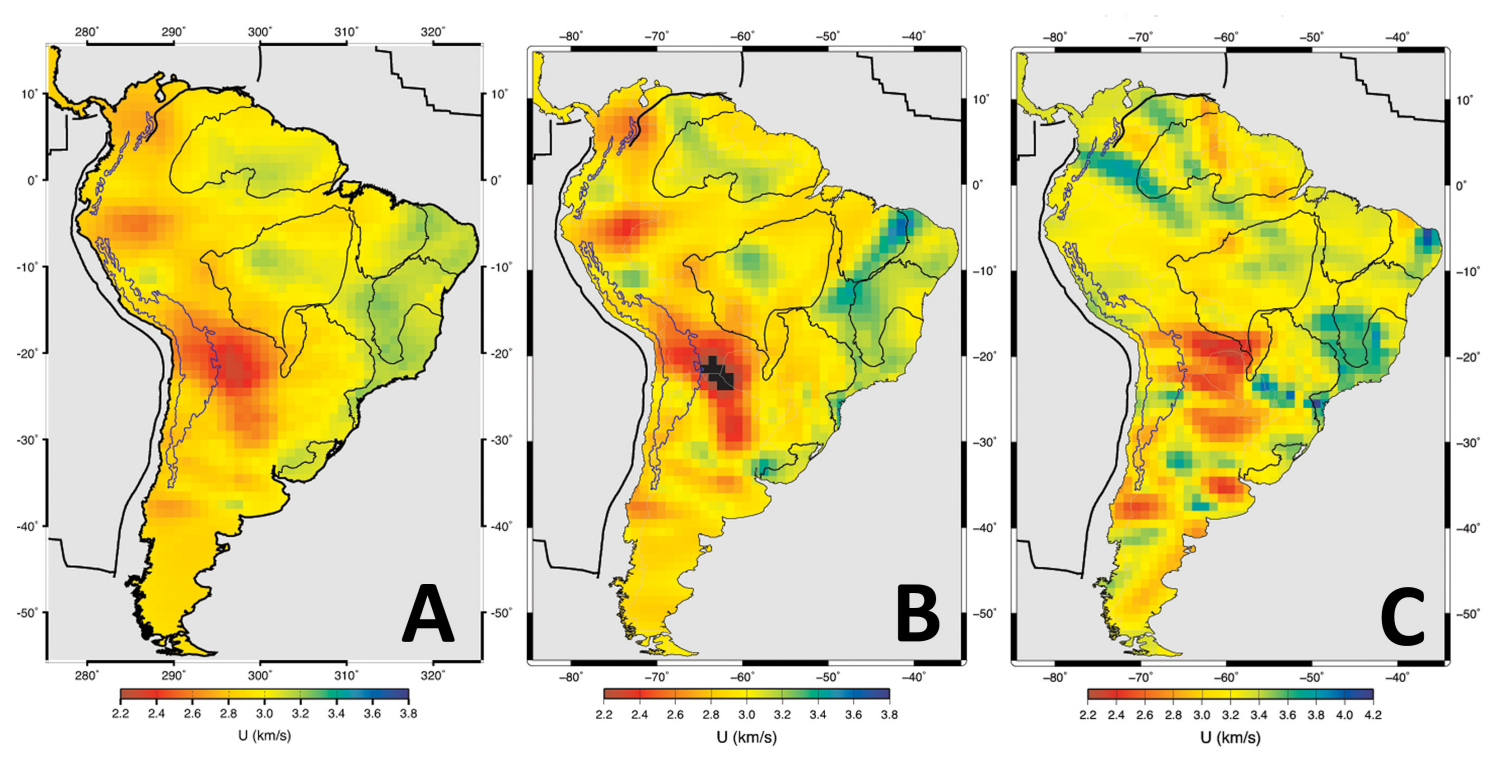

Figura A.1: Group-velocity maps for $\mathrm{T}=10 \mathrm{~s}$. A) Rayleigh waves with $1^{\text {nd }}$ derivative smoothing method. B) Rayleigh waves with $2^{\text {st }}$ derivative smoothing. C) Love waves with $2^{\text {nd }}$ derivative smoothing. At shorter periods, surface waves are more sensitive to shallow crustal structures, like sedimentary basins. 


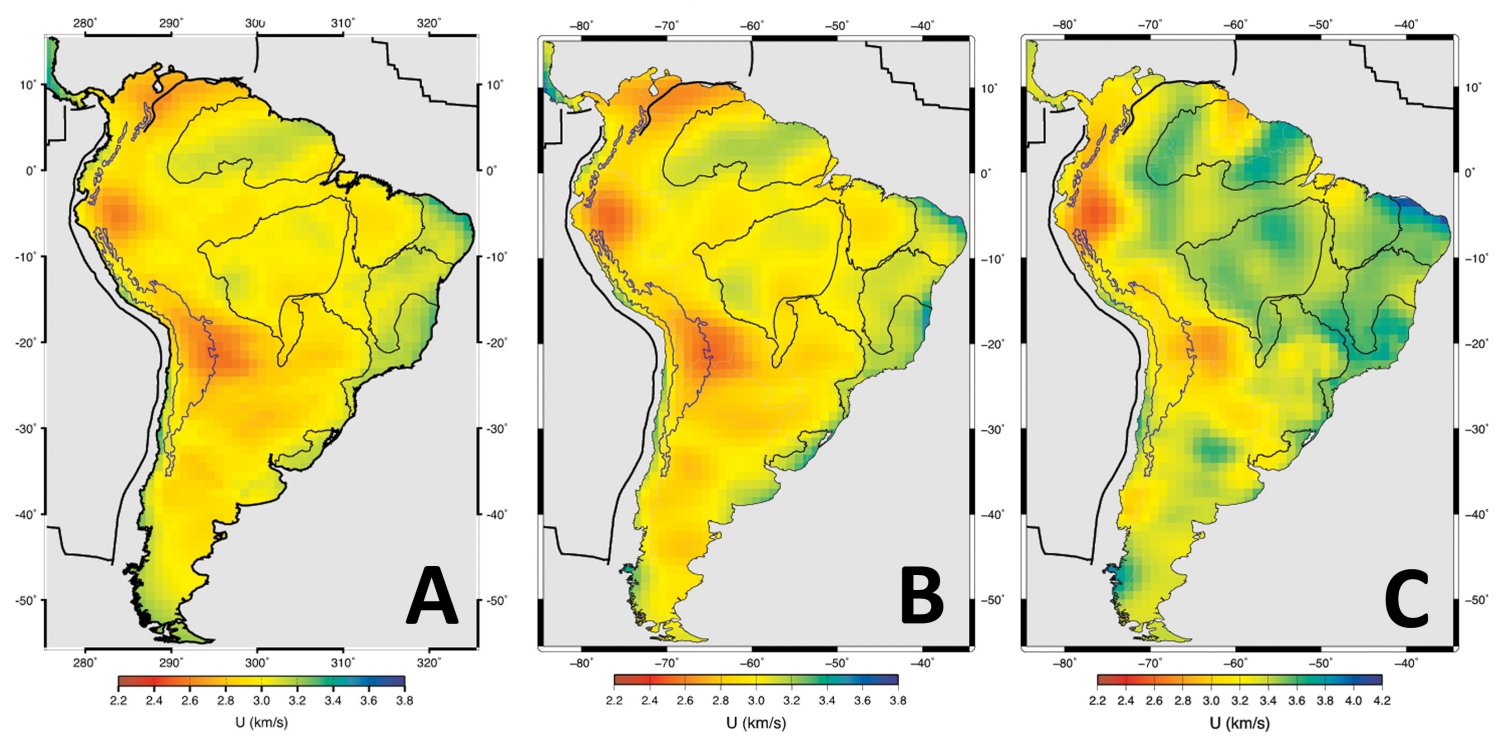

Figura A.2: Group-velocity maps for $\mathrm{T}=20 \mathrm{~s}$. A) Rayleigh waves with $1^{\text {nd }}$ derivative smoothing method. B) Rayleigh waves with $2^{\text {st }}$ derivative smoothing. C) Love waves with $2^{\text {nd }}$ derivative smoothing. At shorter periods, surface waves are more sensitive to shallow crustal structures, like sedimentary basins.

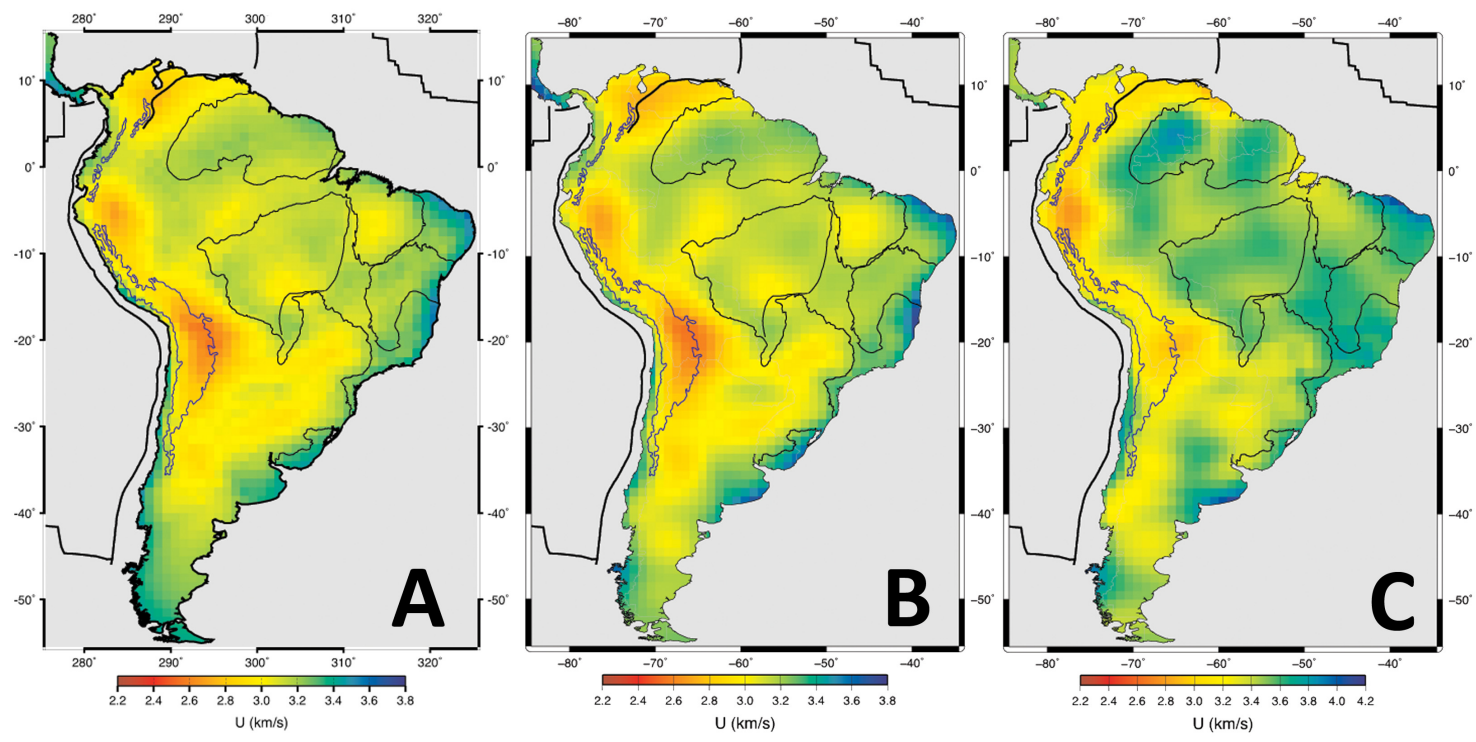

Figura A.3: Group-velocity maps for $\mathrm{T}=25 \mathrm{~s}$. A) Rayleigh waves with $1^{\text {nd }}$ derivative smoothing method. B) Rayleigh waves with $2^{\text {st }}$ derivative smoothing. C) Love waves with $2^{\text {nd }}$ derivative smoothing. At shorter periods, surface waves are more sensitive to shallow crustal structures, like sedimentary basins. 


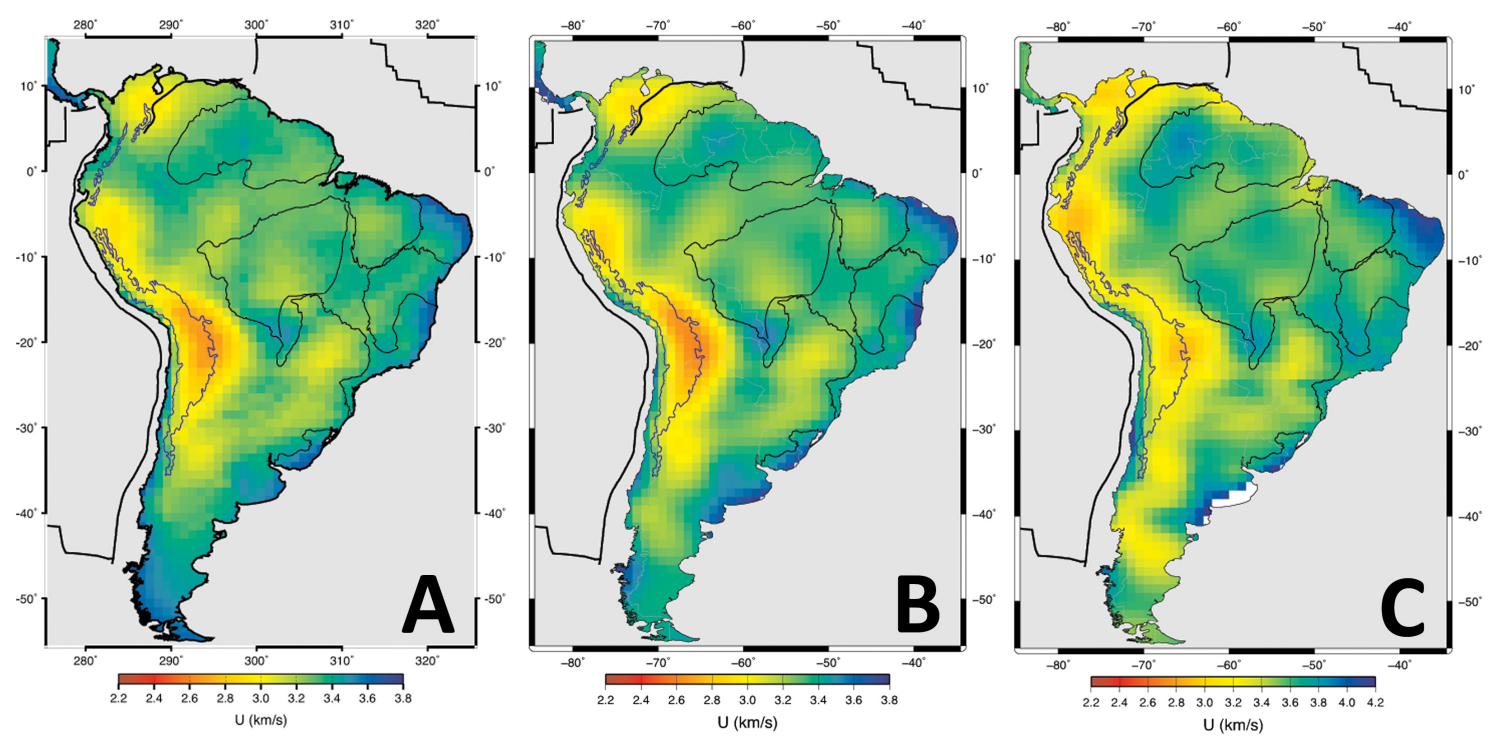

Figura A.4: Group-velocity maps for $\mathrm{T}=30 \mathrm{~s}$. A) Rayleigh waves with $1^{\text {nd }}$ derivative smoothing method. B) Rayleigh waves with $2^{\text {st }}$ derivative smoothing. C) Love waves with $2^{\text {nd }}$ derivative smoothing. At shorter periods, surface waves are more sensitive to shallow crustal structures, like sedimentary basins.

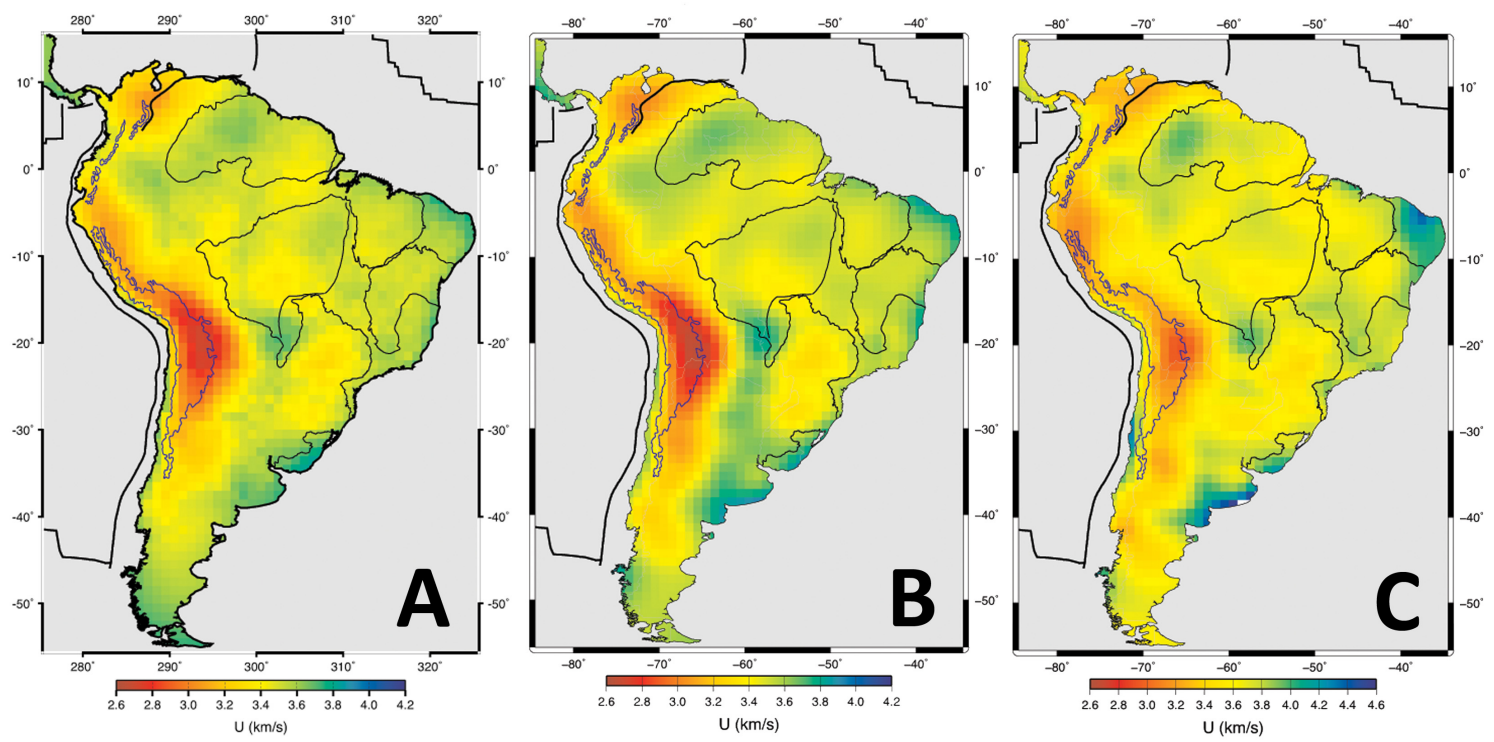

Figura A.5: Group-velocity maps for $\mathrm{T}=35 \mathrm{~s}$. A) Rayleigh waves with $1^{\text {nd }}$ derivative smoothing method. B) Rayleigh waves with $2^{s t}$ derivative smoothing. C) Love waves with $2^{\text {nd }}$ derivative smoothing. At shorter periods, surface waves are more sensitive to shallow crustal structures, like sedimentary basins. 


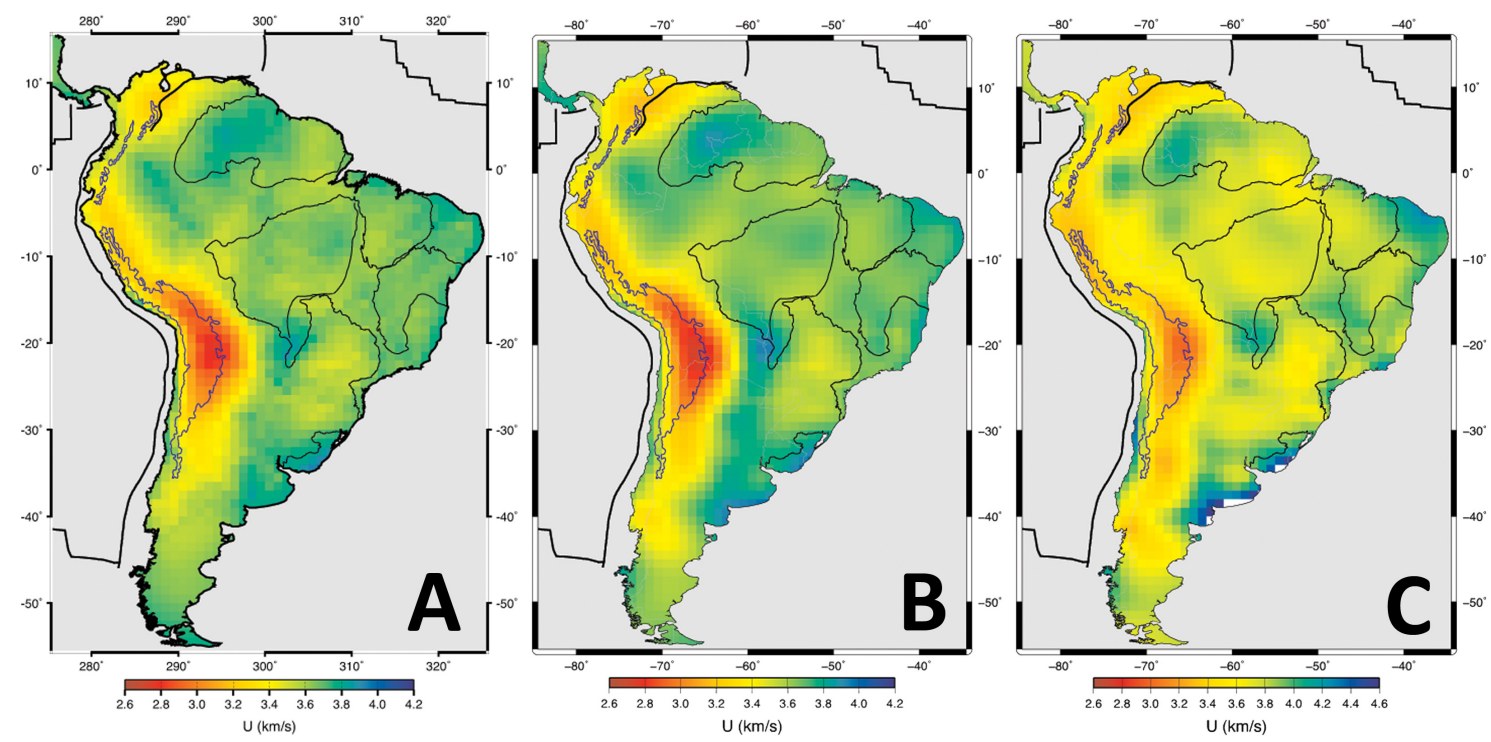

Figura A.6: Group-velocity maps for $\mathrm{T}=40 \mathrm{~s}$. A) Rayleigh waves with $1^{\text {nd }}$ derivative smoothing method. B) Rayleigh waves with $2^{\text {st }}$ derivative smoothing. C) Love waves with $2^{\text {nd }}$ derivative smoothing. At shorter periods, surface waves are more sensitive to shallow crustal structures, like sedimentary basins.

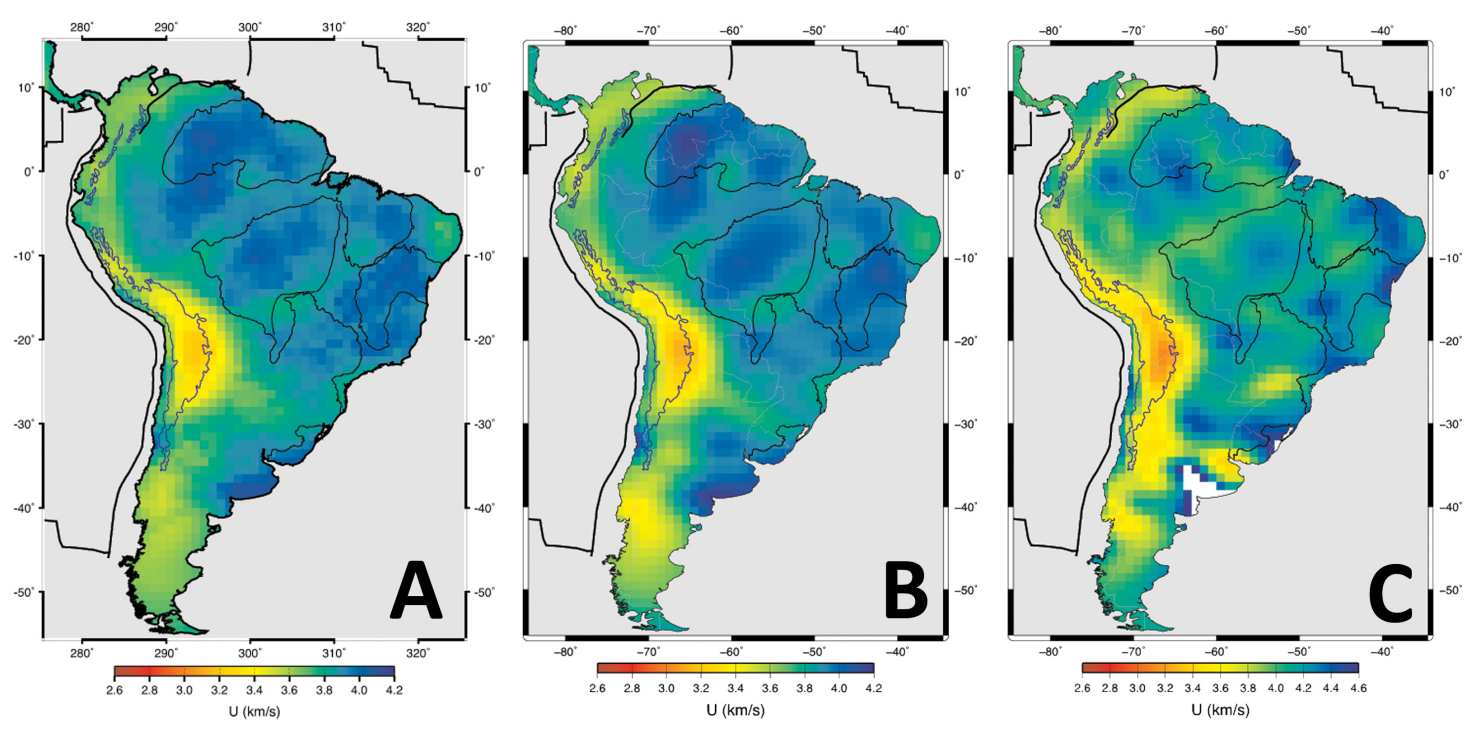

Figura A.7: Group-velocity maps for $\mathrm{T}=60 \mathrm{~s}$. A) Rayleigh waves with $1^{\text {nd }}$ derivative smoothing method. B) Rayleigh waves with $2^{\text {st }}$ derivative smoothing. C) Love waves with $2^{\text {nd }}$ derivative smoothing. At shorter periods, surface waves are more sensitive to shallow crustal structures, like sedimentary basins. 


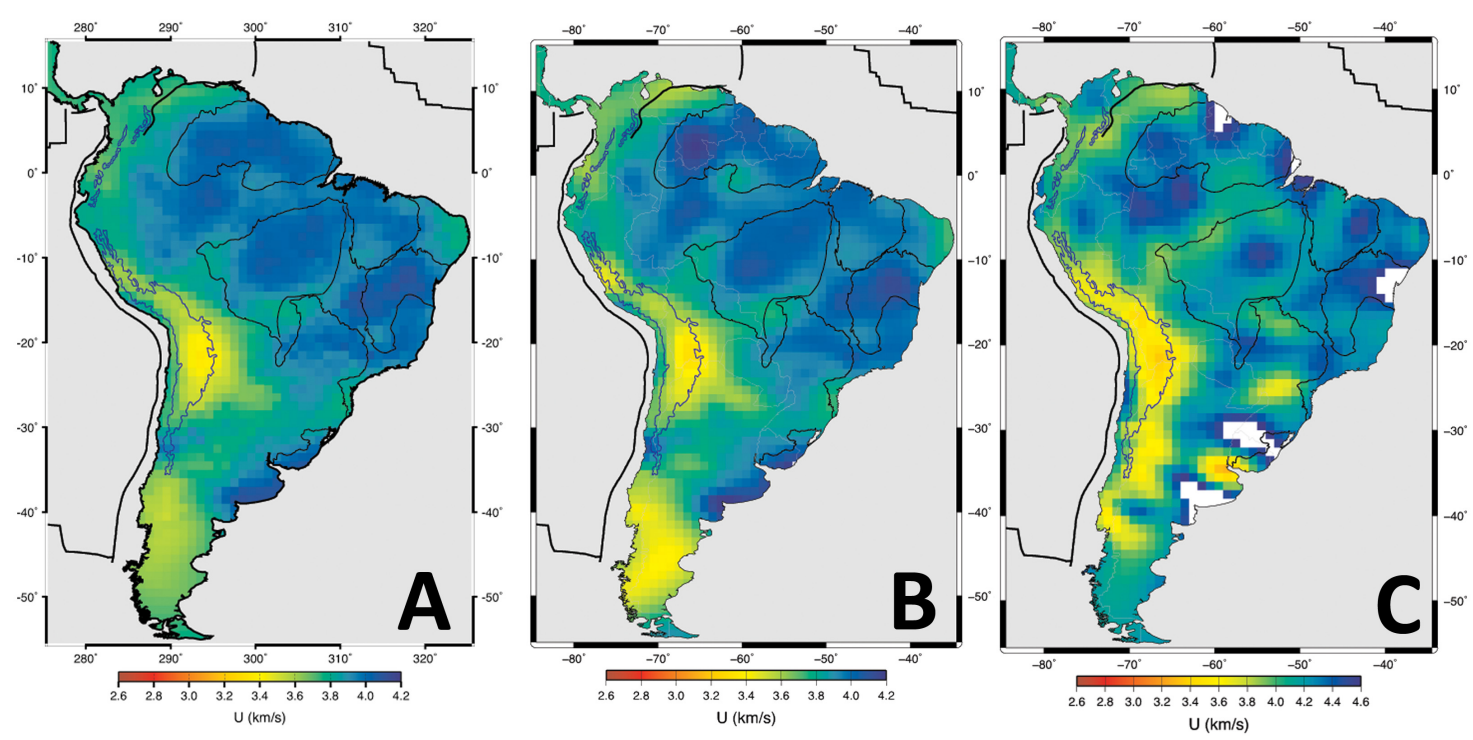

Figura A.8: Group-velocity maps for $\mathrm{T}=70 \mathrm{~s}$. A) Rayleigh waves with $1^{\text {nd }}$ derivative smoothing method. B) Rayleigh waves with $2^{\text {st }}$ derivative smoothing. C) Love waves with $2^{\text {nd }}$ derivative smoothing. At shorter periods, surface waves are more sensitive to shallow crustal structures, like sedimentary basins.

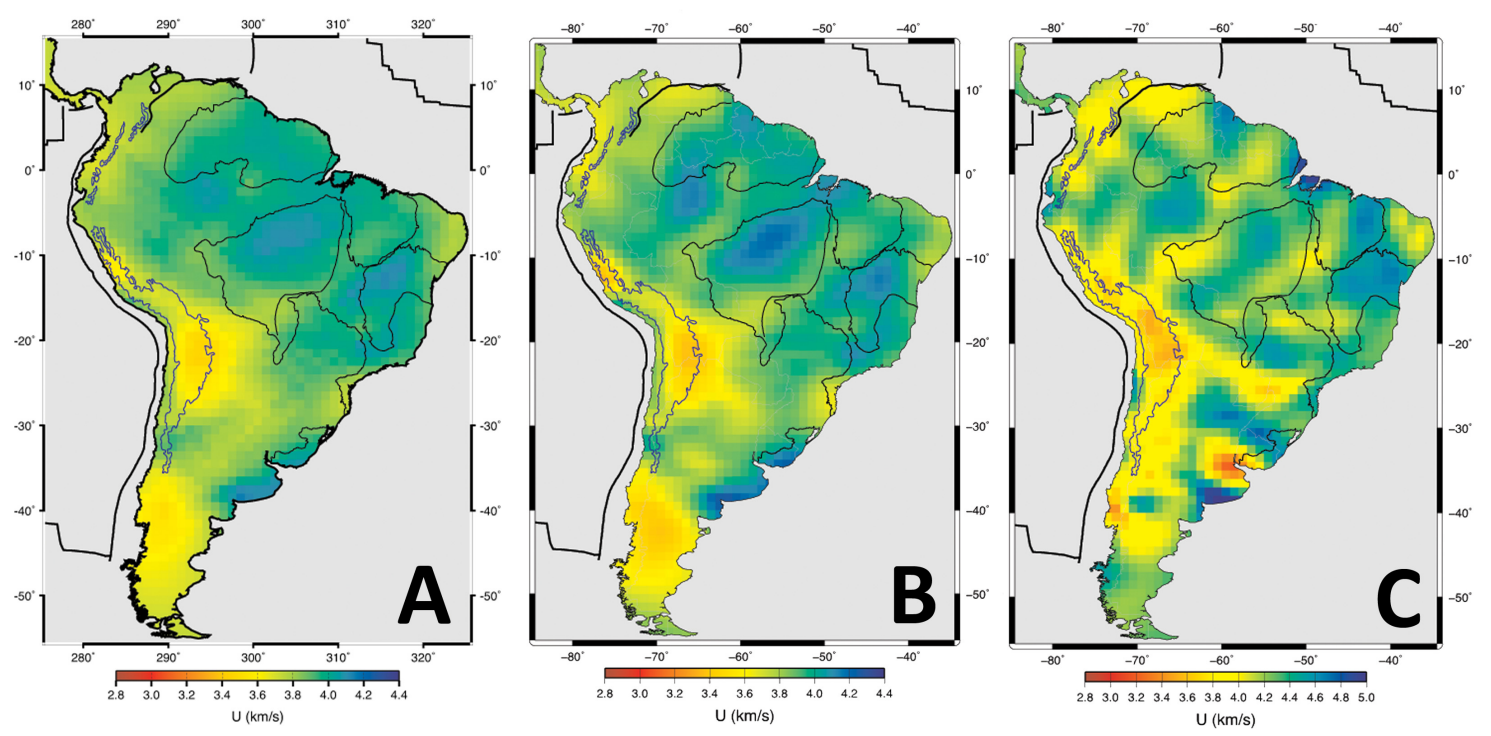

Figura A.9: Group-velocity maps for $\mathrm{T}=80 \mathrm{~s}$. A) Rayleigh waves with $1^{\text {nd }}$ derivative smoothing method. B) Rayleigh waves with $2^{\text {st }}$ derivative smoothing. C) Love waves with $2^{\text {nd }}$ derivative smoothing. At shorter periods, surface waves are more sensitive to shallow crustal structures, like sedimentary basins. 


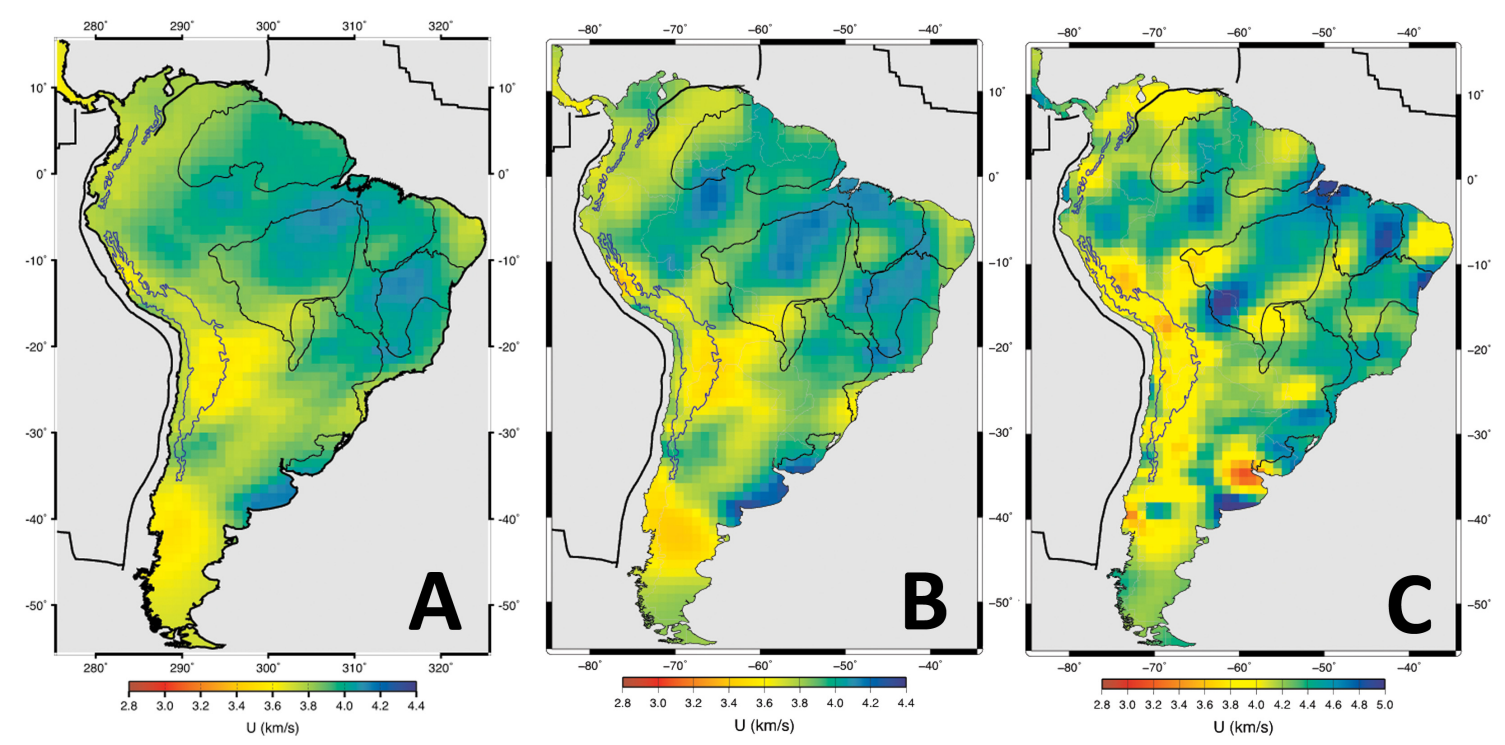

Figura A.10: Group-velocity maps for $\mathrm{T}=90 \mathrm{~s}$. A) Rayleigh waves with $1^{\text {nd }}$ derivative smoothing method. B) Rayleigh waves with $2^{\text {st }}$ derivative smoothing. C) Love waves with $2^{\text {nd }}$ derivative smoothing. At shorter periods, surface waves are more sensitive to shallow crustal structures, like sedimentary basins.

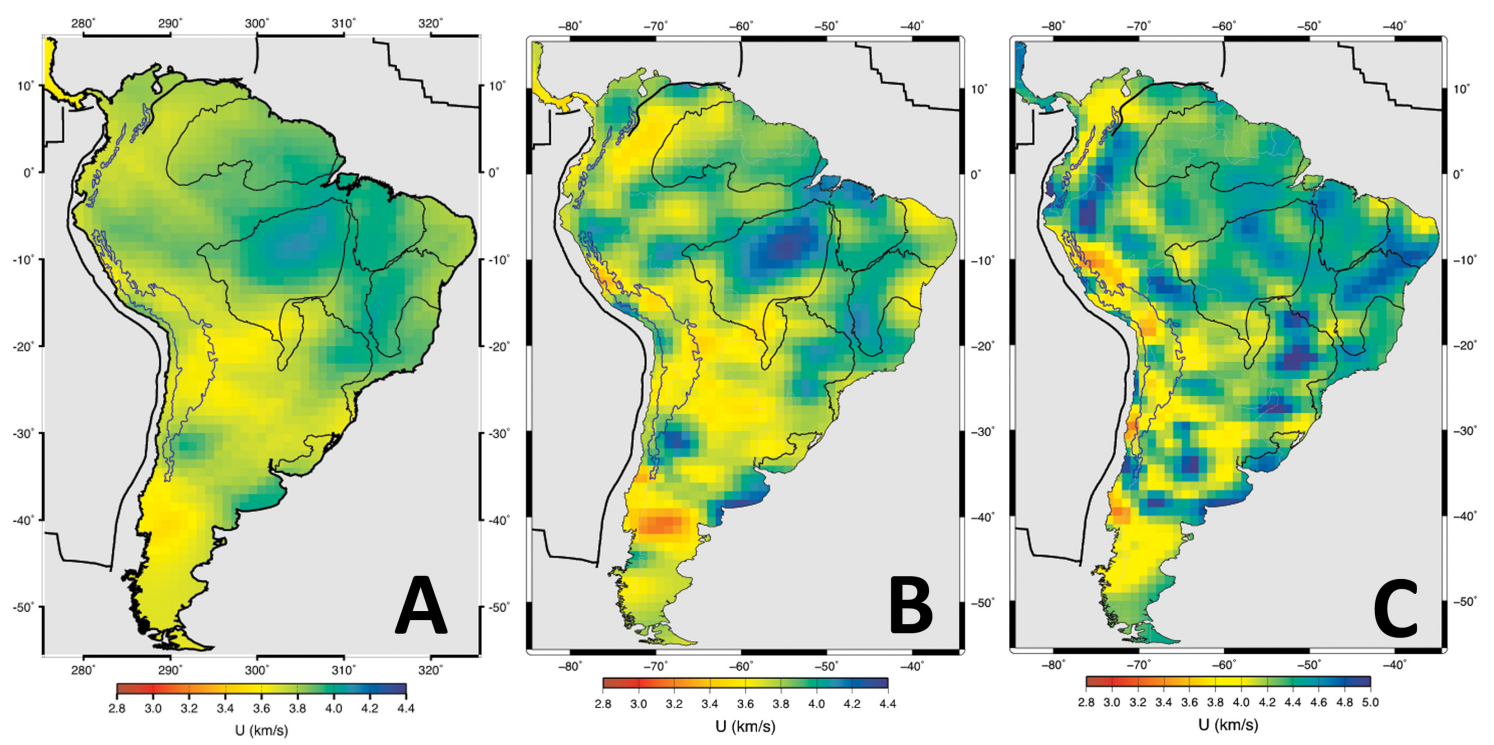

Figura A.11: Group-velocity maps for $\mathrm{T}=120 \mathrm{~s}$. A) Rayleigh waves with $1^{\text {nd }}$ derivative smoothing method. B) Rayleigh waves with $2^{\text {st }}$ derivative smoothing. C) Love waves with $2^{\text {nd }}$ derivative smoothing. At shorter periods, surface waves are more sensitive to shallow crustal structures, like sedimentary basins. 


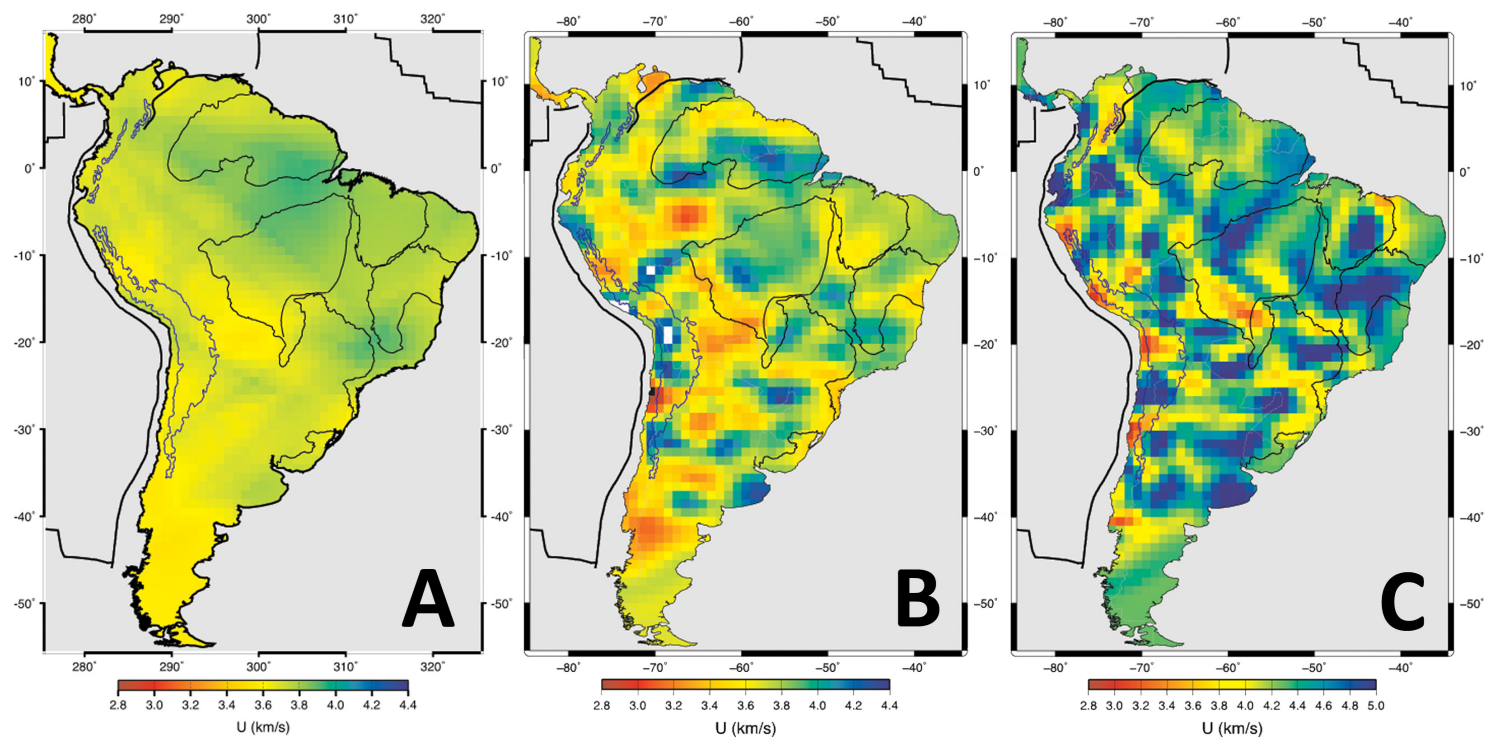

Figura A.12: Group-velocity maps for $\mathrm{T}=150 \mathrm{~s}$. A) Rayleigh waves with $1^{\text {nd }}$ derivative smoothing method. B) Rayleigh waves with $2^{\text {st }}$ derivative smoothing. C) Love waves with $2^{\text {nd }}$ derivative smoothing. At shorter periods, surface waves are more sensitive to shallow crustal structures, like sedimentary basins.

\section{A.2 Distribuição de Percursos}
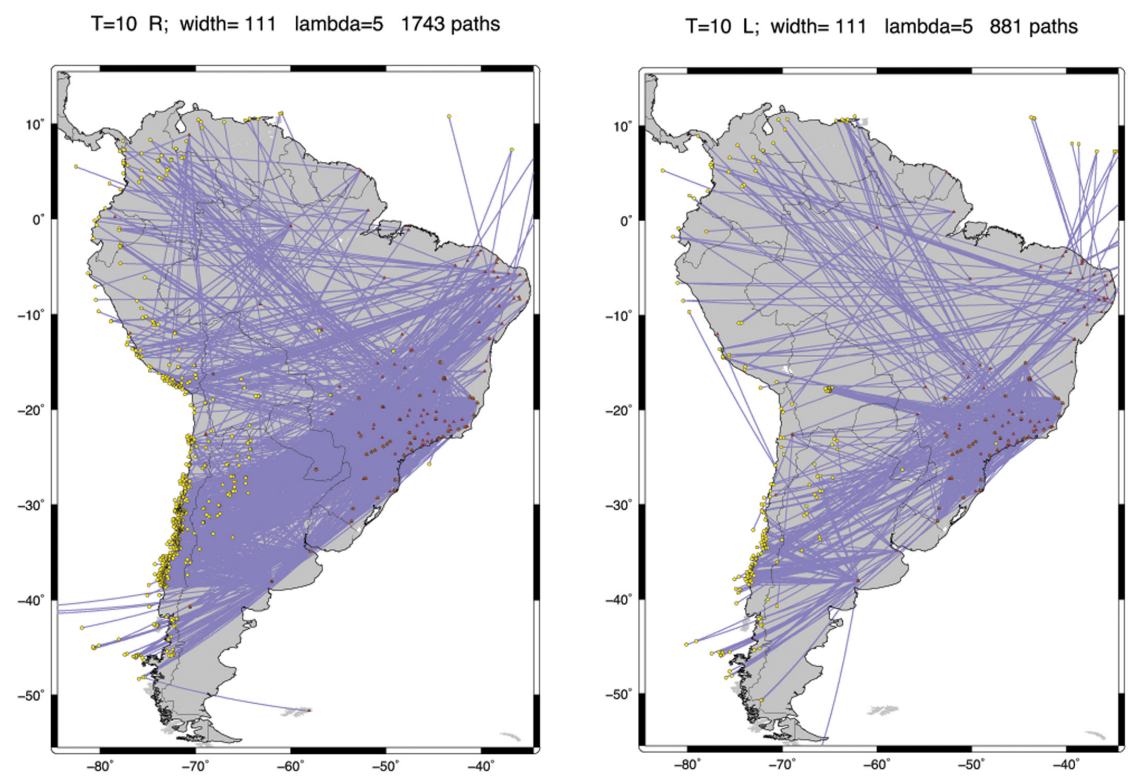

Figura A.13: Path distribution for $\mathrm{T}=10$ s for Rayleigh (left) and Love waves (right). 

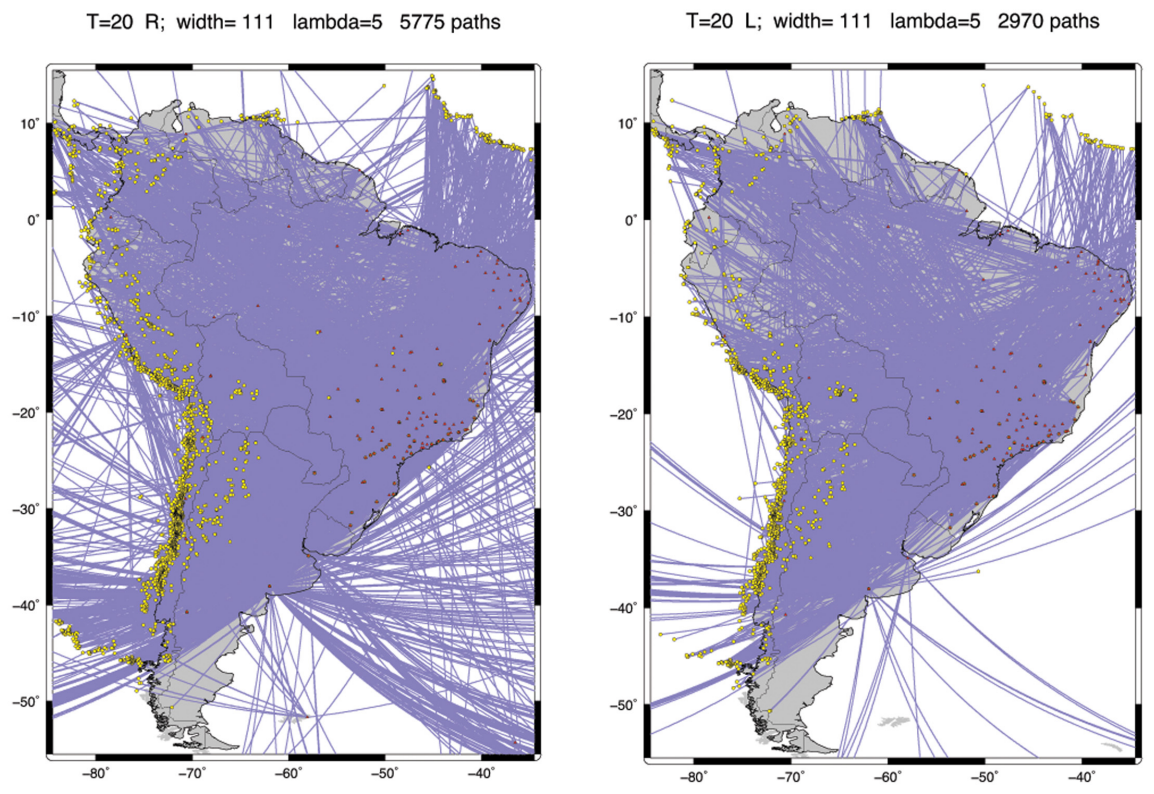

Figura A.14: Path distribution for $\mathrm{T}=20$ s for Rayleigh (left) and Love waves (right).
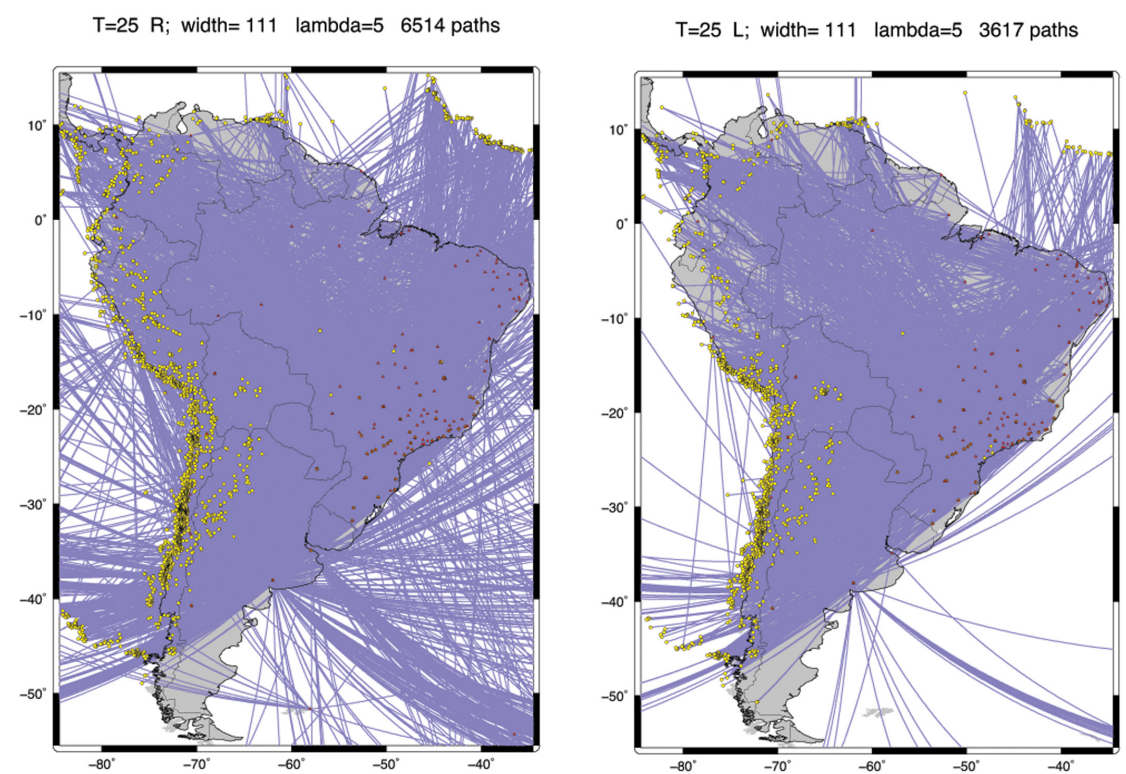

Figura A.15: Path distribution for $\mathrm{T}=25 \mathrm{~s}$ for Rayleigh (left) and Love waves (right). 
$\mathrm{T}=30 \mathrm{R}$; width $=111 \quad$ lambda $=5 \quad 6688$ paths

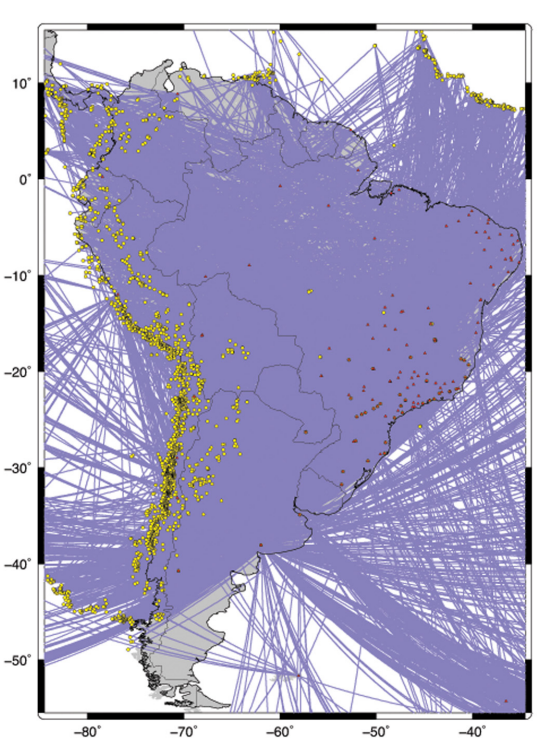

$\mathrm{T}=30 \mathrm{~L} ;$ width $=111 \quad$ lambda $=53843$ paths

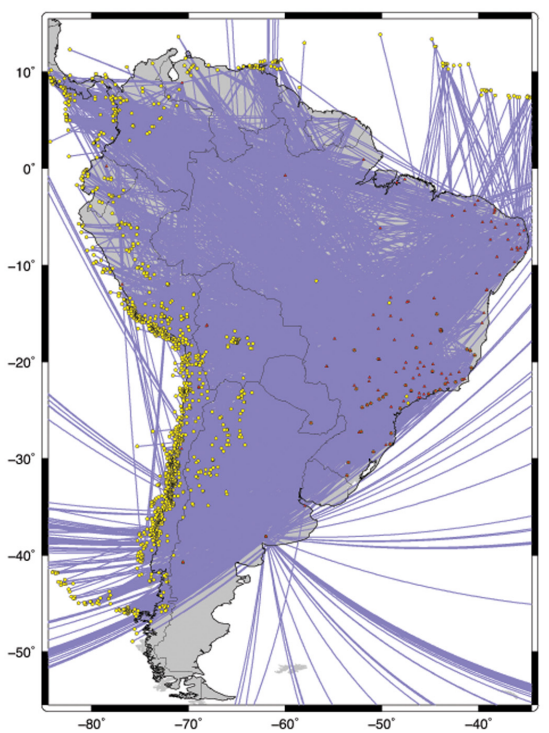

Figura A.16: Path distribution for $\mathrm{T}=30$ s for Rayleigh (left) and Love waves (right).

$T=35 \mathrm{R}$; width $=111 \quad$ lambda $=5 \quad 6739$ paths

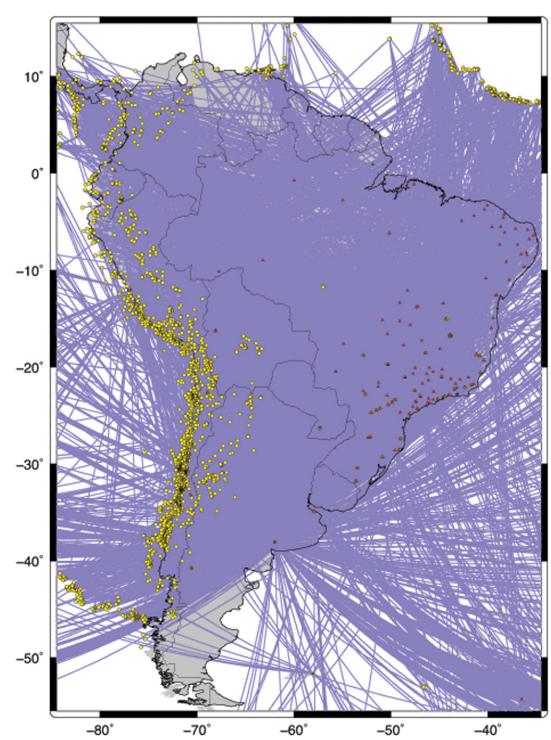

$\mathrm{T}=35 \mathrm{~L} ;$ width $=111$ lambda $=53845$ paths

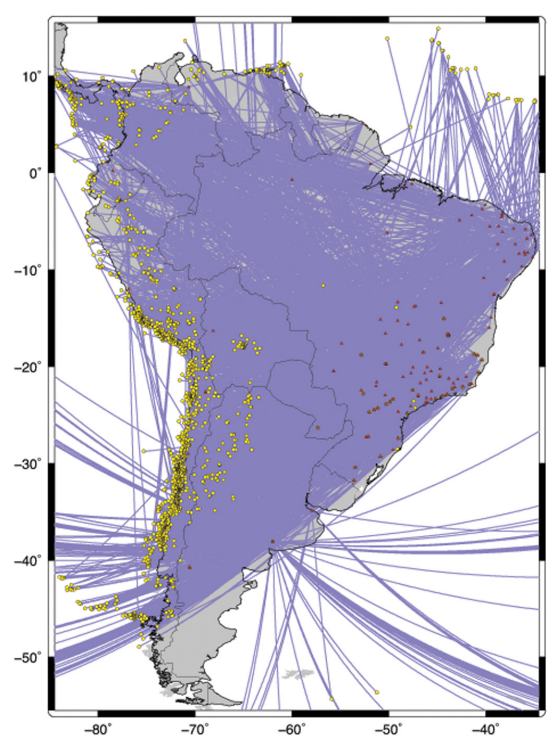

Figura A.17: Path distribution for $\mathrm{T}=35 \mathrm{~s}$ for Rayleigh (left) and Love waves (right). 

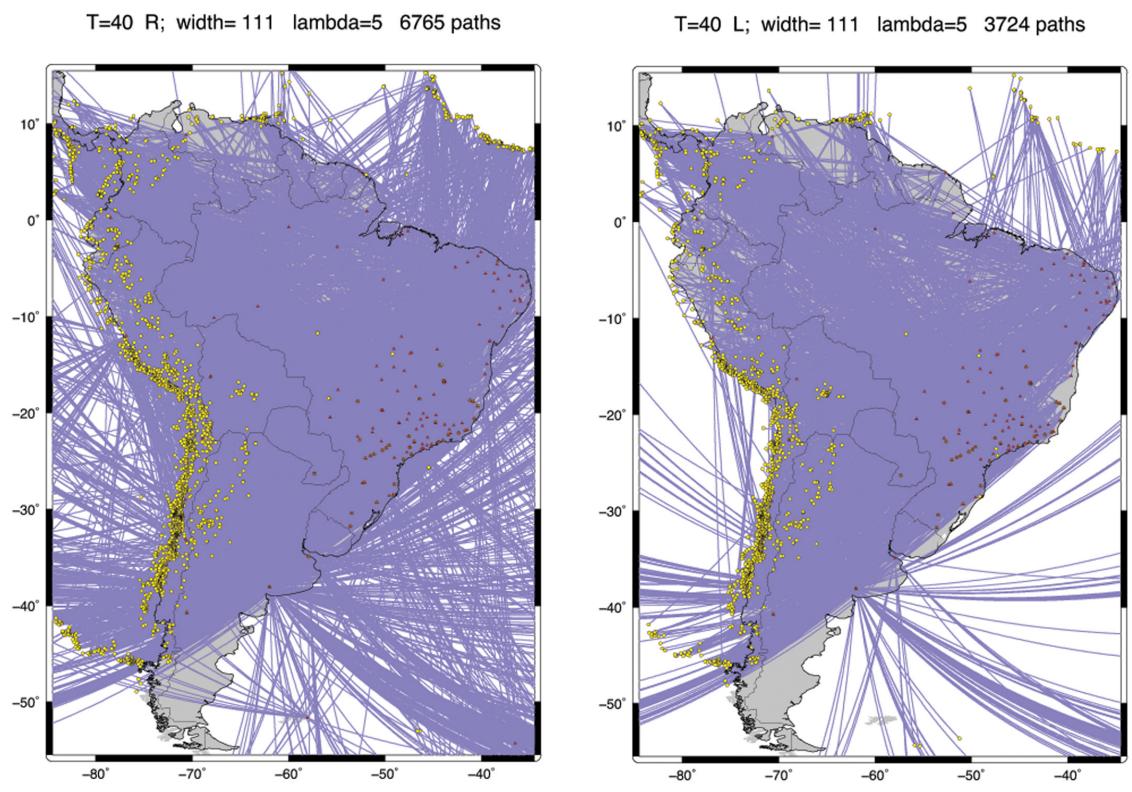

Figura A.18: Path distribution for $\mathrm{T}=40$ s for Rayleigh (left) and Love waves (right).

$T=60 \mathrm{R}$; width $=111$ lambda $=5 \quad 4623$ paths

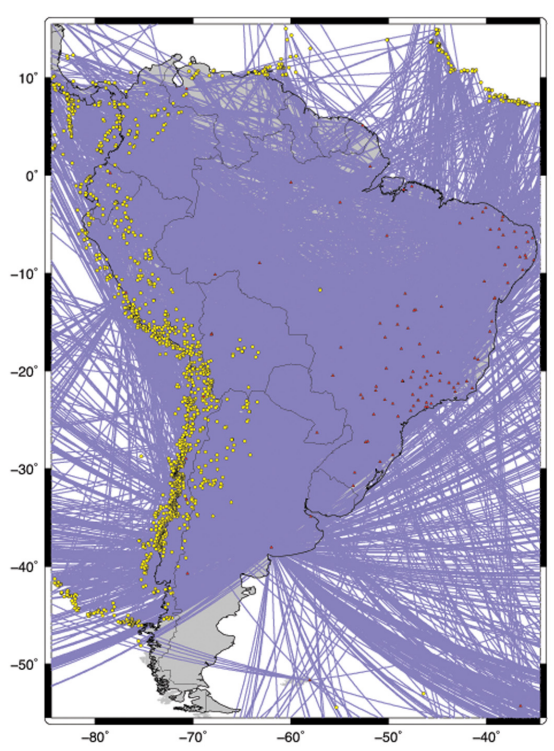

$\mathrm{T}=60 \mathrm{~L}$; width $=111$ lambda $=52093$ paths

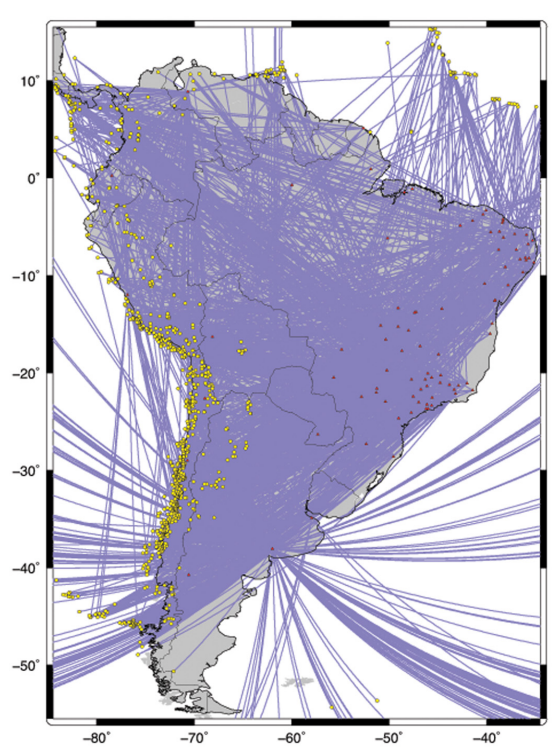

Figura A.19: Path distribution for $\mathrm{T}=60$ s for Rayleigh (left) and Love waves (right). 
T=70 R; width $=111$ lambda $=53789$ paths

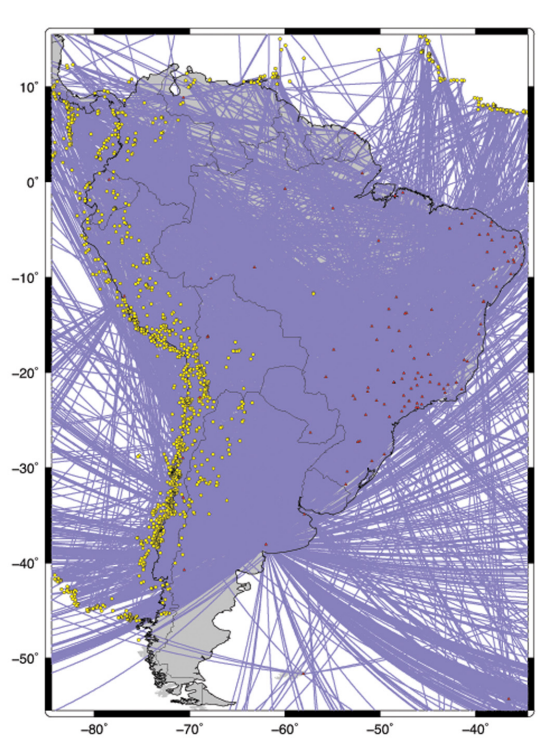

$\mathrm{T}=70 \mathrm{~L} ;$ width $=111$ lambda=5 1647 paths

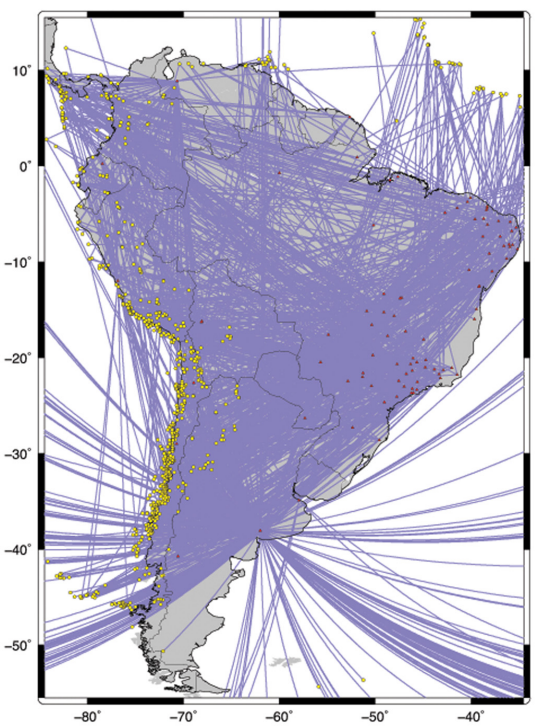

Figura A.20: Path distribution for $\mathrm{T}=70$ s for Rayleigh (left) and Love waves (right).
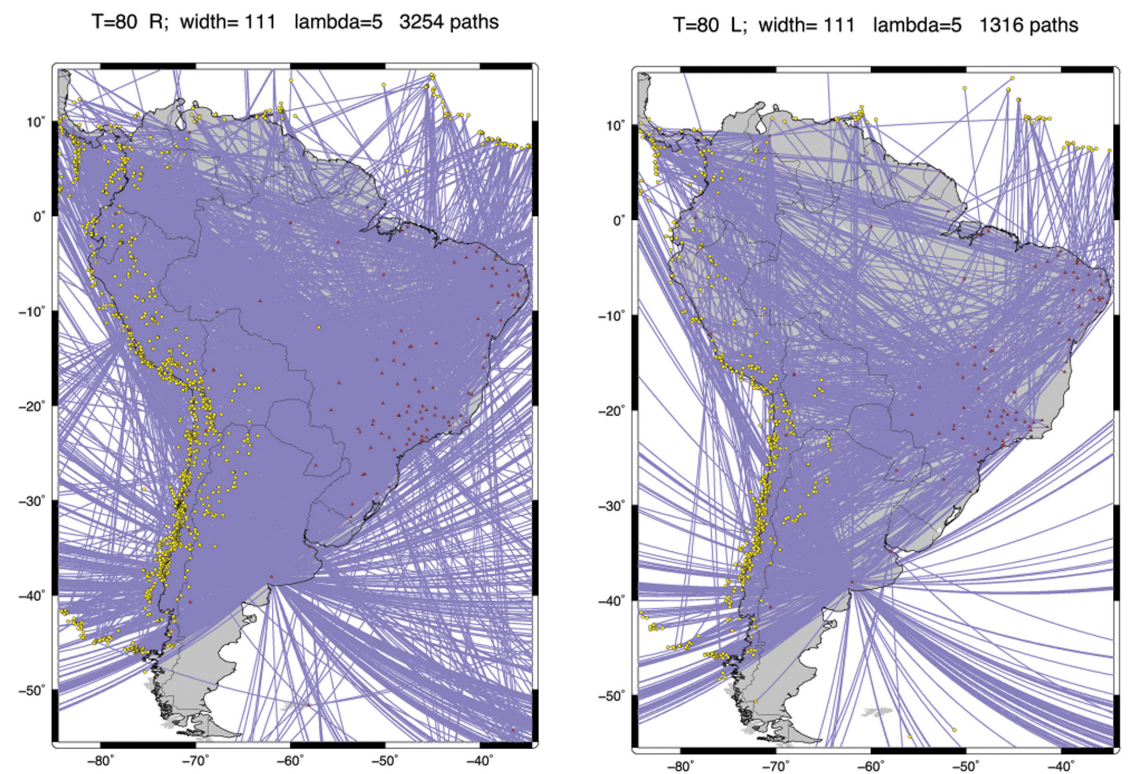

Figura A.21: Path distribution for $\mathrm{T}=80$ s for Rayleigh (left) and Love waves (right). 

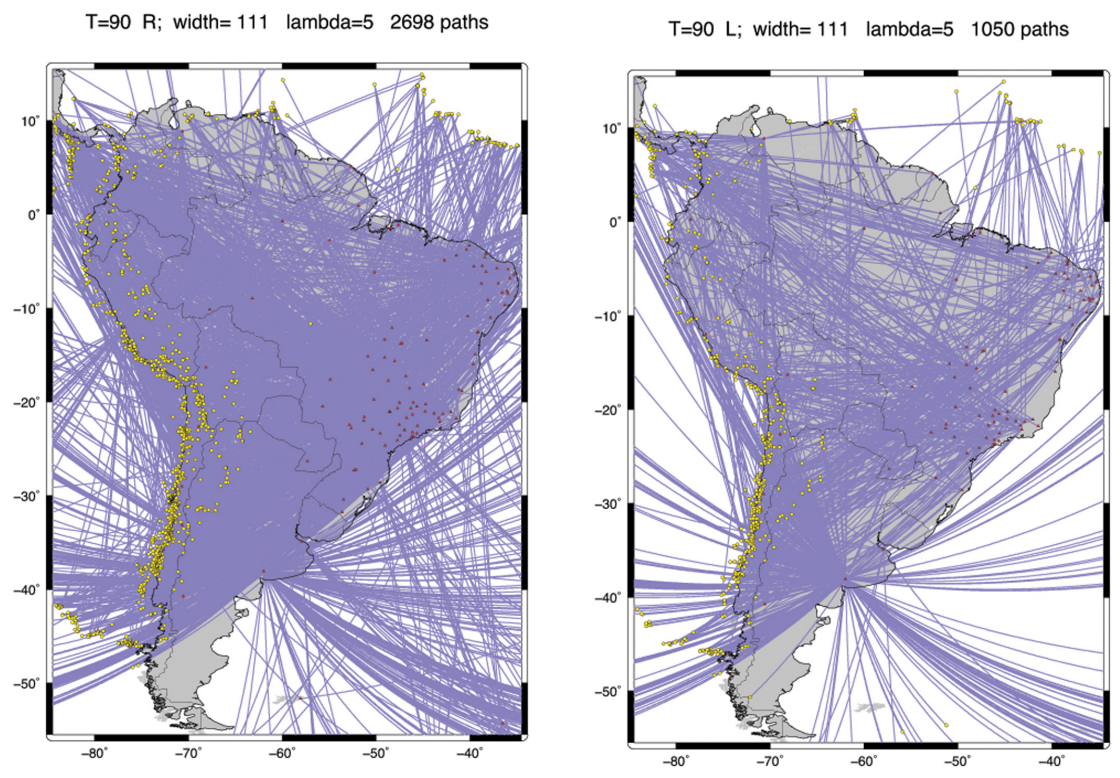

Figura A.22: Path distribution for $\mathrm{T}=90 \mathrm{~s}$ for Rayleigh (left) and Love waves (right).
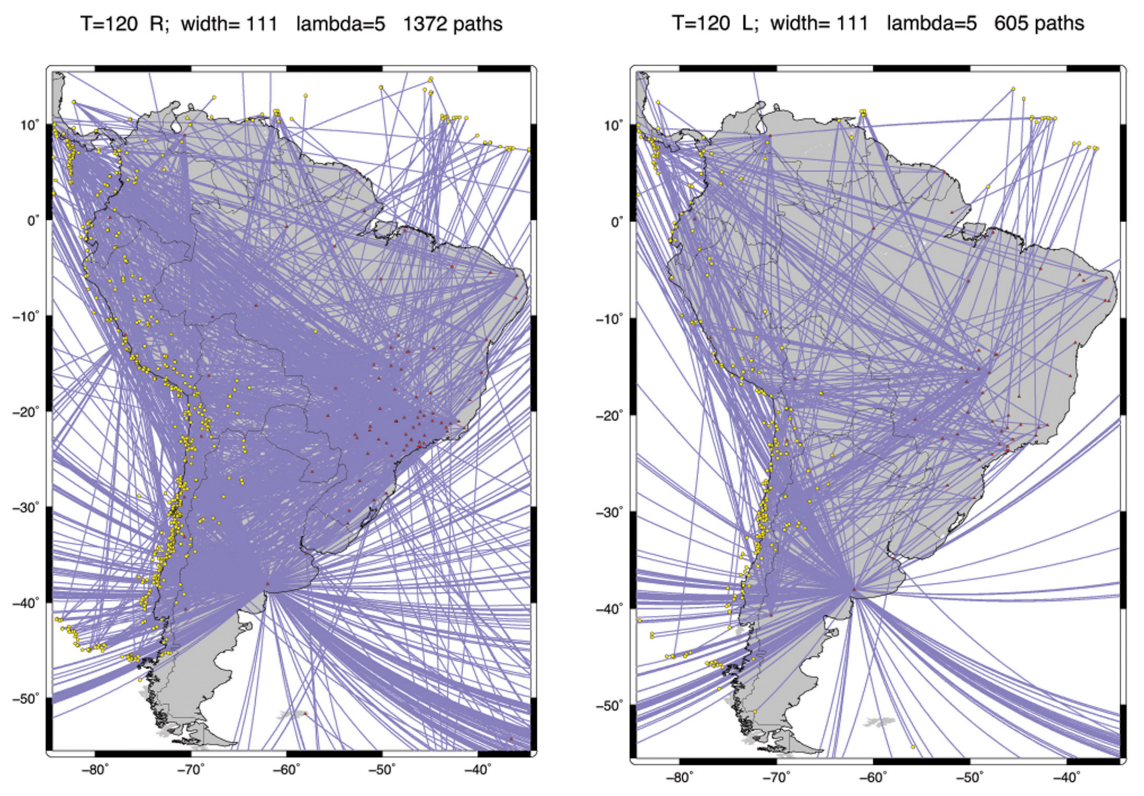

Figura A.23: Path distribution for $\mathrm{T}=120$ s for Rayleigh (left) and Love waves (right). 

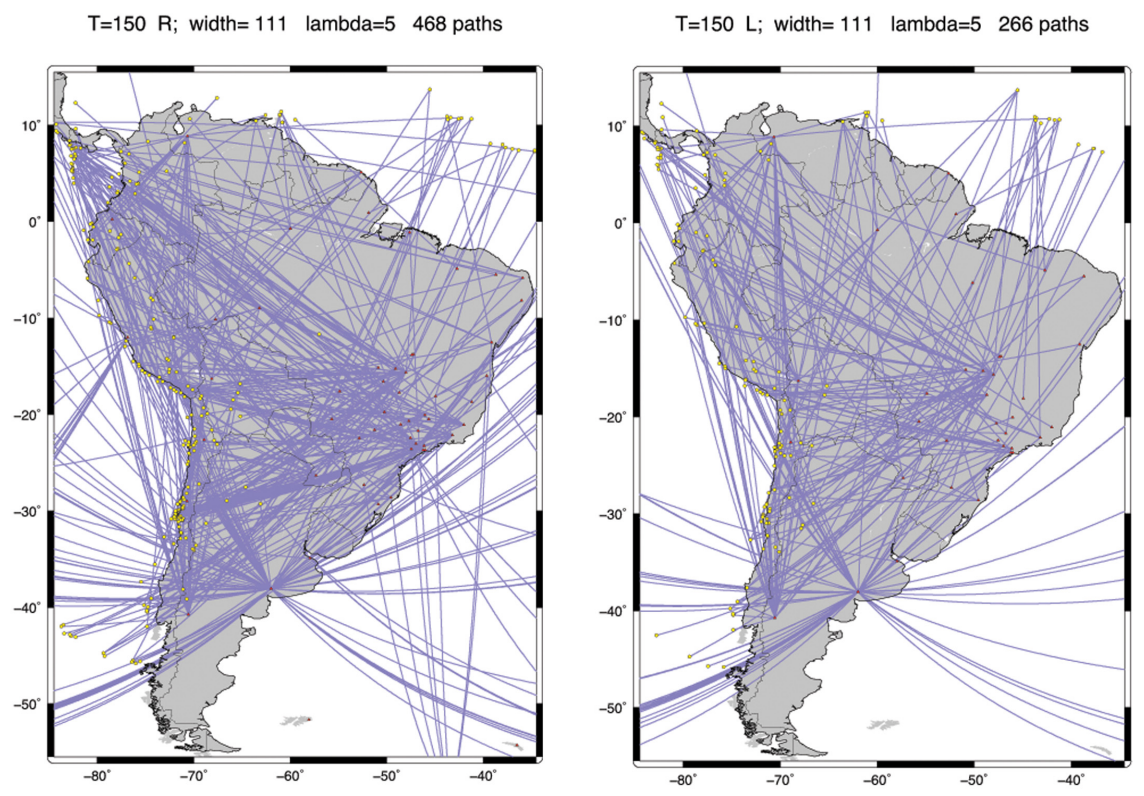

Figura A.24: Path distribution for $\mathrm{T}=150 \mathrm{~s}$ for Rayleigh (left) and Love waves (right). 